\title{
DESENVOLVIMENTO E VALIDAÇÃO DE EQUAÇÕES PARA ESTIMATIVA DE MASSA MAGRA E MASSA GORDA EM HOMENS BRASILEIROS COM 50 ANOS E MAIS DE IDADE
}

\section{LIGIA BEATRIZ BENTO FRANZ}

Tese apresentada na área de concentração de Epidemiologia da Faculdade de Saúde Pública da Universidade de São Paulo para obtenção do Grau de Doutor.

Área de concentração: Epidemiologia

Orientadora:

Profa. Dra. Maria do Rosário Dias de Oliveira Latorre.

São Paulo 2003

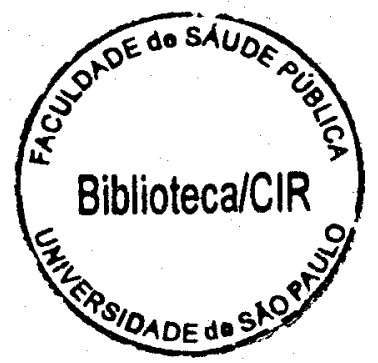




Autorizo, exclusivamente para fins acadêmicos e científicos, a reprodução total
ou parcial desta tese, por processos fotocopiadores. Ao usá-lo, cite a fonte.
Assinatura:
Data:


Ao meu filho:

\section{Lucas Bento Franz,}

minha maior alegria e entusiasmo,

com quem eu aprendo a cada dia a importância da vida,

e que teve minha atenção dividida, nos seus primeiros anos, primeiro com a elaboração final de minha dissertação de mestrado, e após, com o doutorado . 
Aos meus pais:

Emília Beatriz Bento Franz e Cláudio Affonso Franz, pelo carinho e estímulo durante toda esta vida para que eu atinja meus ideais, e por acompanhar meu filho nas horas em que me afasto fisicamente.

Ao meu imão:

Cláudio Alberto Bento Franz, pelo caninho, atenção e estímulo para que eu alcance meus objetivos nesta vida. 


\section{AGRADECIMENTOS}

À Deus, pela oportunidade desta vida.

À Profa. Dra. Maria do Rosário Dias de Oliveira Latorre, orientadora deste trabalho, pelos ensinamentos, dedicação e paciência durante toda esta caminhada, pelo exemplo de profissional que é, pela sua garra em alcançar seus objetivos, e, pela sua amizade.

À Profe. Dra. Patricia Constante Jaime pela oportunidade em trabalhar com - banco de dados que deu origem a esta pesquisa, pelas valiosas colaborações que enriqueceram este estudo, e pela amizade.

Ao grupo da pesquisa "Avaliação clínica dos fatores de risco para osteoporose em homens", desenvolvida pelo Serviço de Reumatologia do Complexo Hospitalar Heliópolis, em conjunto com $\circ$ Departamento de Epidemiologia da Faculdade de Saúde Pública da Universidade de São Paulo, o qual deu origem a este trabalho.

À Prof. Dra. Maria Helena D'Aquino Benício, pela participação no exame de qualificação do projeto desta pesquisa, mas que pela suas inúmeras atividades não pode participar da etapa final. 
Aos membros da banca examinadora, pelas suas importantes contribuições a este trabalho.

Aos homens que fizeram parte da população de estudo, sem os quais não seria possivel a realização desta pesquisa.

Aos colegas do Departamento de Ciências da Saúde da Universidade Regional do Noroeste do Estado do Rio Grande do Sul, pela oportunidade e incentivo em realizar este estudo, em especial à Profa. Maristela Borin Busnello, por substituir-me em alguns momentos em que afastei-me para a finalização desta pesquisa.

Às funcionárias da Biblioteca da Faculdade de Saúde Pública, em especial, Sueli, Márcia e Antônia, pela acolhida, e excelente atendimento durante estes anos de convivência.

À Márcia Cavalheiro Bento, íris Alves Campos, Maria Alves Campos e Família Van der Sand, pela atenção dedicada à minha pessoa e à minha família, para que durante estes três anos e meio eu conseguisse me dedicar a este trabalho.

Muito obrigado! 


\section{RESUMO}

Franz LBB. Desenvolvimento e validação de equações para estimativa de massa magra e massa gorda em homens brasileiros com $\mathbf{5 0}$ anos e mais de idade. São Paulo; 2003. [Tese de Doutorado - Faculdade de Saúde Pública da USP].

Objetivo. O objetivo deste trabalho foi desenvolver e validar equações para estimar percentual de gordura e massa corporal magra em homens entre 50 e 85 anos de idade. Métodos. A população de estudo foi dividida em duas amostras aleatórias, sendo uma utilizada para o desenvolvimento das equações de regressōes, e a outra para validá-las. Os modelos foram desenvolvidos através da análise de regressão linear múltipla, tendo como variáveis dependentes o percentual de gordura (\%G) e a massa corporal magra (MCM) fornecidas pela absorciometria por raio- $X$ de dupla energia (DEXA) e, como variáveis independentes idade (I), massa corporal (MC), estatura (Est), índice de massa corporal (IMC), dobra cutânea tricipital $(D C T)$, perímetro da cintura (PCint), perímetro do quadril $(P Q)$, razão cintura/quadril (RCQ), e, \%G, MCM, resistência e reatância fornecidas pela análise de impedância bioelétrica (BIA) (\%G BIA, MCM BIA, Res e $\chi_{c}$ respectivamente). $A$ análise de validação das equações foi feita através do coeficiente de correlação de Pearson, teste $t$-Student pareado e através do erro padrão de estimativa (EPE). Resultados. A melhor equação para estimar o \%G teve, como variáveis independentes o PCint, \%G BIA, DCT e I 
$\left(r_{\mathrm{aj}}^{2}=0,71 ; \quad r_{i c c}=0,82 ;\right.$ e EPE $\left.=4,0 \%\right)$. Nenhuma das equações forneceu estimativas precisas da MCM. Conclusão. Verifica-se que para $\circ \% \mathrm{G}$ foi possivel estimar uma equação preditiva, porém são necessários outros estudos para definir uma equação para a MCM.

Descritores: equações de predição; composição corporal; análise de impedância bioelétrica; absorciometria por raio-X de dupla energia; homens adultos e idosos. 


\section{SUMMARY}

Franz LBB. Desenvolvimento e validação de equações para estimativa de massa magra e massa gorda em homens brasileiros com 50 e anos e mais de idade. [Development and validation of equations to estimative both the lean mass and the fat mass in men aged 50 years or older]. São Paulo (BR); 2003. [Tese de Doutorado - Faculdade de Saúde Pública da USP].

Objective. The aim of this study was to develop and validade equations to estimative the fat percentage and the lean body mass in men aged $50-85$ years old. Methods. The group was divided into two random samples. One sample was used for the development of the regression equations, and the validation was done on the other one. The models were developed using multiple linear regression analysis, where the dependent variables were the fat percentage (\%Fat) and the lean body mass (LBM) measured by the dualenergy X-ray absorptiometry (DEXA) (\%Fat and LBM, respectively). The independent variables were age $(A)$, body mass $(B M)$, height $(H)$, body mass index (BMI), triceps skinfold thickness (TRSF), waist circunference (WC), hip circunference $(\mathrm{HC})$, waist:hip ratio $(\mathrm{WHR})$, and, \%Fat, LBM, resistence e reactance given by the bioelectrical impedance analysis (BIA) (\%Fat BIA, LBM BIA, $R$ e $\chi_{c}$, respectively). The validation was done using Pearson correlation coefficient, paired $t$-Student test $(p)$ and standard error of estimation (SEE). Results. The best equation to estimative the \%Fat 
included WC, TRSF, \%Fat BIA and $A\left(r^{2}=0,71, r_{i c c}=0,82\right.$ and SEE $\left.=4,0 \%\right)$. No equation could estimative LBM. Conclusion. The \%Fat com be estimated using equation, but it is necessary other studies to found a equation for LBM.

Descriptors: prediction equations; body composition; bioelectrical impedance analysis; dual-energy $\mathrm{X}$-ray absorptiometry, men. 


\section{ÍNDICE}

Páginas

1 - INTRODUÇÃO 1

1.1 - Técnicas para estimar a massa corporal gorda e massa corporal magra 5

1.1.1 - Absorciometria por raios X de dupla energia - DEXA 5

1.1.2 - Análise de impedância bioelétrica - BIA 7

$\begin{array}{ll}\text { 1.1.3 - Interactância de raios infravermelhos } & 10\end{array}$

$\begin{array}{ll}\text { 1.1.4-Pesagem hidrostática } & 11\end{array}$

1.1.5 - Determinação da água corporal total (ACT) por diluição de isótopos 12

- hidrometria

1.1.6 - Contagem de potássio corporal total (KCT) - espectrometria 13

1.1.7 - Tomografia computadorizada (TC) e Ressonância magnética (RM) 13

$\begin{array}{ll}1.2 \text { - Medidas antropométricas } & 15\end{array}$

$\begin{array}{ll}\text { 1.2.1 - Índice de massa corporal - IMC } & 16\end{array}$

$\begin{array}{lr}\text { 1.2.2 - Dobras cutâneas } & 17\end{array}$

$\begin{array}{ll}\text { 1.2.3 - Razão cintura quadril - RCQ } & 18\end{array}$

$\begin{array}{ll}\text { 1.2.4 - Perímetro da cintura - Pcint } & 19\end{array}$

1.3 - Estudos de validação de métodos de avaliação da composição 20

corporal considerando a DEXA como padrão-ouro

1.3.1 - Estudos relacionados com a massa gorda (MG) 21

1.3.2 - Estudos relacionados com a massa corporal magra (MCM) 23

$\begin{array}{ll}2 \text { - JUSTIFICATIVA } & 28\end{array}$

$\begin{array}{ll}3 \text { - OBJETIVOS } & 31\end{array}$

4-MATERIAL E MÉTODOS 
4.1 - Delineamento do estudo

4.2 - População de estudo

4.3 - Metodologia

4.3.1 - Medidas antropométricas

Massa corporal - MC 35

Estatura - Est 36

$\begin{array}{ll}\text { Índice de massa corporal - IMC } & 36\end{array}$

$\begin{array}{ll}\text { Dobra cutânea tricipital - DCT } & 36\end{array}$

Perímetros: cintura e quadril - PCint e PQ

4.3.2 - Técnicas utilizadas para avaliar a composição corporal 38

Absorciometria por raios X de dupla energia - DEXA 38

Análise de impedância bioelétrica - BIA $\quad 39$

4.4 - Variáveis de estudo $\quad 42$

$\begin{array}{ll}\text { Variáveis dependentes } & 42\end{array}$

$\begin{array}{ll}\text { Variáveis independentes } & 42\end{array}$

4.5 - Análise estatística $\quad 43$

$\begin{array}{ll}4.6-\text { Pacotes estatísticos (softwares) } & 48\end{array}$

4.7- Aspectos éticos $\quad 48$

$\begin{array}{lr}\text { 5- RESULTADOS } & 50\end{array}$

5.1 - Características da primeira amostra da população de estudo $\quad 50$

5.2 - Análise estatística do percentual de gordura - \%G 55

5.3 - Análise estatística da massa corporal magra - MCM 64

5.4 - Validação das equações $\quad 69$

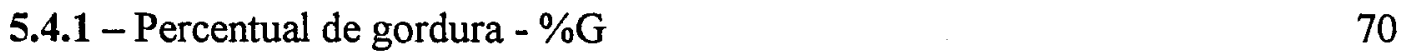


5.4.2 - Massa corporal magra - MCM

6 - DISCUSSÃO

7 - CONCLUSÕES

8 - REFERÊNCIAS

Anexo 1 - Termo de Consentimento Informado do Paciente

Anexo 2 - Aprovação da Comissão de Ética Médica do Hospital Heliópolis

Anexo 3 - Aprovação do Comitê de Ética em Pesquisa da Faculdade de

Saúde Pública da Universidade de São Paulo

Anexo 4 - Gráficos de Análises de Resíduos

Anexo 5 - Artigo 


\section{LISTA DE QUADROS, GRÁFICOS, FIGURAS E}

\section{TABELAS}

Página

Quadro 1 - Estudos relacionados com a MG, considerando a DEXA 22 como padrão ouro.

Quadro 2 - Estudos relacionados com a MCM, considerando a DEXA 26 como padrão-ouro.

Quadro 3 - Equações da literatura para estimar MG e \%G em homens. 45

Quadro 4 - Equações da literatura para estimar MCM em homens. $\quad 46$

Quadro 5 - Valores de referência de erro padrão de estimativa para 47 percentual de gordura e massa corporal magra.

Quadro 6 - Coeficientes de regressão $(\beta)$ das variáveis de cada equação 71 para o cálculo do \%G.

Quadro 7 - Coeficientes de regressão $(\beta)$ das variáveis de cada equação 78 para o cálculo da MCM.

Gráfico 1 - Número de homens, segundo escolaridade. Amostra 1. 51 Hospital Heliópolis, São Paulo, 1997.

Gráfico 2 - Médias de \%G e respectivos intervalos de $95 \%$ de confiança, 73 segundo as diversas equações. Amostra 2. Hospital Heliópolis, São Paulo, 1997.

Gráfico 3 - Diagramas de dispersão entre o valor do \%G medido pela 76 DEXA e o estimado pelas equações. Amostra 2. Hospital Heliópolis, São Paulo, 1997. 
Gráfico 4 - Médias de MCM e respectivos intervalos de confiança,

segundo as diversas equações. Amostra 2. Hospital Heliópolis, São Paulo, 1997.

Gráfico 5 - Diagramas de dispersão entre o valor de MCM medido pela

DEXA e o estimado pelas equações. Amostra 2. Hospital Heliópolis, São

Paulo, 1997.

Figura 1 - Locais de colocação dos eletrodos, para fixar as pinças do impedanciômetro na medida da resistência e reatância.

Tabela 1 - Estatística descritiva das variáveis de estudo. Amostra 1.52 Hospital Heliópolis, São Paulo, 1997.

Tabela 2 - Médias e desvios-padrão das variáveis de estudo, segundo cor da pele. Amostra 1. Hospital Heliópolis, São Paulo, 1997.

Tabela 3 - Médias e desvios-padrão das variáveis de estudo, segundo 54 grupo etário. Amostra 1. Hospital Heliópolis, São Paulo, 1997.

Tabela 4 - Coeficientes de correlação $(r)$ entre o \%G fornecida pela 56 DEXA e as outras variáveis, separados por grupo etário e cor da pele. Amostra 1. Hospital Heliópolis, São Paulo, 1997.

Tabela 5 - Coeficientes de correlação $(r)$ entre o \%G derivado da DEXA 58 e as outras variáveis e ordem da entrada da variável no modelo múltiplo. Amostra 1. Hospital Heliópolis, São Paulo, 1997.

Tabela 6 - Descrição das etapas de modelagem múltipla para a equação 59 do \%G. Amostra 1. Hospital Heliópolis, São Paulo, 1997.

Tabela 7 - Descrição das etapas de modelagem múltipla para a equação 62 do \%G, sem a \%G BIA. Amostra 1. Hospital Heliópolis, São Paulo, 1997. 
Tabela 8 - Coeficientes de correlação entre o valor da MCM (kg) 65 fornecido pela DEXA e as outras variáveis, separados por grupo etário e raça. Amostra 1. Hospital Heliópolis, São Paulo, 1997.

Tabela 9 - Coeficientes de correlação entre o valor da $\mathrm{MCM}$ em $\mathrm{Kg}$ 66 derivada da DEXA e as outras variáveis, e ordem da entrada da variável no modelo múltiplo. Amostra 1. Hospital Heliópolis, São Paulo, 1997.

Tabela 10 - Descrição das etapas de modelagem múltipla para MCM. 68 Amostra 1. Hospital Heliópolis, São Paulo, 1997.

Tabela 11 - Estatística descritiva do \%G fornecido pela DEXA e aqueles 72 fornecidos pela BIA e estimados pelas equações. Amostra 2. Hospital Heliópolis, São Paulo, 1997.

Tabela 12 - Coeficientes de correlação intraclasse $\left(r_{\text {ic }}\right)$ entre o \%G 75 fornecido pela DEXA e aqueles fornecidos pela BIA e estimados pelas equações. Amostra 2. Hospital Heliópolis, São Paulo, 1997.

Tabela 13 - Estatística descritiva do valor da MCM fornecido pela DEXA 79 e os fornecidos pela BIA e estimados pelas equações. Amostra 2. Hospital Heliópolis, São Paulo, 1997.

Tabela 14 - Coeficientes de correlação intraclasse $\left(r_{i c}\right)$ entre o valor da 81 MCM fornecido pela DEXA e BIA e aqueles estimados pelas equações. Amostra 2. Hospital Heliópolis, São Paulo, 1997. 


\section{LISTA DE SIGLAS}

ACT - água corporal total.

DC-dobra cutânea, mm.

DCT - dobra cutânea tricipital, $\mathrm{mm}$.

DEXA - absorciometria por raio-X de dupla energia.

dp - desvio-padrão.

Est-estatura.

Endef - Estudo Nacional de Despesa Familiar.

EPE - erro padrão de estimativa.

F- feminino.

FDA - Food and Drug Administration.

FSP - Faculdade de Saúde Pública.

GCT - gordura corporal total, $\mathrm{Kg}$.

I - idade.

BIA - análise de impedância bioelétrica.

IBGE - Instituto Brasileiro de Geografia e Estatística.

IC - intervalo de confiança.

IMC - índice de massa corporal, $\mathrm{Kg} / \mathrm{m}$.

KCT - potássio corporal total.

M-masculino

MC - massa corporal, $\mathrm{Kg}$. 
MCM - massa corporal magra, $\mathrm{Kg}$.

MCM BIA - massa corporal magra fornecida pela análise de impedância bioelétrica, $\mathrm{Kg}$.

MCM DEXA - massa corporal magra fornecido pela absorciometria por raio-

$\mathrm{X}$ de dupla energia, $\mathrm{Kg}$.

MG - massa gorda, $\mathrm{Kg}$.

MLG - massa livre de gordura, $\mathrm{Kg}$.

OMS - Organização Mundial da Saúde.

ONU - Organização das Nações Unidas.

PAM - Posto de Atendimento Médico.

PCint - perímetro da cintura, $\mathrm{cm}$.

PNSN - Pesquisa Nacional de Saúde e Nutrição.

PQ - perímetro do quadril, cm.

$r$ - coeficiente de correlação.

$r^{2}$ - coeficiente de correlação ajustado.

$\boldsymbol{r}_{i c}-$ coeficiente de correlação intra-classe.

$\mathbf{R}$ - resistência.

$\mathbf{R C Q}$ - razão cintura/quadril.

$\mathbf{R M}$ - ressonância magnética.

TC - tomografia computadorizada.

USP - Universidade de São Paulo. 
WHO - World Health Organization.

$\chi_{c}-$ reatância.

$\% \mathbf{G}$ - percentual de gordura, $\%$.

\%G DEXA - percentual de gordura fornecida pela absorciometria por raio-X

de dupla energia, $\%$.

\%G BIA - percentual de gordura fornecida pela análise de impedância

bioelétrica, \%. 


\section{INTRODUÇÃO}

O estado de saúde de um indivíduo está diretamente relacionado com seu estado nutricional; quando inadequado, este pode conduzir a distúrbios no organismo, como, por exemplo, a obesidade ou desnutrição, ambas associadas a diversas doenças (OMS, 1995) que são influenciadas pelo conteúdo de gordura do corpo humano (AGHDASSI et al., 2001). A avaliação do estado nutricional pode ser feita por inúmeras técnicas, englobando exames clínicos, exames bioquímicos, medidas antropométricas e métodos de avaliação da composição corporal.

Mudanças na massa corporal têm sido um indicador padrão para avaliar problemas nutricionais (tanto desnutrição, como obesidade). Entretanto, o critério ótimo para os diagnósticos de má nutrição pela massa corporal é incerto (ROSENBAUM et al., 2000). Neste trabalho é usado o termo de massa corporal $(\mathrm{Kg})$, que é a medida realizada pela balança, e não o de peso, popularmente utilizado, que é o produto da massa pelo campo gravitacional $(P=m . g)$ e tem como unidade o Newton $-N$ (CARRON e GUIMARĀES, 1997 citado por COSTA, 1999).

A massa corporal (MC) é constituída de ossos, músculos, gorduras e vísceras (DÂMASO, 2001); sendo assim, uma MC elevada pode não significar obesidade, que é a quantidade de gordura acima do recomendado. 
Em 1942, WELHAM e BEHNKE, segundo GUEDES (1994) e DÂMASO (2001), verificaram que jogadores profissionais de futebol americano tiveram sua massa corporal $24,6 \%$ maior do que os padrões recomendados, mas foram considerados magros, porque tinham pouca gordura e massa muscular muito desenvolvida. $O$ inverso também pode ocorrer: pessoas não habituadas a fazer atividade física estarem ganhando MC por aumento de gordura e não de massa muscular (até diminuição dela e de outros componentes), por erro de dieta ou outro fator qualquer (DÂMASO, 2001).

A avaliação da composição corporal pode ser feita fracionando a massa corporal total em seus dois componentes: massa gorda (MG) e massa corporal magra (MCM).

A MG é distribuída em gordura corporal essencial (localizada nos órgãos, intestino, músculos e tecidos ricos em gordura no sistema nervoso central) e gordura corporal de reserva, que tem papel predominante nos processos de obesidade e emagrecimento, estocada para proteger os órgãos internos de traumatismo e também na região subcutânea (DÂMASO, 2001).

Verifica-se, na literatura, o uso de dois termos para a MCM: lean body mass (massa corporal magra-MCM) e fat-free mass (massa livre de gordura$M L G$ ), algumas vezes tratados erroneamente como sinônimos. A MLG constitui-se da massa corporal livre de toda a gordura, excluindo até mesmo 
as gorduras essenciais (possivel apenas em análise de cadáveres), caracterizando-se por um conceito "in vitro". A MCM não exclui gorduras essenciais, caracterizando-se por um conceito "in vivo". Sendo assim, neste trabalho será utilizado o termo $\mathrm{MCM}$, pois se considera este o conceito mais apropriado ao se referir ao componente que é formado pelos tecidos muscular e esquelético, pele, órgãos, além de todos os outros tecidos nãogordurosos (BEHNKE e WILMORE, 1974).

Há interesse crescente no estudo da composição corporal, em particular a avaliação da massa de gordura. As conseqüências adversas à saúde do excesso de gordura corporal estão bem documentadas e quantificações de gordura corporal são usadas em pesquisas como um marcador de risco futuro (JEBB et al., 2000; WHO, 2003). Isso porque o que está associado a doenças é o excesso de gordura e sua localização no corpo e não a massa corporal total.

A avaliação da MCM e MG permite a otimização do suporte nutricional e evita ou minimiza a perda muscular ou obesidade. Por estas razões, a avaliação nutricional deve incluir indicadores objetivos de composição corporal. Métodos recentes e acessiveis para determinação da massa magra são a absorciometria por raio-X de dupla energia (DEXA) e análise de impedância bioelétrica (BIA) (PICHARD et al., 1999). 
Segundo MARTIN e DRINKWATER (1991), citados por GUEDES (1994) e COSTA (2001), pode-se classificar os indicadores em diretos, indiretos e duplamente indiretos. Direto é aquele em que há a separação e a pesagem de cada um dos componentes corporais isoladamente, "in loco", o que só é possivel por dissecação de cadáveres. Indiretos são aqueles nos quais não há a manipulação dos componentes separadamente, mas, a partir de princípios químicos e físicos, é possível extrapolar as quantidades de gordura e de MCM. Como indiretos tem-se a DEXA, a pesagem hidrostática, a determinação da água corporal total (ACT) por diluição de isótopos, a contagem de potássio corporal total (KCT), o método de ar-deslocado para medir o volume corporal (pletismografia), a tomografia computadorizada (TC) e a ressonância magnética (RM), mas as análises de composição corporal por estes métodos são muito caras e laboriosas. Duplamente indiretos são aqueles que envolvem as equações preditivas da MCM e MG, além dos indicadores antropométricos, a BIA e a interactância de raios infravermelhos.

Com o avançar da idade as pessoas apresentam diversas mudanças biológicas, de estilo de vida, antropométricas e de composição corporal. Todas elas podem ter implicações no estado de nutrição, na resposta ao apoio nutricional e farmacológico, na capacidade funcional, no prognóstico e tratamento de pacientes hospitalizados, assim como serem fatores de risco para o desenvolvimento de enfermidades crônico-degenerativas. Hoje em dia, no adulto se reconhece a importância das mudanças na MC, na estatura e na composição corporal. Todas estas mudanças tornam o adulto mais 
vulnerável ao desenvolvimento, ou complicações de diversas enfermidades, que comprometem seu estado de saúde e a capacidade funcional (ALEMÁN-MATEO et al., 1999; WHO, 2003).

A seguir, serão detalhadas as técnicas que avaliam a composição corporal, além das que viabilizam a avaliação do estado nutricional em estudos epidemiológicos.

\subsection{Técnicas para estimar a massa corporal gorda e a massa corporal magra}

\subsubsection{Absorciometria por raios $X$ de dupla energia - DEXA}

O princípio da absorciometria é baseado na atenuação exponencial de raios $\mathrm{X}$ de duas energias, que está diretamente relacionada à espessura e composição do tecido (mineral ósseo ou tecidos moles) do corpo interposto no caminho da emissão (ZERBINI, 1998). Os raios $X$, de diferentes energias, são absorvidos pelos elementos químicos de diferentes densidades de elétrons, tais que a razão da transmissão de raios $X$ fornecerá informação sobre os elementos nos tecidos (JEBB, 1997; PIERSON et al., 1997). 
Os aparelhos DEXA foram originalmente desenvolvidos para quantificar a massa óssea e esta ainda é sua aplicação primária. Contudo, com a propriedade de medir a atenuação de tecidos moles (MCM e MG) este método pode avaliar a composição corporal (VAN LOAN e MAYCLIN, 1992; TATARANI e RAVUSSIN, 1995; ZERBINI, 1998). Este método é não invasivo e requer menos cooperação dos individuos do que a hidrodensitometria (WELLENS et al., 1994).

A quantidade de radiação durante o exame da DEXA é mínima e é aproximadamente 500 vezes menor do que um raio $X$ do tórax ânteroposterior (TATARANI e RAVUSSIN, 1995). A dose efetiva equivalente por avaliação da composição corporal é menos do que $5 \mu S v$ e é indicada pelos níveis básicos de radiação. Esta baixa exposição de radiação permite até mesmo repetidos exames, apropriados para todos indivíduos, incluindo bebês e crianças, embora continue sendo prudente não fazer exames em gestantes. Apesar de não serem portáteis, as máquinas podem ser colocadas em unidades móveis se necessário (JEBB, 1997).

Uma das desvantagens da DEXA é a limitação da mesa do equipamento, pois a exatidão das medidas em pessoas muito altas ou obesas, que excedem as dimensões da área do equipamento, pode ser prejudicada (TATARANI E RAVUSSIN, 1995). Pode haver, também, diferença nos resultados da DEXA entre máquinas dos diversos fabricantes 
por causa das variações nos procedimentos de calibração, unidades de energia irradiadas, além dos softwares que contêm algorítmos usados para estimar a composição corporal dos dados absorvidos (WELLENS et al., 1994). Outra desvantagem é o alto custo de cada exame (particular: cerca de US $\$ 50,00$; tabela do Sistema Único de Saúde-SUS: US $\$ 20,00$; tabela Consórcio Intermunicipal de Saúde do Noroeste do Estado do RS-CISA: US\$18,00 (SMSMA/ljui/RS, 2003, informações verbais), o que acarreta custos elevados em estudos com grandes amostras.

\subsubsection{Análise de impedância bioelétrica - BIA}

A BIA é um método baseado em propriedades dielétricas diferindo tecido magro do gordo. Este método envolve o uso de um analisador de impedância bioelétrica, que pode ser portátil ou de mesa. É um método de injeção de corrente, com intensidade de 500 a 800 mA (Micro Ampéres) e freqüência de $50 \mathrm{kHz}$ (Kilohertz) localizada. Produz uma medida de resistividade corporal total, a qual é o inverso da condutividade. Faz uso do fato de que a impedância do fluxo elétrico de uma corrente injetada é relacionada ao volume do condutor (estatura). Este princípio foi demonstrado por HOFFER et al. (1969) que observaram que a água corporal total e a massa corporal magra foram fortemente correlacionadas com estatura ${ }^{2} /$ resistência, onde resistividade corporal ou impedância foi medida por meio de um método eletrônico, tetra-polar (SEGAL et al., 1985). 
A BIA baseia-se no conceito de que tecidos ricos em água e eletrólitos são menos resistentes a passagem de uma corrente elétrica do que tecidos adiposos ricos em gordura. Na teoria, um indivíduo sem nenhum tecido adiposo deve ter uma impedância minima e a impedância deve aumentar para um, máximo quando todo tecido magro for substituído por tecido adiposo preenchido de gorduras (HEYMSFIELD, 1997). Enquanto que o termo "resistência" aplica-se a uma corrente contínua, o termo "impedância" refere-se a uma corrente alternada e ambos os termos expressam a resistência ou o inverso de condutividade de um campo eletromagnético. Como a MCM contém muita água, ela oferece uma baixa resistência à passagem da corrente elétrica. O tecido adiposo, por sua vez, é um mal condutor da corrente elétrica, oferecendo alta resistência muito embora possua água (RIELLA, 1988). A resistência está relacionada ao contingente eletrolítico contido principalmente na $\mathrm{MCM}$, e a reatância fornece informação quanto à integridade da célula (COSTA, 2001).

A BIA é menos sensível a variações de resistência nos tecidos do tronco do que dos membros, por isso não é um método muito válido para estimativa de gordura visceral e abdominal. O analisador de BIA mede a água corporal e depois calcula, quantitativamente, a gordura por meio de equaçōes preestabelecidas, sendo então um método duplamente indireto (DÂMASO, 2001). 
Durante a década de 80 , a BIA foi introduzida como um método simples, seguro, não invasivo e relativamente econômico, quando comparada com outros métodos já citados, para avaliar a composição corporal (RIELLA, 1988; HEYMSFIELD, 1997; LUKASKI, 2000).

A duração do exame é de cerca de 5 minutos e pode ser realizada em indivíduos de 10 a 90 anos, com MC variando de 27 a $204 \mathrm{~kg}$ e estatura de 121 a $198 \mathrm{~cm}$. O custo por exame varia de US $\$ 7,00$ a US $\$ 42,00$, o preço do equipamento portátil de marca RJL é de US $\$ 3.000,00$ e o de 100 unidades de eletrodos é de US $\$ 35,00$ (CompCorp Ltda., 2003, informaçōes verbais).

Mesmo tendo um valor financeiro menor do que outros métodos de avaliação da composição corporal, o custo do equipamento utilizado na BIA é mais alto do que das medidas antropométricas, motivo porque, atualmente, esta técnica não é muito utilizada em estudos epidemiológicos. Além disso, são necessários certos cuidados durante o exame, como a manutenção das temperaturas do ambiente e corporal, hidratação, posição e concentração sérica de eletrólitos do indivíduo a ser avaliado. Outra desvantagem da BIA é - desconhecimento das equações que acompanham os softwares dos equipamentos, as quais deveriam ser especificas para cada tipo de população.

Mesmo com estas limitações, acredita-se que a BIA também pode ser usada em estudos epidemiológicos, pois ela parece ser mais sensivel do 
que medidas antropométricas para avaliar a composição corporal, sendo seu custo mais baixo do que o de outras técnicas mais sofisticadas como a DEXA. FRANZ et al. (2002) analisando a BIA como método de avaliação da composição corporal de individuos adultos e idosos, de ambos os sexos, ingressantes em projetos denominados "Universidades Abertas à Terceira Idade" de quatro instituições de ensino do municipio de São Paulo, concluiu que é possível sua utilização em estudos epidemiológicos, por ser de fácil aplicação, principalmente quando é utilizado equipamento do tipo portátil.

\subsubsection{Interactância de raios infravermelhos}

Este método baseia-se nos principios de absorção e reflexão de raios infravermelhos pela MG e MCM. O método é duplamente indireto, sendo utilizado um analisador, usualmente o Futrex, composto por um minicomputador, um protetor de luz e um sensor em forma de microfone por onde ocorre a emissão da luz. É necessário fornecer as informações sobre sexo, idade, massa corporal, estatura e compleição física do indivíduo a ser analisado. O sensor do equipamento é apoiado sob o bíceps do indivíduo e o analisador calcula rapidamente a quantidade de MG, MCM e água corporal total. O aparelho tem um custo consideravelmente alto, cerca de US\$3.800,00, apesar da facilidade e rapidez de aplicação. No entanto, as avaliaçōes individuais apresentam baixo custo para o avaliado (DÂMASO, 2001; KAMIMURA et al., 2002). No entanto, comparando-se com as outras técnicas de avaliar a composição corporal, já validadas em várias pesquisas, 
a interactância de raios infravermelhos necessita de mais estudos (HEYWARD, et al., 2000).

\subsubsection{Pesagem hidrostática}

Neste método a pessoa é pesada no meio ambiente e depois submersa em água. Para a submersão, a pessoa tem que retirar o ar dos pulmōes por meio de expiração forçada, porém sabe-se que mesmo assim, ainda resta um volume residual nos pulmōes. As limitações do método são a necessidade de um alto grau de cooperação do avaliado e a adaptação do individuo ao meio líquido. Diferentemente das outras técnicas já citadas (DEXA, BIA e interactância de raios infravermelhos), o treinamento do avaliador não consiste apenas no posicionamento do indivíduo ou colocação de eletrodos. Exige, também, treinamento em atividades subjetivas como, por exemplo, quando considerar que a pessoa já expirou todo o ar do pulmão. É recomendado que sejam feitas de 8 a 12 medições, sendo que alguns autores preconizam que se considere apenas as duas ou três últimas medidas e que seja feita, então, uma média (DÂMASO, 2001).

A pesagem hidrostática é um indicador de referência convencional na avaliação da composição corporal, mas pode necessitar de alterações ou mesmo ser substituído por métodos mais novos (por exemplo, DEXA) para obter medidas de referência válidas em determinadas condições em que se encontra 0 individuo. A pesagem hidrostática é extremamente estressante 
para alguns indivíduos, como os idosos, quando apresentam dificuldade para entrar e sair do tanque de pesagem, flexionar-se o suficiente para ficar totalmente submerso, e expirar ao máximo todo o ar dos pulmões para estimar o volume residual pulmonar. Essas dificuldades podem afetar substancialmente a exatidão e o erro de medida do método de pesagem hidrostática (10 a 15\% da gordura corporal) (CHUMLEA e BAUMGARTNER, 1989).

\subsubsection{Determinação da água corporal total (ACT) por diluição de isótopos - hidrometria}

Para a determinação da ACT, é utilizada a administração de substâncias marcadoras, que se difundem e misturam com a água existente no corpo. Usando-se uma dose oral ou intravenosa, o isótopo é injetado e amostras sangüínea ou urinária são coletadas após algumas horas . Com os valores, é possivel calcular a ACT usando uma equação com uma razão baseada em componente conhecido $(0,73)$. Sabendo-se o valor da ACT, a gordura pode ser calculada como:

$$
G C T=M C-M C M=\frac{A C T}{0,73} \quad \text { (HOFFMAN et al., 2000). }
$$

O tempo gasto em seus procedimentos é de cerca de duas ou três horas, por que somente após este período ocorre a combinação de 
substâncias marcadoras para posterior análise química; se for utilizada análise de plasma sangüíneo, esse tempo pode ser diminuído. Outra desvantagem é que este método não leva em conta a variação da fração aquosa, do balanço hídrico e da própria massa magra, além de ser invasivo (GUEDES, 1994; DÂMASO, 2001).

\subsubsection{Contagem de potássio corporal total (KCT) - espectrometria}

A contagem de KCT é feita por meio de análise de ativação de nêutrons, que se dá através da exposição dos indivíduos a serem avaliados à radiação ionizante (no caso do $\mathrm{K}$, são usados os radioisótopos $\mathrm{K}_{40}$ e $\mathrm{K}_{42}$ ) (HOFFMAN et al., 2000; DÂMASO, 2001). A gordura estimada através do KCT considera a razão K/gordura corporal total como estável e conhecida. No entanto, esta razão varia segundo a idade, sexo, doença e uso de diurético (HOFFMAN et al., 2000).

\subsubsection{Tomografia computadorizada (TC) e ressonância magnética (RM)}

Estes dois métodos de imagem podem quantificar a massa muscular ou o tecido adiposo de regiões específicas do organismo, pois são apresentadas imagens de cortes transversais ao maior eixo do organismo. Com as imagens, reconstrói-se o volume de determinada área que pode ser convertido em $\mathrm{Kg}$, sabendo-se a sua densidade. É possível, também, 
separar o tecido gorduroso do tecido subcutâneo visceral ou intraparenquimatoso, com exceção do tecido gorduroso da medula óssea, que não pode ser bem quantificado (HOFFMAN et al., 2000).

A TC propicia exposição à radiação, enquanto a RM não apresenta este risco. No entanto, a RM é um exame mais demorado, o que pode conduzir a erros de medidas pela maior movimentação das vísceras abdominais durante o exame. Ambos os métodos podem ser utilizados em pesquisas, porém são onerosos (HOFFMAN et al., 2000).

Frente à importância de avaliar corretamente a composição corporal, verifica-se que os métodos indiretos são os que melhor estimam a quantidade de MG e MCM no organismo, sendo a DEXA o mais recomendável dentre eles. Na maioria, as técnicas citadas são altamente sofisticadas necessitando de adaptação dos indivíduos a alguns dos procedimentos, de operadores experientes e de equipamentos e materiais de alto custo. Dentre estas, a BIA e a técnica por raios infravermelhos seriam as menos onerosas para estudos populacionais. No entanto, muitas vezes, principalmente em países em desenvolvimento a opção é trabalhar com medidas antropométricas e estimar os constituintes do corpo através de equações preditivas. 


\subsection{Medidas antropométricas}

A antropometria é um conjunto de indicadores que mede as dimensões físicas do corpo. Estes indicadores são de baixo custo, não invasivos, praticamente inócuos e ideais para consultório ou trabalhos de campo, sendo amplamente usados na avaliação do estado nutricional em humanos (OMS, 1995; DÂMASO, 2001). Ela é constituída pelas medidas de MC, estatura, indice de massa corporal-IMC, dobras cutâneas e perímetros (OMS, 1995).

As principais desvantagens dos métodos antropométricos são decorrentes da precisão e a reprodutibilidade, que são mais baixas do que as de métodos mais sofisticados que medem indiretamente a composição corporal (HEYMSFIELD, 1997), o mesmo ocorrendo na comparação com métodos laboratoriais. Cada método antropométrico deve ser realizado sempre pelo mesmo profissional de saúde, que deve estar convenientemente treinado para evitar erros ainda maiores do que os previstos para os próprios métodos. No entanto, a principal questão, aqui colocada, é seu potencial em avaliar a MG e a MCM. 


\subsection{1 Índice de massa corporal - IMC}

A maioria dos estudos epidemiológicos utiliza dados sobre MC e estatura para avaliar estado nutricional, pois essas variáveis são fáceis e de baixo custo para coletar e podem ser avaliadas por autodepoimento. Uma combinação de massa corporal e estatura é o IMC, considerado um índice alternativo para avaliar gordura corporal (WILLET, 1998). $O$ índice de massa corporal mais amplamente usado é o proposto por Quetelet que define o IMC como sendo a massa corporal/estatura ${ }^{2}$ (massa corporal medida em quilogramas e estatura em metros). Este indice tem a vantagem de ser econômico, seguro e fácil de obter (HEYMSFIELD, 1997). Porém os valores de IMC devem ser interpretados com cautela como estimativas de gordura corporal (WHO, 2000), pois uma pessoa pode estar dentro de um IMC adequado, mas com um percentual de gordura elevado quando sua composição corporal é avaliada por técnicas mais especificas.

O IMC é considerado o método antropométrico mais simples, indicado para estudos populacionais, pois permite classificar o indivíduo em eutrófico, desnutrido, com sobrepeso ou obeso. Porém, é considerado um índice prévio de avaliação, um índice de triagem, havendo necessidade da utilização de outros métodos para maior segurança, principalmente no caso de indivíduos doentes. Tem como limitação não medir os diferentes constituintes do corpo separadamente (DÂMASO, 2001) e seu poder 
preditivo é dependente da idade, em função das perdas substanciais de MCM por alguns, mas não todos indivíduos idosos (WILLET, 1998).

\subsubsection{Dobras cutâneas - DC}

A quantificação da gordura corporal também pode ser feita usando a técnica da espessura de dobras cutâneas, aferidas em locais prédeterminados, podendo ser usadas individualmente, em somatórias, ou incorporadas em equações de regressão. Estas últimas são equações preditivas da gordura corporal total (JEBB et al., 1994; HEYMSFIELD, 1997).

A espessura das dobras cutâneas pode ser medida em vários locais do corpo e as mais comuns são no biceps, triceps, nas regiões subescapular, supra-iliaca, axilar média, abdômen, coxa e panturrilha medial (BEHNKE \& WILMORE, 1974; DÂMASO, 2001). Tais medidas são, usualmente, feitas no lado direito do corpo, com o indivíduo em pé. No mínimo duas medidas são necessárias para cada local, sendo que alguns autores, como DÂMASO (2001), recomendam três medidas, no mínimo. Há baixa reprodutibilidade e baixa precisão das medidas entre operadores e mesmo com o mesmo operador realizando medidas repetidas, sendo recomendado um período de treinamento de 3 meses (PIERSON et al., 1997). 
O equipamento utilizado é o compasso para medir dobra cutânea, também conhecido como adipômetro ou plicômetro. Ele é econômico quando comparado com as outras técnicas de avaliar a composição corporal, variando de US\$150,00 a US\$930,00 dependendo da marca. Só uma cooperação mínima é requisitada do paciente. Medidas da espessura de dobras cutâneas em indivíduos obesos são impossiveis quando a espessura é maior do que a extensão das mandíbulas do plicômetro (PIERSON et al., 1997).

Outra limitação do uso da técnica de dobras cutâneas está relacionada com individuos idosos. Com o envelhecimento, o tecido adiposo é redistribuído, com níveis relativamente maiores de gordura subcutânea $\mathrm{e}$ interna depositados no tronco e não nas extremidades. A diminuição na elasticidade devido à menor hidratação da pele, bem como a diminuição no tamanho das células de gordura, podem aumentar a compressibilidade da gordura subcutânea e tecidos conjuntivos, podendo fornecer resultados alterados de composição corporal (KUCZMARSKI, 1989).

\subsubsection{Razão cintura/quadril $-R C Q$}

Estudos epidemiológicos têm utilizado, também, outro índice, denominado razão cintura/quadril ( $R C Q)$, como medida duplamente indireta da avaliação da massa gorda (COUTINHO, 1998). Este método enfatiza a 
importância da gordura localizada na região abdominal. Quanto maior for a relação, maior a chance da gordura estar localizada na região superior (central), sendo que o aumento dessa relação associa-se ao desenvolvimento de doenças cardiovasculares. A maior chance de o individuo apresentar doença cardiovascular advém do fato de que a gordura central tem caracteristicas diferenciadas da gordura periférica, pois esta apresenta resistência à ação da insulina, podendo resultar em outros distúrbios metabólicos e no desenvolvimento de outras doenças (DÂMASO, 2001).

\subsubsection{Perímetro da cintura - PCint}

Uma série de estudos realizados na Universidade Laval, em Quebec, em 1994, atribuiu uma precisão maior à medida isolada da cintura à da RCQ em identificar o excesso de gordura abdominal visceral e estimar o risco metabólico associado. Foram avaliadas centenas de pacientes por meio de tomografia computadorizada do abdome, demonstrando-se que um perimetro da cintura superior a $95 \mathrm{~cm}$ correspondia, quase sempre, a um acúmulo de tecido adiposo visceral, para qualquer grau de obesidade (COUTINHO, 1998). A RCQ pode, entretanto, continuar como um instrumento de pesquisa útil já que alguns especialistas consideram que a medida do quadril contém informação valiosa relacionada à massa muscular glúteo-fêmur e estrutura óssea (WHO, 2000). Há um risco aumentado de 
complicações metabólicas em homens que apresentam PCint $\geq 102 \mathrm{~cm}$, e em mulheres que apresentam PCint $\geq 88 \mathrm{~cm}$ (WHO, 2003).

As medidas do PCint e RCQ têm a vantagem de serem extremamente econômicas, necessitando apenas de uma fita métrica adequada. Além disso, não são invasivas, e necessitam de padronização da técnica e treinamento, como as demais medidas antropométricas (DÂMASO, 2001).

\subsection{Estudos de validação de métodos de avaliação da composição corporal considerando a DEXA como padrão-ouro.}

Conforme já comentado anteriormente, muitas vezes as medidas antropométricas são muito utilizadas; no entanto, elas não avaliam a composição corporal. Neste sentido, tanto a MCM quanto a MG podem ser estimadas a partir de equações preditivas que utilizam como variáveis independentes as medidas de antropometria, informações fornecidas pela BIA e dados demográficos. A seguir, estão citados trabalhos de literatura que validaram equaçōes para estimar a composição corporal considerando a DEXA como padrão-ouro. 


\subsubsection{Estudos relacionados com a massa gorda (MG)}

O Quadro 1 apresenta os estudos de validação de equações para estimar MG, tendo como padrão-ouro a DEXA.

TAAFFE et al. (1994) desenvolveram equações de predição, com razões derivadas da DEXA (gordura do tronco/gordura total-TrF/TotF; gordura do tronco/massa corporal total-TrF/BW; gordura do tronco/gordura dos membros-TrF/LimbF; e percentual de gordura do tronco-TrF\%) para avaliar distribuição de gordura regional em americanos idosos, e encontraram correlaçōes significativas com a medida antropométrica $\mathrm{RCQ}$ para ambos os sexos, sendo as mais fortes $\operatorname{TrF} / \mathrm{BW}(r=0,50)$ para homens e TrF/LimbF $(r=0,54)$ para mulheres.

STEWART e HANNAN (2000) compararam a capacidade das DCs abdominal e da coxa e BIA para predizer MG em uma amostra de 82 homens atletas, encontrando correlações significativas com a DEXA $(r=0,50$ e $r=0,81$ respectivamente). 
Quadro 1 - Estudos relacionados com a massa gorda, considerando a DEXA como padrão-ouro.

\begin{tabular}{|c|c|c|c|c|}
\hline AUTOR & PAÍS & POPULAÇĀO & EQUAÇĀO & $\boldsymbol{r}$ \\
\hline Taaffe et al.(1994) & EUA & homens idosos & Distribuição de gordura regional $=0,873+0,842 \cdot \mathrm{MG}_{\mathrm{DEXA}} \cdot \frac{\mathrm{TrF}}{\mathrm{BW}}$ & 0,50 \\
\hline \multirow{3}{*}{$\begin{array}{l}\text { Stewart \& Hannan } \\
(2000)\end{array}$} & \multirow{3}{*}{ Reino Unido } & mulheres idosas & Distribuição de gordura regional $=0,666+0,164 \cdot \mathrm{MG}_{\mathrm{DEXA}} \cdot \frac{\mathrm{TrF}}{\operatorname{LimbF}}$ & 0,54 \\
\hline & & homens atletas & $M G(g)=429,4 \cdot M C-283,6 \cdot \frac{E s t^{2}}{R}-73,1 \cdot \chi_{c}-134,1$ & 0,50 \\
\hline & & & $M G(g)=331,5$. DCabdominal $+356,0$. DCcoxa+111,9. MC $-9108,0$ & 0,81 \\
\hline
\end{tabular}




\subsubsection{Estudos relacionados com a massa corporal magra (MCM)}

No Quadro 2 está um resumo dos estudos de validação de equações para estimar MCM, que utilizam a DEXA como padrão-ouro.

LEWY et al. (1999) encontraram forte correlação entre indice de resistência (Est'/R), resistência fornecida pela $B I A(R)$, com MCM fornecida pela DEXA em crianças americanas negras $(r=0,99$ para meninos e $r=0,96$ para meninas), e em meninas com síndrome de ovário policístico e obesas $(r=0,99)$. As diferenças observadas nas equações preditivas de MCM entre crianças americanas brancas e crianças americanas negras levantam a importância do uso de fórmulas específicas por raça na composição corporal.

PICHARD et al. (1999) analisaram a validade de duas fórmulas para estimar MCM pela BIA comparadas com a MCM determinada pela DEXA, em um grupo de 480 indivíduos saudáveis e indivíduos com diversos tipos de doenças. Os resultados mostraram fortes correlações com a MCM medida pela DEXA em homens saudáveis $(r=0,91)$, homens com HIVIAids $(r=0,87)$, homens que fizeram transplante de fígado $(r=0,88)$, mulheres atletas $(r=0,88)$, mulheres que fizeram transplante de fígado $(r=0,93)$ mulheres com fibrose cistica $(r=0,83)$, homens com doença pulmonar $(r=0,89)$, homem hemiplégico $(r=0,92)$, homem com fibrose cística $(r=0,89)$, 
mulher com doença pulmonar $(r=0,92)$ e mulher hemiplégica $(r=0,96)$. Concluíram que a BIA é relevante na avaliação da composição corporal, mas fórmulas apropriadas devem ser utilizadas para indivíduos com caracteristicas diferentes.

PICHARD et al. (2000) validaram estimativas de MCM obtidas pela BIA em relação à DEXA, em população saudável de ambos os sexos, com idade entre 15-64 anos. Foram encontradas correlações significativas entre MCM estimada pela BIA e pela DEXA em homens não obesos $(r=0,97)$, mulheres não obesas $(r=0,96)$, homens obesos $(r=0,95)$ e para mulheres obesas $(r=0,82)$.

STEWART \& HANNAN (2000) verificaram que tanto a BIA quanto as DCs (abdominal, suprailiaca, coxa) podiam predizer a MCM em uma amostra de 82 homens atletas (respectivamente, $r=0,95 ; r=0,98$ ).

YANNAKOULIA et al. (2000) desenvolveram e validaram duas equaçōes para estimar a MCM em dançarinas usando a BIA como um método de avaliação e a DEXA como padrão-ouro $(r=0,91 ; r=0,93$ respectivamente). 
TYRRELL et al. (2001), em estudo com escolares entre 5 a 10 anos de idade, verificaram que as medidas fornecidas pela BIA poderiam estimar a $\operatorname{MCM}(r=0,98)$.

Verifica-se que estes estudos referem-se, em sua maioria, a populações específicas, algumas portadoras de doenças e todos foram feitos em países com características sócio-econômicas e de estilo de vida diferentes das dos brasileiros, necessitando-se assim de estudos locais. 
Quadro 2 - Estudos relacionados com a massa magra, considerando a DEXA como padrão-ouro.

\begin{tabular}{|c|c|c|c|c|}
\hline AUTOR & PAIS & POPULAÇĀO & EQUAÇĀO & $r$ \\
\hline Lewy et al.(1999) & EUA & $\begin{array}{l}\text { meninos americanos negros } \\
\text { meninas americanas negras } \\
\text { meninas com sindrome de ovário } \\
\text { policistico }\end{array}$ & $\begin{array}{c}M M=0.88 \frac{E s t^{2}}{R}+1,92 \\
M M=0,90 \frac{E^{2}}{R}+0.69 \\
M M=0,62 \frac{E^{2}}{R}+0,21 \cdot M C-1,94\end{array}$ & $\begin{array}{l}0,96 \\
0,99\end{array}$ \\
\hline $\begin{array}{l}\text { Pichard et al.(1999): } \\
\text { fórmula de Kotler et } \\
\text { al., } 1996\end{array}$ & Sulça & $\begin{array}{c}\text { homens saudáveis } \\
\text { homens HIV } \\
\text { homens transplante de flgado }\end{array}$ & $M M=0,50\left(\frac{E^{1,48}}{I^{0,55}}-\frac{1,0}{1,21}\right)+0,42-M C+0,49$ & $\mid \begin{array}{l}0,91 ; \\
0,87 ; \\
0,88\end{array}$ \\
\hline & & $\begin{array}{c}\text { mulheres atletas } \\
\text { mulheres transptransplante de .figado } \\
\text { mulheres fibrosecisticas }\end{array}$ & $M M=0,88\left(\frac{E^{1,97}}{I^{0,49}} \cdot \frac{1,0}{22,22}\right)+0,081 \cdot M C+0,07$ & $\begin{array}{l}0,88 ; \\
0,93 ; \\
0,83\end{array}$ \\
\hline fórmula de Geneva & & $\begin{array}{l}\text { homens doenças pulmonares } \\
\text { homens hemiplégicos } \\
\text { homens fibrose clstica } \\
\text { mulheres doença pulmonar }\end{array}$ & $M M=-6,6+$ Est $-0,283+M C-0,207 R-0,024+\operatorname{sex} 0-4,036$ & $\begin{array}{l}0,89 \\
0,92 \\
0,89 \\
0,92\end{array}$ \\
\hline
\end{tabular}




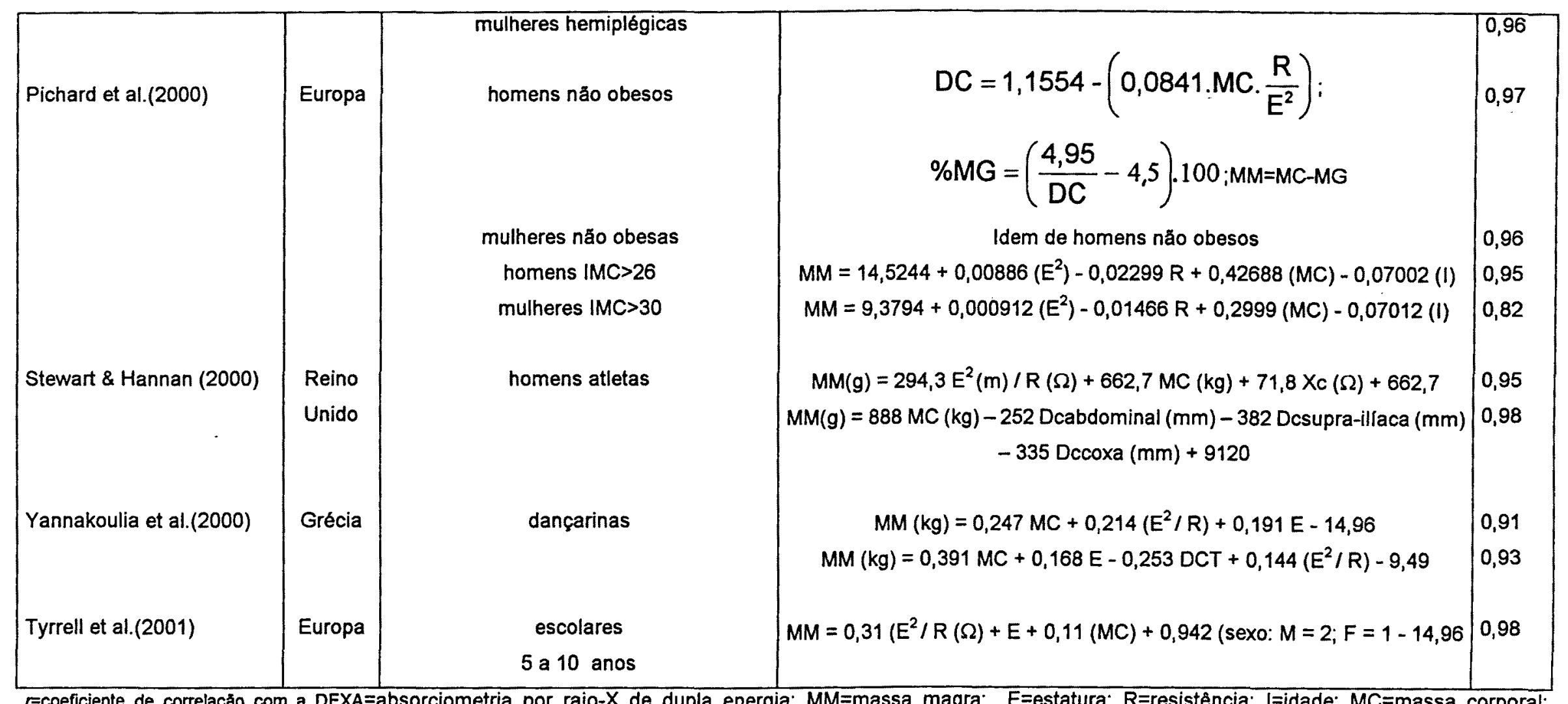

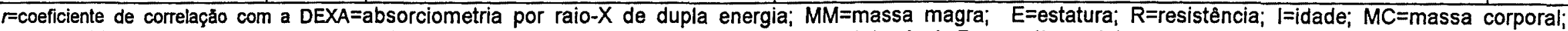

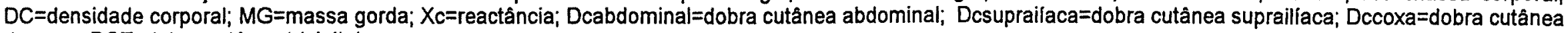
da coxa; DCT=dobra cutânea tricipital. 


\section{JUSTIFICATIVA}

Segundo GULLBERG (1997), em 1990, 16\% da população mundial do sexo masculino e $18 \%$ do sexo feminino estavam com 50 anos ou mais. A previsão para 2025 é a de que estas proporções estejam próximas a $25 \%$. No Brasil, segundo o Censo de $2000,15 \%$ da população do sexo masculino e $17 \%$ do sexo feminino estäo com 50 anos e mais de idade. Em 2020, a previsão é que estas porcentagens aumentem para $19 \%$ e $24 \%$, respectivamente (Fundação IBGE, 2000; Fundação IBGE, 2003). Com este aumento da população na faixa etária de 50 anos ou mais, sente-se necessidade de se conhecer melhor este grupo de indivíduos, com o propósito de proporcionar-lhes uma qualidade de vida melhor.

O Brasil vem passando por uma transição demográfica e epidemiológica, caracterizada por uma população mais velha e com predomínio de doenças crônico-degenerativas (SILVESTRE et al., 1996). Segundo MONTEIRO et al.(2000), também está ocorrendo uma transição nutricional, levando a uma diminuição da prevalência de desnutrição e um aumento da prevalência de obesidade. Prevalências de sobrepeso e obesidade estão aumentando mundialmente, afetando tanto paises desenvolvidos como os em desenvolvimento $e$ as conseqüências do aumento da gordura corporal na saúde dos indivíduos, principalmente nos idosos são muitas: desde riscos aumentados de morte prematura até riscos severos, mas não fatais, que levam a efeitos contrários a uma qualidade de 
vida satisfatória (WHO, 2000). Com isso há a preocupação com as técnicas de avaliação da composição corporal que irão medir ou estimar o componente de gordura corporal, o que vai caracterizar, quando aumentado, a obesidade.

A DEXA é considerada a melhor técnica para avaliar a composição corporal; no entanto, principalmente em países com menos recursos e dificuldades de acesso aos serviços de saúde, muitas vezes são utilizadas apenas as medidas antropométricas tanto nas pesquisas quanto nos serviços de saúde.

O uso de medidas antropométricas na avaliação do estado nutricional, vem sendo questionado, pois estes não avaliam, separadamente, os vários componentes corporais, levando os profissionais a buscarem outras medidas. Um excesso de MC e/ou IMC elevado, comparados com padrões de referência, pode não significar obesidade, e, sim, uma maior quantidade de MCM, como a musculatura desenvolvida dos atletas, por exemplo; ou, também, excesso de líquido, no caso de indivíduos que apresentam edema.

Existem várias técnicas para avaliar separadamente os constituintes do corpo, fornecendo valores especificos para cada finalidade. $0 \% \mathrm{G}$ deve ser medido quando o objetivo for avaliar a gordura corporal, e, conseqüentemente a obesidade, e a MCM quando o objetivo for avaliar a musculatura, elemento quimicamente ativo do organismo. 
Não foi encontrado estudo epidemiológico descrito na literatura brasileira tratando da análise das equações que estimam a composição corporal em homens com idade de 50 anos ou mais, comparando-as com a DEXA e, conforme apontado por diversos autores, estas equações devem ser estimadas a partir de dados da população total. Propõe-se, desta maneira, com este trabalho, estimar equações preditivas de \%G e MCM, e validar não só estas equações, mas aquelas propostas pela literatura e os valores estimados pela BIA. Optou-se por trabalhar especificamente com homens, tendo em vista que a maioria dos estudos avalia mulheres, ou não fazem separação segundo sexo.

Com os resultados deste trabalho, pretende-se propor modelo(s) preditivo(s) para avaliar o \%G e a MCM em estudos epidemiológicos com grandes amostras em homens brasileiros, entre 50 a 85 anos de idade. 


\section{OBJETIVOS}

1 - Desenvolver modelos preditivos para o percentual de gordura e massa corporal magra, para homens entre 50 e 85 anos de idade, tendo como variáveis explicativas as medidas obtidas pela análise de impedância bioelétrica (percentual de gordura, massa magra, resistência e reatância), índice de massa corporal, dobra cutânea tricipital, perímetros da cintura e quadril, razão cintura/quadril, massa corporal e estatura, .

2 - Estimar o percentual de gordura e a massa corporal magra em homens entre 50 e 85 anos de idade, através dos modelos desenvolvidos no presente estudo e dos modelos propostos na literatura.

3 - Validar as estimativas do valor do percentual de gordura e de massa corporal magra dos modelos desenvolvidos neste trabalho e dos valores fornecidos pela análise de impedância bioelétrica, e das equações preditivas da literatura, tendo como padrão-ouro os valores fornecidos pela absorciometria por raios $\mathrm{X}$ de dupla energia. 


\section{MATERIAL E MÉTODOS}

Este estudo está inserido em uma pesquisa intitulada "Avaliação clínica dos fatores de risco para osteoporose em homens", desenvolvida pelo Serviço de Reumatologia do Complexo Hospitalar Heliópolis, em conjunto com o Departamento de Epidemiologia da Faculdade de Saúde Pública (FSP) da Universidade de São Paulo (USP) (ZERBINI, 1998; FLORINDO, 2000a e 2000b; JAIME, 2000 e 2001; TANAKA, 2000; ZERBINI et al., 2000).

O Complexo Hospitalar Heliópolis, fundado em 1969, pertence ao Sistema de Saúde Pública do Estado de São Paulo e compõe-se de um Hospital e um Posto de Atendimento Médico (PAM) situados na região sul da cidade de São Paulo. Sua abrangência de atendimento inclui a própria região sul de São Paulo e as cidades de Santo André, São Bernardo do Campo, São Caetano do Sul e Diadema.

A coleta de dados para a pesquisa citada foi efetuada no período de fevereiro a setembro de 1997. A equipe que a desenvolveu, coordenada por uma docente do Departamento de Epidemiologia da FSPIUSP (orientadora desta tese), contou com três médicos da especialidade de Reumatologia, uma nutricionista, uma técnica em DEXA e uma secretária. 


\subsection{Delineamento do estudo}

Este estudo é do tipo transversal, observacional (PEREIRA, 1999), abrangendo indivíduos voluntários do sexo masculino.

\subsection{População de estudo}

Foram recrutados 357 indivíduos voluntários do sexo masculino com idades entre 50 e 85 anos. O recrutamento foi realizado através da imprensa (anúncios em jornal), avisos colocados no posto de atendimento médico do Hospital Heliópolis, pessoas conhecidas dos membros da equipe, indivíduos submetidos a controle periódico pelo serviço de cardiologia do hospital, cônjuges de mulheres que compareceram para realizar a densitometria óssea e funcionários do complexo hospitalar.

Os critérios de inclusão foram ser do sexo masculino, possuir idade igual ou superior a 50 anos, estar em bom estado de saúde e possuir estatura até 190 centímetros devido à limitação de visibilidade do corpo no aparelho de DEXA. Os critérios de exclusão foram a presença ou antecedência de patologias endócrinas (hipotireoidismo, hipertireoidismo, hiperparatireoidismo e diabetes mellitus), gastrointestinais (doença hepática, gastrectomia e colite), doença reumatóide, cálculo renal, mieloma múltiplo e outras neoplasias. Outro critério de exclusão adotado foi a ingestão de 
medicamentos que possam afetar o metabolismo ósseo ou causar osteoporose, como corticosteróides, anticonvulsivantes, antiácidos e diuréticos e o consumo de suplementos de cálcio e proteína. Estes critérios foram determinados pela pesquisa de origem.

Da população inicial foram excluídos 37 indivíduos por não conterem em suas pastas algumas das medidas necessárias à realização do atual estudo, constituindo-se a população final de 320 indivíduos (198 adultos com idade até 64 anos e 122 idosos com idade igual ou maior que 65 anos). Segundo PASCHOAL (1996), a Organização das Nações Unidas (ONU) define 65 anos como ponto de corte para caracterizar a população idosa em países desenvolvidos, e em países em desenvolvimento, onde a expectativa de vida é menor, esse ponto de corte é de 60 anos. No caso do Brasil, como a população idosa está aumentando rapidamente, e conseqüentemente a expectativa de vida, muitos estudos optam pelo ponto de corte de 65 anos, como foi o caso desta pesquisa.

\subsection{Metodologia}

Foram programadas duas visitas por participante. Na primeira visita, foram colhidos os dados antropométricos e de composição corporal pelas técnicas de BIA e DEXA, além de outros dados que não fazem parte do presente estudo, como anamnese clínica, aplicação do questionário de 
atividade física e orientação para preenchimento do diário alimentar. $\mathrm{Na}$ segunda visita, além de devolverem o formulário do diário alimentar, os participantes receberam os exames analisados e foram informados dos resultados pelos médicos e pela nutricionista, recebendo orientação, e encaminhamento se necessário.

Não foram seguidos os protocolos sugeridos por HEYWARD \& STOLARCZYK, 2000 (não comer ou beber a menos de quatro horas do teste; não fazer exercícios a menos de doze horas do teste; urinar a menos de 30 minutos do teste; não consumir álcool a menos de 48 horas do teste; não tomar medicamentos diuréticos a menos de sete dias do teste).

\subsubsection{Medidas antropométricas}

As medidas antropométricas foram realizadas por uma única pesquisadora, nutricionista treinada para esta atividade.

Massa corporal: medida em quilograma $(\mathrm{kg})$. O equipamento utilizado foi balança Filizola, com capacidade de $150 \mathrm{~kg}$ e sensibilidade de $100 \mathrm{~g}$. Os entrevistados foram pesados sem sapatos e com roupas leves (avental do hospital), sendo adotadas as recomendações da OMS, 1995. 
Estatura: para coleta de dados de estatura corporal utilizou-se um estadiômetro. Os indivíduos foram medidos descalços em posição ortostática, com o corpo erguido em extensão máxima e a cabeça ereta, olhando à frente (arco orbital inferior alinhado em um plano horizontal com o pavilhão auricular - "plano Frankfurt). Obteve-se o ponto de medida com aproximação em cm, sendo adotadas as recomendações da OMS, 1995.

Índice de massa corporal - IMC: foi calculado como a razão entre a massa corporal (em kg) e a estatura ao quadrado (em m) (OMS, 1995).

Dobra cutânea tricipital - DCT: para a mensuração da DCT foi utilizado um compasso, tipo Lange (Cambridge Scientific Instruments), com sensibilidade de $1 \mathrm{~mm}$, sendo adotadas as recomendações técnicas feitas pela OMS, 1995.

A DCT foi medida no lado posterior do braço, sobre o músculo tríceps, no ponto médio entre o acrômio, no ombro, e o olecrânio no cotovelo. Com o cotovelo flexionado em um ângulo de $90^{\circ}$, foi determinado o ponto médio, usando uma fita métrica flexivel de fibra de vidro. O ponto médio foi marcado com o auxílio de uma caneta. $O$ indivíduo foi medido em pé, com o braço pendente, frouxo e confortavelmente, ao lado do corpo. O examinador, com a ajuda dos dedos polegar e indicador de sua mão esquerda, pinçou gentilmente a dobra da pele e tecido subcutâneo, em posição vertical, 
aproximadamente $1 \mathrm{~cm}$ acima do local marcado. Segurando o plicômetro na sua mão direita, as hastes foram aplicadas perpendicular à dobra cutânea no nivel marcado.

Perimetros: cintura e quadril - PCint e $P Q$ : para a mensuração dos perímetros foi utilizada uma fita métrica flexível de fibra de vidro, mas não elástica, e adotadas as técnicas preconizadas pela OMS, 1995.

O perímetro da cintura foi medido com o indivíduo em pé, com a sua MC distribuída sobre ambos os pés, os quais estavam afastados a uma distância de 25 a $30 \mathrm{~cm}$. A medida foi efetuada a uma distância média entre a borda inferior da última costela e a crista ilíaca, em um plano horizontal. Com o observador sentado junto ao indivíduo foi colocada a fita ao redor do corpo na altura da cintura, mas não tão ajustada que comprimisse os tecidos brandos. Foi medido o perímetro até $0,1 \mathrm{~cm}$ mais próximo ao final de uma expiração normal.

O perímetro do quadril foi medido com o indivíduo em pé, com os braços ao longo do corpo e os pés juntos. Com o observador sentado junto ao indivíduo de tal modo que pudesse ver o nível de extensão máxima das nádegas, foi colocada a fita métrica ao redor destas, em um plano horizontal. A fita foi colocada junto à pele, mas sem comprimir os tecidos brandos. Foi registrada a medida até $0,1 \mathrm{~cm}$ mais próximo. 
Razão cintura/quadril - RCQ: foi calculada como a razão entre o perímetro da cintura (cm) e o perímetro do quadril (cm) (OMS, 1995).

\subsubsection{Técnicas utilizadas para avaliar a composição corporal}

Absorciometria por raios $X$ de dupla energia - DEXA: os exames foram realizados por uma única técnica em DEXA, utilizando um único equipamento de dupla energia por raios X modelo DPX (Lunar Corp., Madison, WI, Estados Unidos). Foi adotado procedimento padrão para o posicionamento dos pacientes durante a fase de realização do exame, que foi analisado com o software Lunar versão $3,6 z$.

Antes de cada sessão foi realizado o controle de qualidade do aparelho, que era calibrado com um standart phantom de alumínio fornecido pelo próprio fabricante cujo valor nominal da densidade é de $1,215 \mathrm{~g} / \mathrm{cm}^{2}$. Este modelo de alumínio é construído para simular as vértebras lombares $\left(L_{2}-L_{4}\right)$ no processo de absorção/espalhamento dos fótons de raios-X (TANAKA, 2000).

O coeficiente de variação das medidas densitométricas do aparelho foi de $1,5 \%$ tanto para a coluna lombar quanto para a região proximal do fêmur. Este valor foi calculado através dos resultados de densitometria óssea de coluna lombar e fêmur proximal de 35 homens (duas vezes por 
semana durante um mês, totalizando oito medidas por homem). A variação das medidas da densidade do phantom (erro de precisão) obtidas diariamente durante a realização do estudo ficou restrita a 1,5\%. No mesmo período, a média do valor obtido nas diversas medidas representou um afastamento do valor nominal (erro de exatidão) de $-0,42 \%$ (TANAKA, 2000).

Todos os exames foram analisados por um único médico.

Análise de impedância bioelétrica - BIA: a análise de impedância bioelétrica foi realizada por uma única pesquisadora, nutricionista treinada para esta atividade. As medidas de resistência e reatância utilizadas para o cálculo da análise de impedância bioelétrica foram realizadas com um aparelho analisador modelo BIA 101 Q - portátil, fabricado pela RJL Systems Inc, o qual era testado a cada dia de coleta de dados, anteriormente à série de medidas, conforme orientação fornecida pelo Manual do Usuário CompCorp (LARSSON e PRADO, s/d). Para testar o aparelho utilizou-se a resistência padrão (500 Ohm) que acompanha o sistema para testar o circuito eletrônico de leitura da impedância, a integridade dos cabos, as pinças de conexão dos eletrodos e a bateria. A técnica utilizada para medir a resistência e reatância foi a do Manual do Usuário CompCorp (LARSSON e PRADO, s/d). 
A medida foi realizada com o indivíduo deitado em decúbito dorsal, em seu lado direito, colocando-se eletrodos na mão e no pé. As pernas foram afastadas uma da outra, evitando contato dos tornozelos e joelhos e as mãos e braços foram afastados do corpo. A pele onde foram colocados os eletrodos foi limpa com algodão embebido com álcool. Os eletrodos foram colocados em uma linha imaginária que dividia a cabeça da ulna e se iniciava na protuberância óssea do punho. $\mathrm{O}$ outro eletrodo foi colocado acima do nó do dedo médio da mão. No pé, o eletrodo foi colocado em uma linha imaginária que dividia os maléolos medial e lateral. 0 outro foi colocado acima do nó do dedo médio do pé. Os cabos pretos do aparelho foram colocados nos eletrodos distais, e os cabos vermelhos nos eletrodos proximais. As pinças de conexão (jacarés) de cor preta foram conectadas nos eletrodos distais (próximos aos dedos), e as pinças de conexão (jacarés) de cor vermelha foram conectadas nos eletrodos proximais (punho e tornozelo) (Figura 1). Após este procedimento, com o aparelho ligado era realizada a leitura da resistência e reatância. 
Figura 1 - Locais de colocação dos eletrodos, para fixar as pinças do impedanciômetro na medida da resistência e reatância.

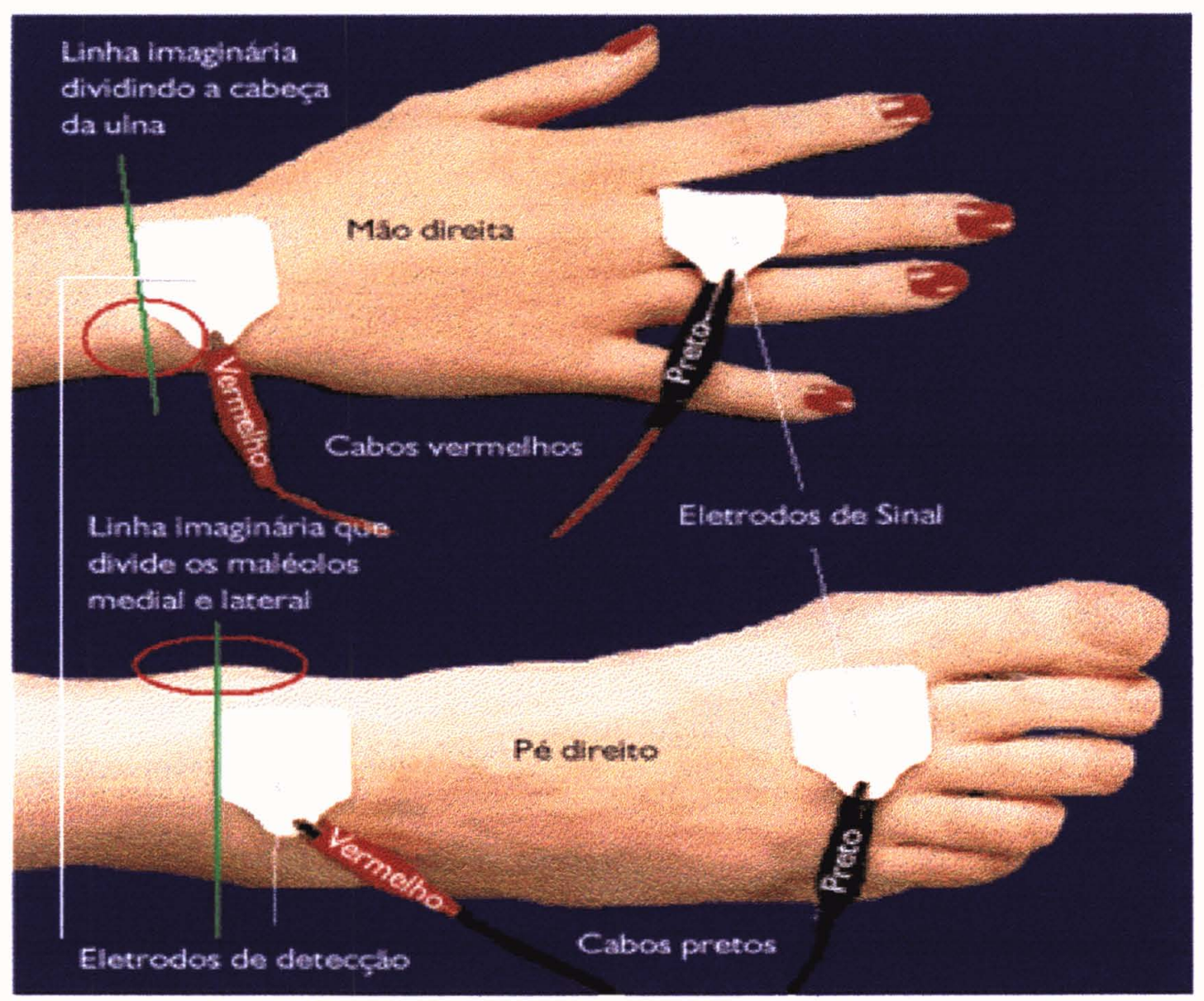

Fonte: Larsson EJ, Prado RR, s/d (autorizado). 


\subsection{Variáveis de estudo}

\section{-Variáveis dependentes}

Percentual de gordura medida pela DEXA (\%)

Massa corporal magra medida pela DEXA (Kg)

\section{-Variáveis independentes}

Idade (em anos)

Cor da pele: brancos e não brancos

Percentual de gordura medida pela BIA (\%)

Massa corporal magra medida pela BIA $(\mathrm{Kg})$

Índice de massa corporal (IMC, $\frac{\mathrm{Kg}}{\mathrm{m}^{2}}$ )

Dobra cutânea tricipital (DCT, mm)

Perimetro da cintura (Pcint, $\mathrm{cm}$ )

Perimetro do quadril $(\mathrm{PQ}, \mathrm{cm})$

Razão cintura/quadril (RCQ)

Massa corporal (MC, $\mathrm{Kg}$ )

Estatura (Est, m)

Resistência (R, Ohm)

Reatância $\left(\chi_{\mathrm{c}}, \mathrm{Ohm}\right)$ 


\subsection{Análise estatística}

Para desenvolver e validar as equações de regressão para a estimativa do percentual de gordura e valor de massa corporal magra, a populaçãó de estudo foi dividida em duas amostras aleatórias independentes. Uma amostra foi utilizada para o desenvolvimento das equações de regressões, e a outra para validar as equações desenvolvidas (CARVALHO E PIRES NETO, 1998; HEYWARD e STOLARCZYK, 2000).

Com os dados da amostra 1, primeiramente as variáveis foram analisadas de forma descritiva por meio de médias, desvios padrão, valores mínimos e máximos e medianas. Nesta etapa foi avaliado se as variáveis tinham distribuição normal pelo teste de Kolmogorov-Smirnov.

Foram comparadas as médias de $\% \mathrm{G}$ e valores de MCM estimadas pela DEXA segundo cor da pele e faixa etária através do teste t-Student. Esta avaliação foi feita para verificar se havia necessidade de se estimar modelos específicos para brancos e não brancos ou segundo faixa etária.

Foi feita a análise de correlação de Pearson ou Spearmam. Por último, foram desenvolvidos modelos de predição para o percentual de gordura e outro para massa corporal magra através da análise de regressão 
linear múltipla, tendo como variáveis dependentes medidas de DEXA e as demais variáveis como preditoras.

Para a elaboração do modelo múltiplo foi utilizado o procedimento stepwise forward selection, sendo que a ordem de entrada das variáveis no modelo foi definida pelo valor do coeficiente de correlação. Foi feita a análise de residuos dos modelos múltiplos e em todos foi verificado que havia homocedasticidade dos mesmos (Anexo 4).

Em uma segunda etapa, utilizando a segunda amostra, foram estimados os valores de \%G e MCM através das equações propostas em literatura (Quadros 3 e 4) e das equações propostas por esta pesquisa. Optou-se por trabalhar com todas as equações propostas, independente da faixa etária, pois restaria apenas uma equação para ser analisada. 
Quadro 3 - Equações da literatura para estimar massa gorda em homens.

\begin{tabular}{|l|c|c|}
\hline \multicolumn{1}{|c|}{ AUTOR } & $\begin{array}{c}\text { POPULAÇAOO } \\
\text { E IDADE }\end{array}$ & EQUAÇAOO \\
\hline Garrow \& Webster (1985): & $\begin{array}{c}n=24 \\
\text { homens } \\
(14-60 \text { anos) }\end{array}$ & $M G=(0,715 . I M C-12,1) . E^{2}$ \\
Deurenberg et al. (1991): & $\begin{array}{c}n=661 \\
216 \text { anos } \\
\text { Lean et al. (1996): }\end{array}$ & $\% G=-5,4+1,2$. IMC $+0,23.1-10,8$. sexo \\
& $\begin{array}{c}n=63 \\
\text { homens } \\
(16,8-65,4 \text { anos) }\end{array}$ & $\% G=-31,8+0,567$. PCint $+0,101.1$ \\
\hline
\end{tabular}

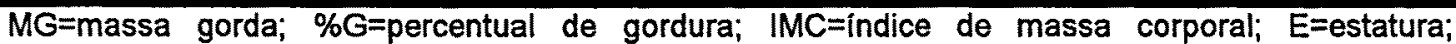
PCint=perimetro da cintura; $l=i d a d e ;$ Sexo: $M=1, F=0$. 


\section{Quadro 4 - Equações da literatura para estimar massa magra em} homens.

\begin{tabular}{|c|c|c|}
\hline AUTOR & $\begin{array}{l}\text { POPULAÇÃO } \\
\text { EIDADE }\end{array}$ & EQUAÇAOO \\
\hline $\begin{array}{l}\text { Segal et al. (1988): equações } \\
\text { preditivas dos fabricantes (RJL) }\end{array}$ & & $\mathrm{MCM}=6,493+0,4936 \cdot \frac{\mathrm{Est}^{2}}{\mathrm{R}}+0,332 \cdot \mathrm{MC}$ \\
\hline Segal et al.(1988): & $\begin{array}{c}n=1069 \\
(17-62 \text { anos }) \\
\text { geral }\end{array}$ & $M C M=22,66827+0,00132 . E^{2}-0,04394 . R+0,30520 . M C-0,16760.1$ \\
\hline Gray et al. (1989) & $\begin{array}{c}n=25 \\
\text { homens } \\
(19-70 \text { anos })\end{array}$ & $M C M=39,830+0,00139 . E s t^{2}-0,0801 . R+0,187 . M C$ \\
\hline Deurenberg et al. (1991) & $\begin{array}{c}n=661 \\
16-83 \text { anos }\end{array}$ & $M C M=-12,44+0,340 \cdot 10^{4} \cdot \frac{E_{s t}^{2}}{R}+15,34 \cdot E s t+0,273 \cdot M C-0,127.1+4,56 \cdot s e x$ \\
\hline Lohman (1992) & $\begin{array}{l}\text { homens } \\
\text { (50-70 anos) }\end{array}$ & $M C M=-10,9+0,600 \cdot \frac{E^{2} t^{2}}{R}+0,186 \cdot M C+0,226 \cdot \chi_{c}$ \\
\hline
\end{tabular}

$M C M=$ massa corporal magra; Est=estatura; $R=$ resistência; $M C=$ massa corporal; l=idade; Sexo: $M=1$, $\mathrm{F}=0 ; \chi_{c}=$ reatância. 
Por último foi feita a análise de validação das equações propostas e das medidas derivadas da BIA através do coeficiente de correlação intraclasse de Pearson $\left(r_{i c c}\right)$, teste t-Student pareado e erro padrão de estimativa (EPE) (HEYWARD e STOLARCZYK, 2000).

A estimativa foi considerada boa quando o $P 0,80$ (HEYWARD e STOLARCZYK, 2000).

Para o cálculo $e$ análise do EPE foi utilizada a fórmula EPE = $s=\sqrt{1-r^{2}}$, onde $s=$ desvio-padrão e $r$ coeficiente de correlação, segundo os padrões de LOHMAN (1992) (Quadro 5).

Quadro 5 - Valores de referência de erro padrão de estimativa para percentual de massa gorda e valores de massa magra.

\begin{tabular}{|lcc|}
\hline \multicolumn{1}{|c}{ Escala Subjetiva } & EPE \% MG & EPE MCM (kg) \\
\hline Ideal & 2,0 & $2,0-2,5$ \\
Excelente & 2,5 & 2,5 \\
Muito bom & 3,0 & 3,0 \\
Bom & 3,5 & 3,5 \\
Razoavelmente bom & 4,0 & 4,0 \\
Razoável & 4,5 & 4,5 \\
Não recomendada & 5,0 & $>4,5$ \\
\hline
\end{tabular}

Fonte: Quadro adaptado a partir das tabelas 1.2 (p.3) e1.4 (p.4) de LOHMAN, 1992. 
Em todas as análises foi utilizado o nível de significância de $5 \%$.

\subsection{Pacotes estatísticos (softwares)}

- Epi Info versão 6.04 e Excel: digitação e consistência do banco de dados.

- Word: digitação da tese.

- Statistical Package for the Social Sciences-SPSS para Windows (versão 10.0): análise descritiva, análise de correlação, análise de regressão linear múltipla, teste $t$ pareado.

\subsection{Aspectos éticos}

Todos os participantes assinaram o Termo de Consentimento Informado (Anexo 1) e receberam os resultados dos exames, sendo orientados de acordo com os resultados. Quando diagnosticado osteoporose, o paciente foi agendado para tratamento no ambulatório do Hospital Heliópolis.

A pesquisa foi aprovada pelo Comitê de Ética do Hospital Heliópolis (Anexo 2) e Comitê de Ética em Pesquisa da Faculdade de Saúde Pública da Universidade de São Paulo (Anexo 3). 
0 artigo científico referente ao presente trabalho encontra-se em anexo (Anexo 4), o qual foi encaminhado à Revista de Saúde Pública da Faculdade de Saúde Pública da Universidade de São Paulo. Esta é uma exigência da Comissão de Pós Graduação do Departamento de Epidemiologia da Faculdade de Saúde Pública da Universidade de São Paulo. 


\section{RESULTADOS}

A amostra deste estudo foi composta por 320 homens e, conforme foi descrito no capítulo de Material e Métodos, esta casuistica foi dividida em duas amostras aleatórias independentes, de 160 homens em cada. A primeira amostra foi utilizada para o desenvolvimento das equações de regressōes e, a segunda, para estimar os valores de \%G e MCM pelas equações desenvolvidas neste trabalho e as propostas pela literatura, além de validar as equaçōes e comparar com os valores fornecidos pela BIA.

\subsection{Características da primeira amostra da população de estudo}

Foram analisados 160 homens, sendo 128 brancos (80\%) e 32 não brancos (20\%). A idade variou de 50 a 85 anos, sendo $61,9 \%$ entre 50 a 64 anos de idade e $38,1 \%$ entre 65 a 85 anos, com média de 62,21 anos. A maioria tinha até o $1^{\circ} \mathrm{grau}$ incompleto, conforme apresentado no Gráfico 1. 
Gráfico 1 - Número de homens, segundo a escolaridade. Amostra 1.Hospital Heliópolis, São Paulo, 1997.




A Tabela 1 apresenta a estatistica descritiva das variáveis de estudo. Observa-se que os valores médios para massa corporal, estatura, e IMC foram $72,14 \mathrm{~kg}, 1,65 \mathrm{~m}$ e $26,32 \mathrm{~kg} / \mathrm{m}^{2}$, respectivamente. Os valores medianos foram muito semelhantes aos da média e apenas DCT e ० \%G estimado pela BIA não tiveram aderência à distribuição normal.

Tabela 1 - Estatística descritiva das variáveis de estudo. Amostra 1. Hospital Heliópolis, São Paulo, 1997.

\begin{tabular}{l|c|c|c|c}
\hline \multicolumn{1}{c|}{ Variáveis } & Média (dp) & Mínimo - Máximo & Mediana & $\boldsymbol{p}^{*}$ \\
\hline Idade (anos) & $62,21(7,97)$ & $50-85$ & 61,00 & 0,067 \\
Massa corporal (Kg) & $72,14(11,87)$ & $42,10-108,20$ & 71,50 & 0,719 \\
Estatura (m) & $1,65(0,06)$ & $1,48-1,82$ & 1,65 & 0,200 \\
IMC (Kg/m²) & $26,32(3,90)$ & $15,48-35,38$ & 26,00 & 0,270 \\
DCT (mm) & $14,30(6,20)$ & $5,00-43,67$ & 13,00 & 0,005 \\
PCint (cm) & $95,30(10,04)$ & $69,00-123,00$ & 95,00 & 0,569 \\
PQ (cm) & $100,12(6,90)$ & $83,00-117,00$ & 99,00 & 0,221 \\
RCQ & $0,95(0,06)$ & $0,82-1,12$ & 0,95 & 0,515 \\
\%G BIA & $21,65(5,59)$ & $11-38$ & 20,00 & 0,003 \\
\%G DEXA & $22,76(6,32)$ & $4-39$ & 22,50 & 0,749 \\
MCM BIA (Kg) & $56,11(7,63)$ & $35-82$ & 56,00 & 0,529 \\
MCM DEXA (Kg) & $52,30(6,95)$ & $36,30-70,59$ & 51,87 & 0,949 \\
R (Ohms) & $484,34(65,28)$ & $355-738$ & 475,50 & 0,100 \\
Xc (Ohms) & $52,28(7,90)$ & $31-72$ & 52,00 & 0,711 \\
\hline$p$ & & & \\
\hline
\end{tabular}


A comparação das médias das variáveis de composição em relação à cor da pele está apresentada na Tabela 2, onde se observa que não houve diferença significativa das médias para nenhuma das variáveis.

Tabela 2 - Médias e desvios-padrão das variáveis de estudo, segundo cor da pele. Amostra 1. Hospital Heliópolis, São Paulo, 1997.

\begin{tabular}{|c|c|c|c|}
\hline \multirow[t]{2}{*}{ Variáveis } & $\begin{array}{l}\text { Branca } \\
n=128\end{array}$ & $\begin{array}{c}\text { Não branca } \\
n=32\end{array}$ & \multirow[t]{2}{*}{$p^{*}$} \\
\hline & Média (dp) & Média (dp) & \\
\hline Idade (anos) & $62,34(8,23)$ & $61,72(6,97)$ & 0,697 \\
\hline Massa corporal $(\mathrm{Kg})$ & $71,97(12,2)$ & $72,83(10,61)$ & 0,717 \\
\hline Estatura (m) & $1,65(0,06)$ & $1,65(0,064)$ & 0,867 \\
\hline $\operatorname{IMC}\left(\mathrm{Kg} / \mathrm{m}^{2}\right)$ & $26,24(3,95)$ & $26,63(3,72)$ & 0,617 \\
\hline $\mathrm{DCT}(\mathrm{mm})$ & $14,28(6,30)$ & $14,36(5,88)$ & 0,950 \\
\hline PCint $(\mathrm{cm})$ & $95,55(10,20)$ & $94,33(9,46)$ & 0,541 \\
\hline $\mathrm{PQ}(\mathrm{cm})$ & $100,26(7,05)$ & $99,53(6,35)$ & 0,594 \\
\hline $\mathrm{RCQ}$ & $0,95(0,06)$ & $0,95(0,06)$ & 0,704 \\
\hline$\% G B I A$ & $21,98(5,78)$ & $20,31(4,60)$ & 0,131 \\
\hline$\% G$ DEXA & $23,83(6,51)$ & $23,13(6,61)$ & 0,586 \\
\hline MCM BIA $(\mathrm{Kg})$ & $57,66(6,51)$ & $55,72(7,86)$ & 0,200 \\
\hline MCM DEXA $(\mathrm{Kg})$ & $53,06(7,57)$ & $52,10(6,80)$ & 0,487 \\
\hline
\end{tabular}

"p:nivel descritivo do teste $t$-Student. 
Na comparação das médias segundo grupo etário (Tabela 3), verificase que elas foram semelhantes em relação a todas as variáveis, exceto para a estatura onde os homens mais velhos foram, em média, mais baixos, e para a razão cintura/quadril onde os homens mais velhos apresentaram, em média, razão maior do que os homens na idade 50 a 64 anos.

Tabela 3 - Médias e desvios-padrão das variáveis de estudo, segundo grupo etário. Amostra 1. Hospital Heliópolis, São Paulo, 1997.

\begin{tabular}{|c|c|c|c|}
\hline Variáveis & $\begin{array}{c}50-64 \text { anos } \\
n=99\end{array}$ & $\begin{array}{c}65-85 \text { anos } \\
n=61\end{array}$ & $\overline{p^{*}}$ \\
\hline & Média (dp) & Média (dp) & \\
\hline Massa corporal (Kg) & $72,30(12,31)$ & $71,90(11,21)$ & 0,836 \\
\hline Estatura (m) & $1,66(0,06)$ & $1,64(0,06)$ & 0,045 \\
\hline $\mathrm{IMC}\left(\mathrm{Kg} / \mathrm{m}^{2}\right)$ & $26,12(3,90)$ & $26,64(3,91)$ & 0,408 \\
\hline $\mathrm{DCT}(\mathrm{mm})$ & $14,86(6,54)$ & $13,39(5,55)$ & 0,146 \\
\hline PCint (cm) & $94,17(10,15)$ & $97,14(9,65)$ & 0,069 \\
\hline$P Q(\mathrm{~cm})$ & $99,68(7,12)$ & $100,82(6,53)$ & 0,313 \\
\hline $\mathrm{RCQ}$ & $0,94(0,05)$ & $0,96(0,06)$ & 0,034 \\
\hline$\% G \mathrm{BIA}$ & $21,28(5,39)$ & $22,25(5,90)$ & 0,291 \\
\hline \%G DEXA & $22,14(6,49)$ & $23,77(5,96)$ & 0,134 \\
\hline MCM BIA (Kg) & $56,47(7,86)$ & $55,51(7,26)$ & 0,438 \\
\hline MCM DEXA (Kg) & $51,75(7,09)$ & $53,18(6,68)$ & 0,207 \\
\hline
\end{tabular}

${ }^{\star} p$ :nivel descritivo do teste $t$-Student. 


\subsection{Análise estatística do percentual de gordura}

A Tabela 4 apresenta os coeficientes de correlação entre o percentual de gordura fornecido pela DEXA e as outras variáveis de estudo. Houve correlação estatisticamente significativa com todas as variáveis para o total da população, exceto com relação à idade $(p=0,428)$ e estatura $(p=0,872)$. Quando se analisa segundo o grupo etário observa-se o mesmo, porém nos homens com 65 anos e mais não houve correlação com a reatância $(p=0,402)$. Em relação à cor da pele, não houve correlação com idade e estatura, sendo que a reatância foi correlacionada significativamente com o \%G fornecido pela DEXA apenas para a cor da pele não branca. No total de homens, as correlações mais fortes foram com PCint $(r=0,81)$, IMC $(r=0,76)$, $\%$ G BIA $(r=0,76)$ e $P Q(r=0,71)$, sem grandes diferenças no seu valor numérico em relação ao grupo etário e cor da pele. 
Tabela 4 - Coeficientes de correlação $(r)$ entre $0 \% G$ fornecido pela DEXA e as outras variáveis, separadas por grupo etário e cor da pele. Amostra 1. Hospital Heliópolis, São Paulo, 1997.

\begin{tabular}{|c|c|c|c|c|c|}
\hline \multirow{2}{*}{ Variáveis } & \multirow{2}{*}{$\begin{array}{l}\text { Total } \\
r(p)\end{array}$} & \multicolumn{2}{|c|}{ Grupo etário } & \multicolumn{2}{|c|}{ Cor da pele } \\
\hline & & $\begin{array}{l}50-64 \\
r(p)\end{array}$ & $\begin{array}{c}65-85 \\
r(p)\end{array}$ & $\begin{array}{c}\text { Branca } \\
r(p)\end{array}$ & $\begin{array}{c}\text { Não Branca } \\
r(p)\end{array}$ \\
\hline Idade (anos) & ${ }^{*} 0,06(0,428)$ & $-0,02(0,875)$ & * $0,18(0,160)$ & $0,05(0,574)$ & ${ }^{*} 0,12(0,517)$ \\
\hline Massa corporal ( $\mathrm{kg}$ ) & ${ }^{*} 0,69(<0,001)$ & ${ }^{*} 0,70(<0,001)$ & ${ }^{*} 0,69(<0,001)$ & ${ }^{*} 0,68(<0,001)$ & ${ }^{*} 0,73(<0,001)$ \\
\hline Estatura ( $m$ ) & ${ }^{*} 0,01(0,872)$ & $* 0,07(0,470)$ & $*-0,04(0,751)$ & ${ }^{*} 0,01(0,937)$ & ${ }^{*} 0,03(0,862)$ \\
\hline IMC $\left(\mathrm{kg} / \mathrm{m}^{2}\right)$ & $* 0,76(<0,001)$ & $* 0,76(<0,001)$ & ${ }^{\star} 0,77(<0,001)$ & ${ }^{*} 0,76(<0,001)$ & ${ }^{*} 0,77(<0,001)$ \\
\hline $\mathrm{DCT}(\mathrm{mm})$ & ${ }^{* \star} 0,68(<0,001)$ & $\star 0,64(<0,001)$ & ${ }^{*} 0,73(<0,001)$ & $\star \star 0,69(<0,001)$ & ${ }^{*} 0,66(<0,001)$ \\
\hline$P C(\mathrm{~cm})$ & $* 0,81(<0,001)$ & ${ }^{*} 0,82(<0,001)$ & ${ }^{*} 0,76(<0,001)$ & ${ }^{*} 0,81(<0,001)$ & ${ }^{*} 0,80(<0,001)$ \\
\hline$P Q(\mathrm{~cm})$ & ${ }^{*} 0,71(<0,001)$ & ${ }^{*} 0,70(<0,001)$ & ${ }^{*} 0,73(<0,001)$ & ${ }^{*} 0,72(<0,001)$ & ${ }^{*} 0,70(<0,001)$ \\
\hline $\mathrm{RCQ}$ & $* 0,61(<0,001)$ & $\star 0,67(<0,001)$ & ${ }^{*} 0,49(<0,001)$ & $* 0,62(<0,001)$ & $* 0,56(0,001)$ \\
\hline$\% G$ BIA & ${ }^{* *} 0,76(<0,001)$ & $* 0,76(<0,001)$ & ${ }^{*} 0,76(<0,001)$ & ** $0,76(<0,001)$ & ${ }^{*} 0,74(<0,001)$ \\
\hline$\chi_{c}(\mathrm{Ohm})$ & $*-0,21(0,009)$ & ${ }^{*}-0,22(0,028)$ & $*-0,11(0,402)$ & $*-0,13(0,154)$ & $*-0,55(0,001)$ \\
\hline $\mathrm{R}(\mathrm{Ohm})$ & ${ }^{*}-0,31(<0,001)$ & ${ }^{*}-0,34(<0,001)$ & ${ }^{*}-0,27(0,038)$ & ${ }^{*}-0,31(<0,001)$ & ${ }^{*}-0,41(0,021)$ \\
\hline
\end{tabular}

Pearson ${ }^{*}$ Spearman $^{* \star}$ 
Devido às semelhanças das médias das diversas variáveis, segundo cor da pele e faixa etária, bem como dos valores da maioria dos coeficientes de correlação, optou-se em fazer um modelo único para o total de homens e testar as variáveis idade (em anos) e cor da pele (branco=1 e não branco=0) no modelo múltiplo.

Um modelo de regressão linear múltiplo foi elaborado com a finalidade de estimar o percentual de gordura. A Tabela 5 apresenta a ordem de entrada das variáveis no modelo múltiplo, sendo a ordenação feita a partir do valor do coeficiente de correlação encontrado com o percentual de gordura fornecido pela DEXA (Tabela 4). A variável cor da pele foi testada no modelo múltiplo em último lugar.

A Tabela 6 apresenta a descrição das etapas de modelagem. As variáveis foram acrescentadas uma a uma no modelo, iniciando-se pelo PCint. O IMC, na presença do PCint, perdeu sua significância, sendo então, retirado do modelo. $\mathrm{O} \% \mathrm{G}$ fornecido pela BIA teve efeito independente e permaneceu no modelo. Na presença de PCint e \%G BIA, O PQ foi significativo e permaneceu no modelo; no entanto esta variável perdeu a significância na presença da DCT. Ocorreu uma inversão do sinal do coeficiente de regressão da massa corporal e, por isso, esta variável foi retirada do modelo múltiplo. As variáveis $R C Q, R, \chi_{C}$, estatura e cor da pele não foram significativas e foram retiradas do modelo múltiplo. A mesma coisa aconteceu com a variável idade, porém optou-se por selecionar dois 
modelos múltiplos: um sem a idade (modelo 7) e outro com esta variável (modelo 11).

Tabela 5 - Coeficientes de correlação $(r)$ entre o \%G derivado do DEXA e as outras variáveis e ordem da entrada da variável no modelo múltiplo. Amostra 1. Hospital Heliópolis, São Paulo, 1997.

\begin{tabular}{l|c|c}
\hline Variáveis & $\begin{array}{c}\text { Total } \\
r(p)\end{array}$ & Ordem de entrada no modelo \\
\hline Pcint $(\mathrm{cm})$ & $0,81(<0,001)$ & 1 \\
IMC (Kg/m²) & $0,76(<0,001)$ & 2 \\
\%G BIA & $0,76(<0,001)$ & 3 \\
PQ (cm) & $0,71(<0,001)$ & 4 \\
Massa corporal $(\mathrm{Kg})$ & $0,69(<0,001)$ & 5 \\
DCT (mm) & $0,68(<0,001)$ & 6 \\
RCQ & $0,61(<0,001)$ & 7 \\
R (Ohm) & $-0,31(<0,001)$ & 8 \\
$\chi_{\mathrm{c}}(\mathrm{Ohm})$ & $-0,21(0,009)$ & 9 \\
Idade (anos) & $0,06(0,428)$ & 10 \\
Estatura (m) & $0,01(0,872)$ & 11 \\
\hline
\end{tabular}


Tabela 6 - Descrição das etapas de modelagem múltipla para a equação do percentual de gordura. Amostra 1. Hospital Heliópolis, São Paulo, 1997.

\begin{tabular}{|c|c|c|c|c|c|}
\hline Modelo & Variáveis & $\beta$ & $I_{95 \%}(\boldsymbol{\beta})$ & p modelo & $r^{2}$ ajustado \\
\hline 1 & PCint & $\begin{array}{l}0,507 \\
\beta_{0}=25,563\end{array}$ & {$[0,448 ; 0,566]$} & $<0,001$ & 0,65 \\
\hline 2 & $\begin{array}{l}\text { PCint } \\
\text { IMC }\end{array}$ & $\begin{array}{l}0,411 \\
0,272 \\
\beta_{0}=23,595\end{array}$ & $\begin{array}{l}{[0,273 ; 0,550]} \\
{[-0,085 ; 0,628]}\end{array}$ & $<0,001$ & 0,65 \\
\hline 3 & $\begin{array}{l}\text { PCint } \\
\% G \text { BIA }\end{array}$ & $\begin{array}{l}0,355 \\
0,380 \\
\beta_{0}=-19,259\end{array}$ & $\begin{array}{l}{[0,276 ; 0,433]} \\
{[0,240 ; 0,520]}\end{array}$ & $<0,001$ & 0,70 \\
\hline 4 & $\begin{array}{l}\text { PCint } \\
\% G \text { BIA } \\
\text { PQ }\end{array}$ & $\begin{array}{l}0,255 \\
0,402 \\
0,154 \\
\beta_{0}=-25,694\end{array}$ & $\begin{array}{l}{[0,129 ; 0,380]} \\
{[0,262 ; 0,543]} \\
{[0,002 ; 0,307]}\end{array}$ & $<0,001$ & 0,70 \\
\hline 5 & $\begin{array}{l}\text { PCint } \\
\% \text { G BIA } \\
\text { PQ } \\
\text { Massa corporal }\end{array}$ & $\begin{array}{l}0,355 \\
0,382 \\
0,323 \\
-0,181 \\
\beta_{0}=-38,689\end{array}$ & $\begin{array}{l}{[0,212 ; 0,499]} \\
{[0,244 ; 0,521]} \\
{[0,129 ; 0,518]} \\
{[-0,314 ;-0,048]}\end{array}$ & $<0,001$ & 0,71 \\
\hline 6 & $\begin{array}{l}\text { PCint } \\
\text { PQ } \\
\% G \text { BIA } \\
\text { DCT }\end{array}$ & $\begin{array}{l}0,233 \\
0,121 \\
0,372 \\
0,135 \\
\beta_{0}=-21,565\end{array}$ & $\begin{array}{l}{[0,108 ; 0,358]} \\
{[-0,032 ; 0,275]} \\
{[0,231 ; 0,514]} \\
{[0,021 ; 0,250]}\end{array}$ & $<0,001$ & 0,71 \\
\hline 7 & $\begin{array}{l}\text { PCint } \\
\% G \text { BIA } \\
\text { DCT }\end{array}$ & $\begin{array}{l}0,306 \\
0,352 \\
0,152 \\
\beta_{0}=-16,177\end{array}$ & $\begin{array}{l}{[0,221 ; 0,391]} \\
{[0,213 ; 0,491]} \\
{[0,039 ; 0,265]}\end{array}$ & $<0,001$ & 0,71 \\
\hline 8 & $\begin{array}{l}\text { PCint } \\
\% \text { BIA } \\
\text { DCT } \\
\text { RCQ }\end{array}$ & $\begin{array}{l}0,350 \\
0,368 \\
0,137 \\
-10,149 \\
\beta_{0}=-10,835\end{array}$ & $\begin{array}{l}{[0,240,0,459]} \\
{[0,227 ; 0,509]} \\
{[0,022 ; 0,253]} \\
{[-26,107 ; 5,810]}\end{array}$ & $<0,001$ & 0,71 \\
\hline 9 & $\begin{array}{l}\text { PCint } \\
\text { \%G BIA } \\
\text { DCT } \\
\text { R }\end{array}$ & $\begin{array}{l}0,216 \\
0,491 \\
0,134 \\
-0,012 \\
\beta_{0}=-4,535\end{array}$ & $\begin{array}{l}{[0,073 ; 0,359]} \\
{[0,264 ; 0,717]} \\
{[0,019 ; 0,249]} \\
{[-0,028 ; 0,004]}\end{array}$ & $<0,001$ & 0,71 \\
\hline
\end{tabular}




\begin{tabular}{|c|c|c|c|c|c|}
\hline Modelo & Variáveis & $\beta$ & $\mathrm{IC}_{95 \%}(\boldsymbol{\beta})$ & $p$ modelo & $r^{2}$ ajustado \\
\hline 10 & $\begin{array}{l}\text { PCint } \\
\% G \text { BIA } \\
\text { DCT } \\
\chi_{c}\end{array}$ & $\begin{array}{l}0,290 \\
0,373 \\
0,153 \\
-0,022 \\
\beta_{0}=14,016\end{array}$ & $\begin{array}{l}{[0,186 ; 0,395]} \\
{[0,211 ; 0,535]} \\
{[0,040 ; 0,267]} \\
{[-0,108 ; 0,064]}\end{array}$ & $<0,001$ & 0,70 \\
\hline 11 & $\begin{array}{l}\text { PCint } \\
\% G \text { BIA } \\
\text { DCT } \\
\text { Idade }\end{array}$ & $\begin{array}{l}0,296 \\
0,349 \\
0,173 \\
0,039 \\
\beta_{0}=-17,970\end{array}$ & $\begin{array}{l}{[0,210 ; 0,383]} \\
{[0,210 ; 0,488]} \\
{[0,054 ; 0,292]} \\
{[-0,031 ; 0,110]}\end{array}$ & $<0,001$ & 0,71 \\
\hline 12 & $\begin{array}{l}\text { PCint } \\
\text { \%G BIA } \\
\text { DCT } \\
\text { Idade } \\
\text { Estatura }\end{array}$ & $\begin{array}{l}0,319 \\
0,323 \\
0,176 \\
0,022 \\
-11,183 \\
\beta_{0}=-0,017\end{array}$ & $\begin{array}{l}{[0,232 ; 0,406]} \\
{[0,184 ; 0,461]} \\
{[0,058 ; 0,293]} \\
{[-0,049 ; 0,093]} \\
{[-20,241 ;-2,125]}\end{array}$ & $<0,001$ & 0,72 \\
\hline 13 & $\begin{array}{l}\text { PCint } \\
\text { \%G BIA } \\
\text { DCT } \\
\text { Cor da pele }\end{array}$ & $\begin{array}{l}0,306 \\
0,355 \\
0,151 \\
-0.236 \\
\beta_{0}=-16,009\end{array}$ & $\begin{array}{l}{[0,220 ; 0,391]} \\
{[0,214 ; 0,496]} \\
{[0,037 ; 0,264]} \\
{[-0,031 ; 0,110]} \\
{[-1,585 ; 1,11]}\end{array}$ & $<0,001$ & 0.71 \\
\hline 14 & $\begin{array}{l}\text { PCint } \\
\% G \text { BIA } \\
\text { DCT } \\
\text { Idade } \\
\text { Cor da pele }\end{array}$ & $\begin{array}{l}0,296 \\
0,352 \\
0,172 \\
0,0395 \\
-0,242 \\
\beta_{0}=-17,803\end{array}$ & $\begin{array}{l}{[0,209 ; 0,383]} \\
{[0,211 ; 0,493]} \\
{[0,052 ; 0,292]} \\
{[-0,031 ; 0,110]} \\
{[-1,590 ; 1,106]}\end{array}$ & $<0,001$ & 0.71 \\
\hline
\end{tabular}

Em resumo, foram selecionados os modelos 7 e 11 como modelos finais (que a partir de agora, serão denominados LigiaA e LigiaB, respectivamente). No modelo LigiaA permaneceram as variáveis perímetro da cintura, \% de gordura fornecida pela BIA e dobra cutânea tricipital. Os resíduos do modelo LigiaA não apresentaram viés e tiveram distribuição normal (Anexo 4); embora houvesse a presença de 7 valores aberrantes, optou-se por deixá-los na análise. Permaneceram no modelo LigiaB as 
variáveis: perimetro da cintura, \% de gordura fornecida pela BIA, dobra cutânea tricipital e a idade. Os resíduos do modelo LigiaB não apresentaram viés e tiveram distribuição normal (Anexo 4) e embora houvesse a presença de 6 valores aberrantes, optou-se por deixá-los na análise.

Os dois modelos escolhidos para a estimativa do percentual de gordura tiveram $r^{2}$ ajustado=0,71 e suas equaçōes foram:

LigiaA

$\% G=-16,177+0,306(P C i n t, c m)+0,352(\% G$ BIA $)+0,152(D C T, m m)$

LigiaB

$\% G=-17,970+0,296(P C i n t, c m)+0,349(\% G B I A)+0,173(D C T, m m)+0,039(1$, anos $)$

Foi realizado outro processo de modelagem de regressão linear múltipla com a finalidade de estimar o percentual de gordura, mas retirando a variável \%G BIA do processo, pois esta já é resultante de outra equação utilizada pelos fabricantes do equipamento RJL. A Tabela 7 apresenta a descrição das etapas desta segunda modelagem. Iniciou-se o processo com a $P$ Cint e na presença desta variável, O IMC, O PQ e a massa corporal não foram significativos. A DCT foi significativa independente da PCint e quando foi acrescentada a RCQ esta não foi significativa. A seguir foram acrescentadas a $\mathrm{R}$ e a $\chi_{\mathrm{c}}$ que não permaneceram no modelo múltiplo, pois 
houve uma inversão de sinal de seus coeficientes de regressão. O mesmo aconteceu com a variável estatura (modelo 10). Também neste segundo processo de modelagem múltipla a idade não foi significativa, mas optou-se por trabalhar com dois modelos múltiplos: o de número 5 (sem a idade) e o de número 9 (com a variável idade). A variável cor da pele não foi significativa em nenhum dos dois modelos (11 e 12).

Tabela 7 - Descrição das etapas de modelagem múltipla para a equação do \%G, sem o \%G BIA. Amostra 1. Hospital Heliópolis, São Paulo, 1997.

\begin{tabular}{|c|c|c|c|c|c|}
\hline Modelo & Variáveis & $\bar{\beta}$ & $I_{95 \%}(\boldsymbol{\beta})$ & p modelo & $r^{2}$ ajustado \\
\hline 1 & PCint & $\begin{array}{l}0,507 \\
\beta_{0}=-25,563\end{array}$ & {$[0,448 ; 0,566]$} & $<0,001$ & 0,65 \\
\hline 2 & $\begin{array}{l}\text { PCint } \\
\text { IMC }\end{array}$ & $\begin{array}{l}0,411 \\
0,272 \\
\beta_{0}=-23,595\end{array}$ & $\begin{array}{l}{[0,273 ; 0,550]} \\
{[-0,085 ; 0,628]}\end{array}$ & $<0,001$ & 0,65 \\
\hline 3 & $\begin{array}{l}\text { PCint } \\
P Q\end{array}$ & $\begin{array}{l}0,456 \\
0,086 \\
\beta_{0}=-29,356\end{array}$ & $\begin{array}{l}{[0,343 ; 0,570]} \\
{[-0,079 ; 0,251]}\end{array}$ & $<0,001$ & 0,65 \\
\hline 4 & $\begin{array}{l}\text { PCint } \\
\text { Massa corporal }\end{array}$ & $\begin{array}{l}0,602 \\
-0,089 \\
\beta_{0}=-28,153\end{array}$ & $\begin{array}{l}{[0,470 ; 0,734]} \\
{[-0,201 ; 0,022]}\end{array}$ & $<0,001$ & 0,65 \\
\hline 5 & $\begin{array}{l}\text { PCint } \\
\text { DCT }\end{array}$ & $\begin{array}{l}0,430 \\
0,195 \\
\beta_{0}=-21,007\end{array}$ & $\begin{array}{l}{[0,356 ; 0,504]} \\
{[0,075 ; 0,315]}\end{array}$ & $<0,001$ & 0,66 \\
\hline 6 & $\begin{array}{l}\text { PCint } \\
\text { DCT } \\
\text { RCQ }\end{array}$ & $\begin{array}{l}0,443 \\
0,192 \\
-2,721 \\
\beta_{0}=-19,634\end{array}$ & $\begin{array}{l}{[0,332 ; 0,554]} \\
{[0,069 ; 0,314]} \\
{[-19,654 ; 14,212]}\end{array}$ & $<0,001$ & 0,66 \\
\hline 7 & $\begin{array}{l}\text { PCint } \\
\text { DCT } \\
\text { R }\end{array}$ & $\begin{array}{l}0,479 \\
0,196 \\
0,015 \\
\beta_{0}=-32,795\end{array}$ & $\begin{array}{l}{[0,399 ; 0,559]} \\
{[0,079 ; 0,314]} \\
{[0,005 ; 0,025]}\end{array}$ & $<0,001$ & 0,68 \\
\hline
\end{tabular}




\begin{tabular}{|c|c|c|c|c|c|}
\hline Modelo & Variáveis & $\beta$ & $\mathrm{IC}_{95 \%}(\boldsymbol{\beta})$ & p modelo & $r^{2}$ ajustado \\
\hline 8 & $\begin{array}{l}\mathrm{PC} \\
\mathrm{DCT} \\
\chi_{c}\end{array}$ & $\begin{array}{l}0,459 \\
0,181 \\
0,078 \\
\beta_{0}=-27,672\end{array}$ & $\begin{array}{l}{[0,308 ; 0,538]} \\
{[0,061 ; 0,301]} \\
{[0,001 ; 0,157]}\end{array}$ & $<0,001$ & 0,67 \\
\hline 9 & $\begin{array}{l}\text { PCint } \\
\text { DCT } \\
\text { Idade }\end{array}$ & $\begin{array}{l}0,418 \\
0,219 \\
0,046 \\
\beta_{0}=-23,060\end{array}$ & $\begin{array}{l}{[0,341 ; 0,495]} \\
{[0,093 ; 0,346]} \\
{[-0,030 ; 0,122]}\end{array}$ & $<0,001$ & 0,67 \\
\hline 10 & $\begin{array}{l}\text { PCint } \\
\text { DCT } \\
\text { idade } \\
\text { Estatura }\end{array}$ & $\begin{array}{l}0,435 \\
0,218 \\
0,023 \\
-14,409 \\
\beta_{0}=+0,565\end{array}$ & $\begin{array}{l}{[0,359 ; 0,511]} \\
{[0,095 ; 0,342]} \\
{[-0,052 ; 0,099]} \\
{[-23,922 ;-4,895]}\end{array}$ & $<0,001$ & 0,68 \\
\hline 11 & $\begin{array}{l}\text { PCint } \\
\text { DCT } \\
\text { Idade } \\
\text { Cor da pele }\end{array}$ & $\begin{array}{l}0,419 \\
0,220 \\
0,046 \\
0,199 \\
\beta_{0}=-23,158\end{array}$ & $\begin{array}{l}{[0,340 ; 0,494]} \\
{[0,093 ; 0,347]} \\
{[-0,030 ; 0,122]} \\
{[-1,235 ; 1,633]}\end{array}$ & $<0,001$ & 0,66 \\
\hline 12 & $\begin{array}{l}\text { PCint } \\
\text { DCT } \\
\text { Cor da pele }\end{array}$ & $\begin{array}{l}0,429 \\
0,196 \\
0,211 \\
\beta_{0}=-21,117\end{array}$ & $\begin{array}{l}{[0,355 ; 0,504]} \\
{[0,075 ; 0,317]} \\
{[-1,225 ; 1,647]}\end{array}$ & $<0,001$ & 0,66 \\
\hline
\end{tabular}

Foram selecionados, então, os modelos 5 e 9 como modelos finais (a partir de agora denominados LigiaC e LigiaD, respectivamente), permanecendo no modelo LigiaC as variáveis: perímetro da cintura e dobra cutânea tricipital e no modelo LigiaD as mesmas variáveis e mais a idade. Os residuos destes modelos não apresentaram viés e tiveram distribuição normal (Anexo 4); embora houvesse a presença de 8 valores aberrantes em cada um dos modelos, optou-se por deixá-los nas análises. 
Os modelos finais para a estimativa do percentual de massa gorda, sem a variável $\%$ G BIA, tiveram $r^{2}$ ajustado $=0,66$ e 0,67 e suas equações são:

\begin{tabular}{|l|l|}
\hline LigiaC & $\% \mathrm{G}=-21,007+0,430(\mathrm{PC}$ int, $\mathrm{cm})+0,195(\mathrm{DCT}, \mathrm{mm})$ \\
\hline
\end{tabular}

LigiaD

$\% G=-23,060+0,418(P C i n t, c m)+0,219(D C T, m m)+0,046$ (Idade,anos)

\subsection{Análise estatística da massa corporal magra}

A Tabela 8 apresenta os coeficientes de correlação entre a massa corporal magra fornecida pela DEXA e as outras variáveis de estudo. Houve correlação estatisticamente significativa em quase todas as variáveis para o total da população, exceto com relação à idade $(p=0,300)$, DCT $(p=0,344)$ e reatância $(p=0,389)$ que não foram significativas. Quando se analisa segundo o grupo etário, observa-se o mesmo, com pequenas alterações para IMC, $P Q, R C Q$ e resistência. Em relação à cor da pele, verifica-se resultado similar ao do total da população, com pequenas alterações para estatura, IMC, PCint, resistência e maior para RCQ e reatância. Os maiores valores das correlações foram para massa corporal $(r=0,37)$, MCM BIA $(r=0,34)$, $P$ Cint $(r=0,32)$ e $P Q(r=0,31)$, sem grandes diferenças no seu valor numérico em relação ao grupo etário e cor da pele. Por isto optou-se em fazer um modelo único para o total de homens. 
Tabela 8 - Coeficientes de correlação entre o valor da MCM $(\mathrm{Kg})$ fornecido pela DEXA e as outras variáveis, separadas por grupo etário e raça. Amostra 1. Hospital Heliópolis, São Paulo, 1997.

\begin{tabular}{|c|c|c|c|c|c|}
\hline \multirow[t]{2}{*}{ Variáveis } & \multirow{2}{*}{$\begin{array}{l}\text { Total } \\
r(p)\end{array}$} & \multicolumn{2}{|c|}{ Grupo etário } & \multicolumn{2}{|c|}{ Raça } \\
\hline & & $\begin{array}{l}50-64 \\
r(p)\end{array}$ & $\begin{array}{r}65-85 \\
r(p)\end{array}$ & $\begin{array}{c}\text { Branca } \\
r(p)\end{array}$ & $\begin{array}{c}\text { Não Branca } \\
r(p)\end{array}$ \\
\hline Idade (anos) ${ }^{*}$ & $0,08(0,300)$ & $0,03(0,796)$ & $-0,05(0,698)$ & $0,00(0,983)$ & $0,10(0,245)$ \\
\hline Massa corporal $(\mathrm{Kg})^{*}$ & $0,37(<0,001)$ & $0,39(<0,001)$ & $0,34(0,007)$ & $0,35(0,050)$ & $0,37(<0,001)$ \\
\hline Estatura $(m)^{*}$ & $0,22(0,005)$ & $0,22(0,031)$ & $0,28(0,028)$ & $0,26(0,152)$ & $0,21(0,18)$ \\
\hline $\operatorname{IMC}\left(\mathrm{Kg} / \mathrm{m}^{2}\right)^{\star}$ & $0,29(<0,001)$ & $0,32(0,001)$ & $0,23(0,076)$ & $0,24(0,184)$ & $0,30(<0,001)$ \\
\hline $\mathrm{DCT}(\mathrm{mm})^{\star \star}$ & $0,07(0,344)$ & $0,10(0,304)$ & $0,09(0,493)$ & $0,05(0,567)$ & $0,17(0,344)$ \\
\hline $\mathrm{PC}(\mathrm{cm})^{*}$ & $0,32(<0,001)$ & $0,32(0,001)$ & $0,28(0,030)$ & $0,28(0,119)$ & $0,33(<0,001)$ \\
\hline$P Q(\mathrm{~cm})^{*}$ & $0,31(<0,001)$ & $0,35(<0,001)$ & $0,21(0,096)$ & $0,38(0,031)$ & $0,30(0,001)$ \\
\hline $\mathrm{RCQ}^{*}$ & $0,21(0,006)$ & $0,19(0,060)$ & $0,22(0,082)$ & $0,09(0,621)$ & $0,25(0,004)$ \\
\hline MM IB $(\mathrm{kg})^{*}$ & $0,34(<0,001)$ & $0,36(<0,001)$ & $0,33(0,010)$ & $0,41(0,020)$ & $0,32(<0,001)$ \\
\hline$\chi_{c}(\mathrm{Ohm})^{*}$ & $-0,07(0,389)$ & $-0,09(0,353)$ & $0,05(0,713)$ & $-0,10(0,572)$ & $-0,06(0,506)$ \\
\hline $\mathrm{R}(\mathrm{Ohm})^{*}$ & $-0,22(0,005)$ & $-0,25(0,013)$ & $-0,17(0,184)$ & $-0,29(0,111)$ & $-0,20(0,021)$ \\
\hline
\end{tabular}

Pearson* Spearman** 
A Tabela 9 apresenta a ordem de entrada das variáveis no modelo múltiplo, conforme os valores dos coeficientes de correlação apresentados na Tabela 8.

Tabela 9 - Coeficientes de correlação entre o valor da MCM em Kg derivado da DEXA e as outras variáveis, e ordem da entrada da variável no modelo múltiplo. Amostra 1. Hospital Heliópolis, São Paulo, 1997.

\begin{tabular}{l|c|c}
\hline Variáveis & $\begin{array}{c}\text { Total } \\
\end{array}$ & Ordem de entrada no modelo \\
\hline Massa corporal $(\mathrm{Kg})$ & $0,37(<0,001)$ & 1 \\
MCM BIA (Kg) & $0,34(<0,001)$ & 2 \\
PCint (cm) & $0,32(<0,001)$ & 3 \\
PQ (cm) & $0,31(<0,001)$ & 4 \\
IMC (Kg/m²) & $0,29(<0,001)$ & 5 \\
R (Ohm) & $-0,22(0,005)$ & 6 \\
Estatura (m) & $0,22(0,005)$ & 7 \\
RCQ & $0,21(0,006)$ & 8 \\
Idade (anos) & $0,08(0,300)$ & 9 \\
DCT (mm) & $0,07(0,344)$ & 10 \\
$\chi_{c}($ Ohm) & $-0,07(0,389)$ & 11 \\
\hline
\end{tabular}


A Tabela 10 apresenta a descrição das etapas de modelagem. As variáveis foram acrescentadas uma a uma no modelo, a partir da massa corporal. Na presença da massa corporal, a MCM fornecida pela BIA, o $P C i n t, \quad O P Q, 0 I M C$, a resistência, a estatura e a $R C Q$ não foram significativas. A variável idade foi mantida no modelo, independente de sua significância estatística, porém ao acrescentar a $\chi_{c}$, a idade passou a ser significativa. Quando as variáveis MC e idade estavam no modelo, a DCT e a cor da pele não foram significativas. Optou-se, então, por trabalhar com duas equações: uma em que a idade foi não significativa (modelo 9) e outra em que a idade foi significativa independente da MC (modelo 11). A partir de agora estas equações serão denominadas Ligia1 e Ligia2. 
Tabela 10 - Descrição das etapas de modelagem múltipla para MCM. Amostra 1. Hospital Heliópolis, São Paulo, 1997.

\begin{tabular}{|c|c|c|c|c|c|}
\hline Modelos & Variáveis & $\beta$ & $I C_{95 \%}(\beta)$ & $p$ modelo & $r^{2}$ ajustado \\
\hline 1 & Massa corporal & $\begin{array}{l}0,216 \\
\beta_{0}=36,715\end{array}$ & {$[0,130 ; 0,302]$} & $<0,001$ & 0,13 \\
\hline 2 & $\begin{array}{l}\text { Massa corporal } \\
\text { MCM IB }\end{array}$ & $\begin{array}{l}0,184 \\
0,056 \\
\beta_{0}=35,877\end{array}$ & $\begin{array}{l}{[-0,004 ; 0,371]} \\
{[-0,235 ; 0,348]}\end{array}$ & $<0,001$ & 0,13 \\
\hline 3 & $\begin{array}{l}\text { Massa corporal } \\
\text { PCint }\end{array}$ & $\begin{array}{l}0,250 \\
-0,045 \\
\beta_{0}=38,545\end{array}$ & $\begin{array}{l}{[0,056 ; 0,444]} \\
{[-0,275 ; 0,184]}\end{array}$ & $<0,001$ & 0,13 \\
\hline 4 & $\begin{array}{l}\text { Massa corporal } \\
\text { PQ }\end{array}$ & $\begin{array}{l}0,304 \\
-0,165 \\
\beta_{0}=46,870\end{array}$ & $\begin{array}{l}{[0,091 ; 0,517]} \\
{[-0,531 ; 0,202]}\end{array}$ & $<0,001$ & 0,13 \\
\hline 5 & $\begin{array}{l}\text { Massa corporal } \\
\text { IMC }\end{array}$ & $\begin{array}{l}0,307 \\
-0,312 \\
\beta_{0}=38,332\end{array}$ & $\begin{array}{l}{[0,118 ; 0,496]} \\
{[-0,887 ; 0,263]}\end{array}$ & $<0,001$ & 0,13 \\
\hline 6 & $\begin{array}{l}\text { Massa corporal } \\
\mathrm{R}\end{array}$ & $\begin{array}{l}0,224 \\
0,023 \\
\beta_{0}=34,984\end{array}$ & $\begin{array}{l}{[0,113 ; 0,335]} \\
{[-0,018 ; 0,022]}\end{array}$ & $<0,001$ & 0,13 \\
\hline 7 & $\begin{array}{l}\text { Massa corporal } \\
\text { Estatura }\end{array}$ & $\begin{array}{l}0,197 \\
8,522 \\
\beta_{0}=23,977\end{array}$ & $\begin{array}{l}{[0,102 ; 0,292]} \\
{[-9,928 ; 26,973]}\end{array}$ & $<0,001$ & 0,13 \\
\hline 8 & $\begin{array}{l}\text { Massa corporal } \\
\text { RCQ }\end{array}$ & $\begin{array}{l}0,207 \\
3,595 \\
\beta_{0}=33,940\end{array}$ & $\begin{array}{l}{[106 ; 0,308]} \\
{[-17,868 ; 25,059]}\end{array}$ & $<0,001$ & 0,13 \\
\hline 9 & $\begin{array}{l}\text { Massa } \\
\text { corporal } \\
\text { Idade }\end{array}$ & $\begin{array}{l}0,226 \\
0,114 \\
\beta_{0}=28,904\end{array}$ & $\begin{array}{l}{[0,140 ; 0,311]} \\
{[-0,013 ; 0,242]}\end{array}$ & $<0,001$ & 0,14 \\
\hline 10 & $\begin{array}{l}\text { Massa corporal } \\
\text { Idade } \\
\text { DCT }\end{array}$ & $\begin{array}{l}0,278 \\
0,100 \\
-0,157 \\
\beta_{0}=28,236\end{array}$ & $\begin{array}{l}{[0,166 ; 0,390]} \\
{[-0,028 ; 0,229]} \\
{[-0,374 ; 0,060]}\end{array}$ & $<0,001$ & 0,15 \\
\hline 11 & $\begin{array}{l}\text { Massa } \\
\text { corporal } \\
\text { Idade } \\
\chi_{e}\end{array}$ & $\begin{array}{l}0,252 \\
0,159 \\
0,111 \\
\beta_{0}=18,432\end{array}$ & $\begin{array}{l}{[0,160 ; 0,344]} \\
{[0,019 ; 0,299]} \\
{[-0,036 ; 0,258]}\end{array}$ & $<0,001$ & 0,15 \\
\hline 12 & $\begin{array}{l}\text { Massa corporal } \\
\text { Idade } \\
\text { Cor da pele }\end{array}$ & $\begin{array}{l}0,225 \\
0,115 \\
0,838 \\
\beta_{0}=27,876\end{array}$ & $\begin{array}{l}{[0,139 ; 0,311]} \\
{[-0,012 ; 0,243]} \\
{[-1,682 ; 3,358]}\end{array}$ & $<0,001$ & 0,15 \\
\hline 13 & $\begin{array}{l}\text { Massa corporal } \\
\text { Idade } \\
\chi_{c} \\
\text { Cor da pele }\end{array}$ & $\begin{array}{l}0,251 \\
0,160 \\
-0,111 \\
0,848 \\
\beta_{0}=17,368\end{array}$ & $\begin{array}{l}{[0,159 ; 0,343]} \\
{[0,020 ; 0,301]} \\
{[-0,036 ; 0,259]} \\
{[-1,662 ; 3,359]}\end{array}$ & $<0,001$ & 0,15 \\
\hline
\end{tabular}


Na equação Ligia1 ficaram as variáveis massa corporal e idade, e no modelo Ligia2 ficaram as variáveis massa corporal, idade e reatância. A análise de residuos para os dois modelos (Anexo 4) mostrou que os erros tinham distribuição normal e não demonstraram vieses. Houve a presença de 10 valores aberrantes em cada modelo, porém foram mantidos na análise. As equações finais para a estimativa de MCM foram:

Ligia1

$\operatorname{MCM}(\mathrm{kg})=28,904+0,226(\mathrm{MC}, \mathrm{Kg})+0,114(\mathrm{l}$, anos $)$

Ligia2

$\operatorname{MCM}(\mathrm{kg})=18,432+0,252(\mathrm{MC}, \mathrm{Kg})+0,159(\mathrm{l}$, anos $)+0,111\left(\chi_{\mathrm{c},}, \Omega\right)$

\subsection{Validação das equações}

Nesta etapa foram utilizados os indivíduos da amostra 2. Foram analisados 160 homens, sendo 131 brancos (82\%) e 29 não brancos (18\%). A idade variou de 50 a 81 anos, sendo que a maioria estava entre 50 a 64 anos de idade $(62,5 \%)$, com média de 56,95 anos. As categorias de escolaridade mais freqüentes foram sabe ler e escrever $(34,4 \%)$ e $1^{\circ} \mathrm{grau}$ incompleto $(33,1 \%)$. 


\subsubsection{Percentual de gordura}

As equações de literatura a serem utilizadas na validação já foram apresentadas no Quadro 3, no sub-item análise estatistica do item material e métodos, sendo as resultantes deste trabalho as seguintes:

LigiaA

$\% G=-16,177+0,306$ (PCint, cm)+0,352(\%G BIA)+0,152(DCT,mm)

LigiaB

$\% G=-17,970+0,296$ (PCint, cm) $+0,349$ (\%G BIA)+0,173(DCT,mm)+0,039(l,anos)

LigiaC

$\% G=-21,007+0,430(P C i n t, c m)+0,195(D C T, m m)$

LigiaD

$\% G=-26,060+0,418(P C i n t, c m)+0,219(D C T, m m)+0,046$ (Idade, anos)

Quadro 6 apresenta as variáveis e seus coeficientes de regressão ( $\beta$ ) que constituem cada uma das equaçōes que serão validadas neste trabalho. Observa-se que as equações de literatura apresentam menos variáveis que as equações desenvolvidas pelo presente estudo. As duas primeiras 
equaçōes desenvolvidas por este estudo utilizaram uma variável derivada da BIA e vale lembrar que ela teve um efeito independente na presença da PCint e DCT. O modelo proposto por Garrow e Webster (1985) e o proposto por Deurenberg et al. (1991) são os que consideram o IMC; neste último também são consideradas variáveis demográficas (sexo e idade). Apenas no modelo de Lean et al.(1996) a PCint estava presente, assim como nos modelos propostos por este trabalho; nos modelos LigiaB e LigiaD a variável idade também foi considerada como preditiva.

Quadro 6 - Coeficientes de regressão $(\beta)$, das variáveis de cada equação para o cálculo do \%G.

\begin{tabular}{|l|c|c|c|c|c|c|c|}
\hline Equação & $\beta_{0}$ & IMC & Idade & Sexo & PCint & DCT & \%G BIA \\
\cline { 2 - 8 } & & $\beta$ & $\beta$ & $\beta$ & $\beta$ & $\beta$ & $\beta$ \\
\hline $\begin{array}{l}\text { Garrow \& } \\
\text { Webster (1985) }\end{array}$ & 71,50 & $-1210^{\circ}$ & - & - & - & - & - \\
\hline $\begin{array}{l}\text { Deurenberg et } \\
\text { al.(1991) }\end{array}$ & $-5,4$ & 1,2 & 0,23 & $-10,8$ & - & - & - \\
\hline $\begin{array}{l}\text { Lean et al. } \\
\text { (1996) }\end{array}$ & $-31,8$ & - & 0,101 & & 0,567 & - & - \\
\hline LigiaA & $-16,177$ & - & - & - & 0,306 & 0,152 & 0,352 \\
\hline LigiaB & $-17,970$ & - & 0,039 & - & 0,296 & 0,173 & 0,349 \\
\hline LigiaC & $-21,007$ & - & - & - & 0,430 & 0,195 & - \\
\hline LigiaD & $-23,060$ & - & 0,046 & - & 0,418 & 0,219 & - \\
\hline
\end{tabular}

* nesta equação o coeficiente de regressão multiplica o inverso do IMC (1/IMC).

A Tabela 11 apresenta a estatística descritiva das estimativas do percentual de gordura. Verifica-se que a média do percentual de gordura fornecida pela DEXA foi subestimada pela BIA, não apresentando diferença 
estatisticamente significativa $(p=0,062)$ e superestimada pelas outras equaçōes, apresentando diferenças estatisticamente significativas $(p<0,001)$ com as equações de literatura. As médias estimadas pelas equaçōes elaboradas pelo presente estudo se apresentaram semelhantes, do ponto de vista estatístico, quando comparadas com a média do \%G da DEXA (LigiaA, $p=0,138 ;$ LigiaB, $p=0,227 ;$ LigiaC, $p=0,211$ e LigiaD, $p=0,281$ ). O Gráfico 2 apresenta esta análise.

Tabela 11 - Estatística descritiva do \%G fornecido pela DEXA ou pela BIA e estimados pelas equações. Amostra 2. Hospital Heliópolis, São Paulo, 1997.

\begin{tabular}{|c|c|c|c|c|c|}
\hline Equação/ método & Média (dp) & $P^{*}$ & Mínimo - Máximo & Mediana & $\begin{array}{c}\text { Percentis } \\
25-75\end{array}$ \\
\hline DEXA & $22,99(6,94)$ & & $4-45$ & 24,00 & $18,00-28,00$ \\
\hline BIA & \begin{tabular}{|l|}
$22,25(6,05)$ \\
\end{tabular} & 0,062 & $11-52$ & 21,00 & $18,00-25,00$ \\
\hline $\begin{array}{l}\text { Garrow \& } \\
\text { Webster(1985) }\end{array}$ & $25,79(6,83)$ & $<0,001$ & $9,70-42,52$ & 27,06 & $20,30-30,95$ \\
\hline $\begin{array}{l}\text { Deurenberg et } \\
\text { al.(1991) }\end{array}$ & $30,58(5,18)$ & $<0,001$ & $20,52-46,56$ & 30,43 & $26,34-34,00$ \\
\hline Lean et al. (1996) & $29,26(5,91)$ & $<0,001$ & $17,29-44,91$ & 29,54 & $24,64-32,69$ \\
\hline LigiaA & $23,47(5,64)$ & 0,138 & $11,30-45,50$ & 23,44 & $19,11-26,85$ \\
\hline LigiaB & $23,37(5,61)$ & 0,227 & $11,38-45,14$ & 23,16 & $18,90-26,66$ \\
\hline LigiaC & $23,42(5,42)$ & 0,211 & $12,09-39,33$ & 23,47 & $18,84-26,89$ \\
\hline LigiaD & $23,42(5,41)$ & 0,206 & $12,23-39,08$ & 23,42 & $19,12-26,66$ \\
\hline
\end{tabular}

${ }^{\star} p=$ nivel descritivo do teste t-Student pareado. 
Gráfico 2 - Médias do \%G e respectivos intervalos de $95 \%$ de confiança, segundo as diversas equações. Amostra 2. Hospital Heliópolis, São Paulo, 1997.

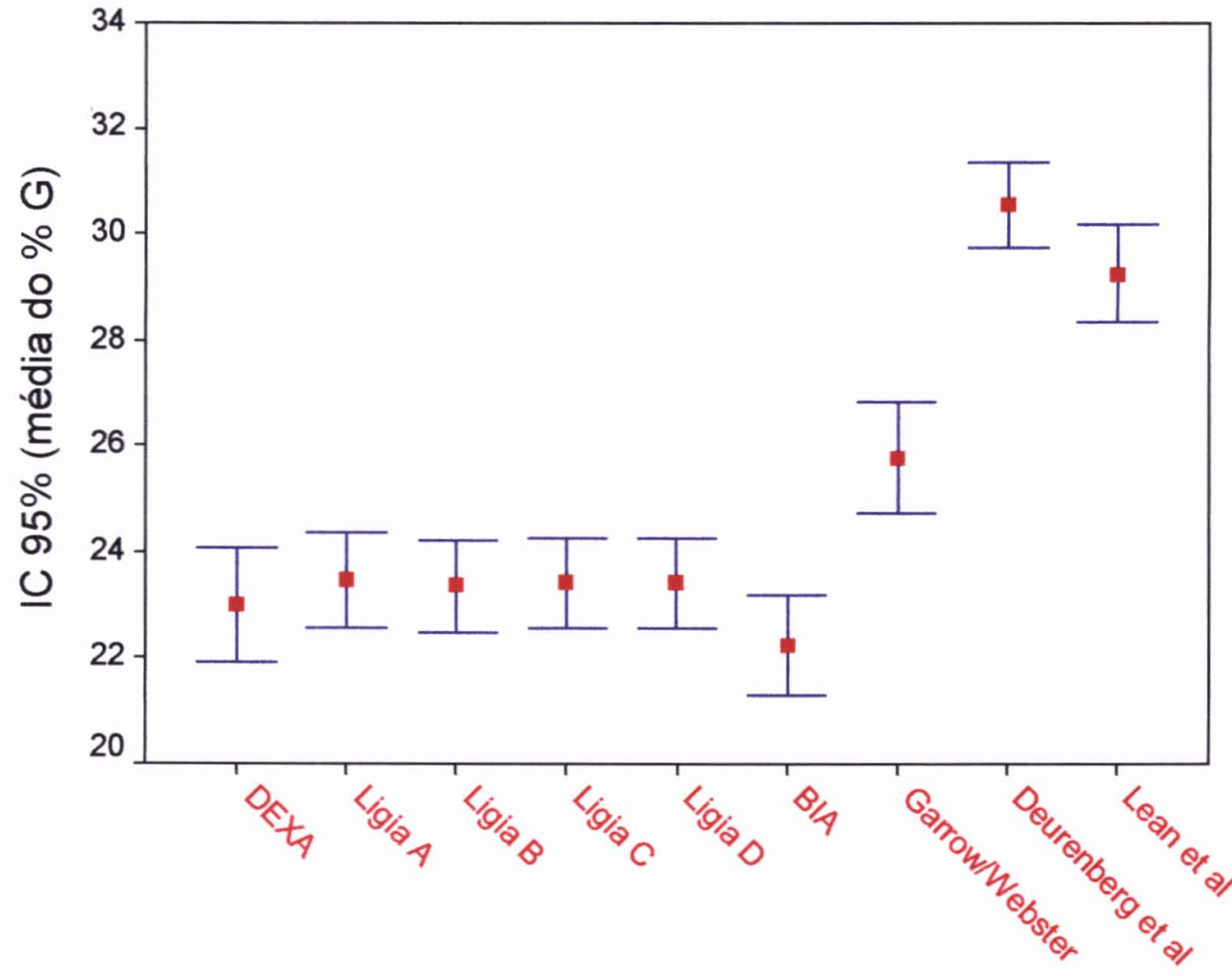

$\% G$ 
Verifica-se, na Tabela 12, que as equações que apresentaram maiores coeficientes de correlação intraclasse com o padrão-ouro foram as equações resultantes do presente trabalho $\left(r_{i c c}=0,82,0,82,0,79\right.$ e 0,79 respectivamente); estas apresentaram, também, menores valores de EPEs $(4,0 \%, 4,0 \%, 4,3 \%$ e $4,3 \%$ respectivamente). Estes valores, seguindo as classificaçōes referenciadas por LOHMAN (1992), resultam em um aceitável coeficiente de correlação e um erro padrão de estimativa razoavelmente bom. As outras estimativas tiveram $r_{i c c}$ sempre superiores a 0,70 , porém inferiores a 0,80 , e seus EPE's foram iguais ou superiores a $4,5 \%$. O Gráfico 3 apresenta os diagramas de dispersão para cada uma das estimativas.

Optou-se por escolher a equação LigiaB como a preditora do \%G em homens brasileiros com 50 anos e mais, pois foi a que apresentou o maior valor do $r_{i c c}$ e menor valor do EPE. .No entanto, vale ressaltar que, na ausência de um aparelho de BIA, pode-se definir como equação preditora a LigiaD. 
Tabela 12 - Coeficientes de correlação intraclasse (ric) entre o \%G fornecido pela DEXA e aquele fornecido pela BIA e os estimados pelas equações. Amostra 2. Hospital Heliópolis, São Paulo, 1997.

\begin{tabular}{l|c|c|c}
\hline \multicolumn{1}{c|}{ Equações } & $r_{\text {icc }}$ & $p$ & EPE (\%) \\
\hline BIA & 0,71 & $<0,001$ & 4,9 \\
Garrow \& Webster (1985) & 0,72 & $<0,001$ & 4,8 \\
Deurenberg et al.(1991) & 0,72 & $<0,001$ & 4,8 \\
Lean et al. (1996) & 0,76 & $<0,001$ & 4,5 \\
LigiaA & 0,82 & $<0,001$ & 4,0 \\
LigiaB & 0,82 & $<0,001$ & 4,0 \\
LigiaC & 0,79 & $<0,001$ & 4,3 \\
LigiaD & 0,79 & $<0,001$ & 4,3 \\
\hline
\end{tabular}


Gráfico 3 - Diagramas de dispersão entre o valor de \%G medido pela DEXA e os estimados pelas equações. Amostra 2. Hospital Heliópolis, São Paulo, 1997.
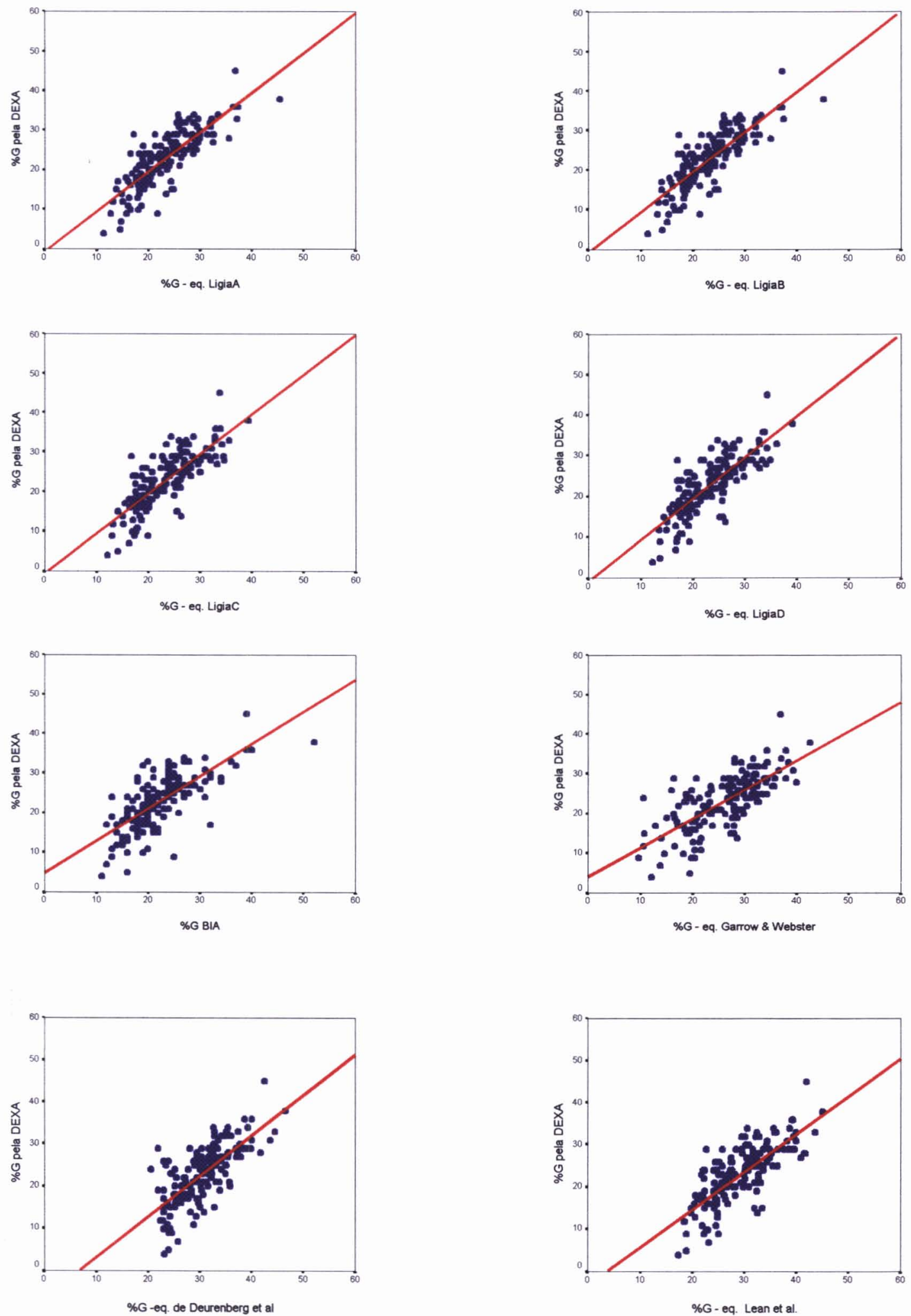


\subsubsection{Massa corporal magra}

As equações de literatura a serem utilizadas na validação já foram apresentadas no Quadro 4, no sub-item análise estatística do item material e métodos, sendo as equações resultantes deste trabalho as seguintes:

\section{Ligia1}

$$
M C M(K g)=28,904+0,226(M C, K g)+0,114(l, a n o s)
$$

\section{Ligia2}

$$
\operatorname{MCM}(\mathrm{Kg})=18,432+0,252(\mathrm{MC}, \mathrm{Kg})+0,159(\mathrm{l}, \text { anos })+0,111\left(\chi_{\mathrm{c}}, \Omega\right)
$$

O Quadro 7 apresenta as variáveis e seus coeficientes de regressão ( $\beta$ ) que constituem cada uma das equações validadas neste trabalho. Observa-se que a massa corporal é a variável que aparece em todas as equações, seguindo-se da idade que aparece em 4 equações, da estatura e indice de resistência que aparecem em 2 equações, resistência e reatância que também aparecem em 2 equações, e sexo que aparece somente em uma equação. 
Quadro 7 - Coeficientes de regressão ( $\beta$ ) para as variáveis de cada equação para o cálculo da MCM.

\begin{tabular}{|l|c|c|c|c|c|c|c|c|}
\hline \multicolumn{1}{|c|}{ Equação } & \multicolumn{1}{|c|}{$\beta_{0}$} & Estatura & Idade & Sexo & $\mathbf{R}$ & MC & $E^{2} / \mathbf{R}$ & Rea \\
\cline { 3 - 9 } & & $\beta$ & $\beta$ & $\beta$ & $\beta$ & $\beta$ & $\beta$ & $\beta$ \\
\hline Segal et al.(1988): RJL & 6,493 & - & - & - & - & 0,332 & 0,4936 & - \\
\hline Segal et al.(1988):geral & 22,66827 & 0,00132 & $-0,1676$ & - & $-0,04394$ & 0,30520 & - & - \\
\hline Gray et al.(1989) & 39,830 & 0,00139 & - & - & $-0,0801$ & 0,187 & - & - \\
\hline Deurenberg et.al. (1991) & $-12,44$ & 15,34 & $-0,127$ & 4,56 & - & 0,273 & $0,340 \times 10^{4}$ & - \\
\hline Lohman (1992) & $-10,9$ & - & - & - & - & 0,186 & 0,600 & 0,226 \\
\hline Ligia1 & 28,904 & - & 0,114 & - & - & 0,226 & - & - \\
\hline Ligia2 & 18,432 & - & 0,159 & - & - & 0,252 & - & 0,111 \\
\hline
\end{tabular}


A Tabela 13 apresenta a estatística descritiva para a MCM fornecida pela DEXA e as estimativas das equações. Verifica-se que as médias do valor de massa corporal magra fornecido pela DEXA não diferiram estatisticamente daquelas estimadas pelas equações elaboradas pelo presente trabalho (Ligia1 e Ligia2) e pela equação de Gray et al.(1989).

A média estimada por Segal et al.(1988):RJL foi a que mais subestimou o valor da média fornecida pela DEXA, e a MCM fornecida pela BIA foi a que mais superestimou. O Gráfico 4 apresenta estas comparações.

Tábela 13 - Estatística descritiva do valor de MCM fornecido pela DEXA, e aqueles fornecidos pela BIA e estimados pelas equações. Amostra 2. Hospital Heliópolis, São Paulo, 1997.

\begin{tabular}{l|c|c|c|c|c}
\hline \multicolumn{1}{c|}{ Equação/método } & Média (dp) & $\boldsymbol{p}^{*}$ & Minimo-Máximo & Mediana & $\begin{array}{c}\text { Percentis } \\
\mathbf{2 5}\end{array}$ \\
\hline DEXA & $\mathbf{5 2 , 6 0 ( 7 , 3 3 )}$ & & $33,42-75,23$ & 51,39 & $47,73-52,22$ \\
\hline BIA & $57,09(8,14)$ & $<0,001$ & $41,00-82,00$ & 56,00 & $51,00-62,00$ \\
Segal et al. (1988):RJL & $31,10(4,48)$ & $<0,001$ & $23,00-45,17$ & 30,23 & $28,00-34,01$ \\
Segal et al.(1988):geral & $50,07(7,99)$ & $<0,001$ & $33,10-73,50$ & 48,62 & $44,30-56,55$ \\
Gray et al.(1989) & $53,57(7,75)$ & 0,154 & $37,23-76,34$ & 52,69 & $47,65-59,21$ \\
Deurenberg et al.(1991) & $49,65(7,30)$ & $<0,001$ & $34,50-72,24$ & 48,16 & $44,59-55,30$ \\
Lohman (1992) & $49,73(6,97)$ & $<0,001$ & $35,18-70,86$ & 48,90 & $44,73-54,83$ \\
Ligia1 & $52,73(3,01)$ & 0,813 & $47,38-61,50$ & 52,37 & $50,57-54,42$ \\
Ligia2 & $52,80(3,11)$ & 0,728 & $46,85-62,42$ & 52,49 & $50,62-54,56$ \\
\hline
\end{tabular}

* $p$ : nivel descritivo do teste t-Student pareado. 
Gráfico 4 - Médias de MCM e respectivos intervalos de confiança, segundo as diversas estimativas. Amostra 2. Hospital Heliópolis, São Paulo, 1997.

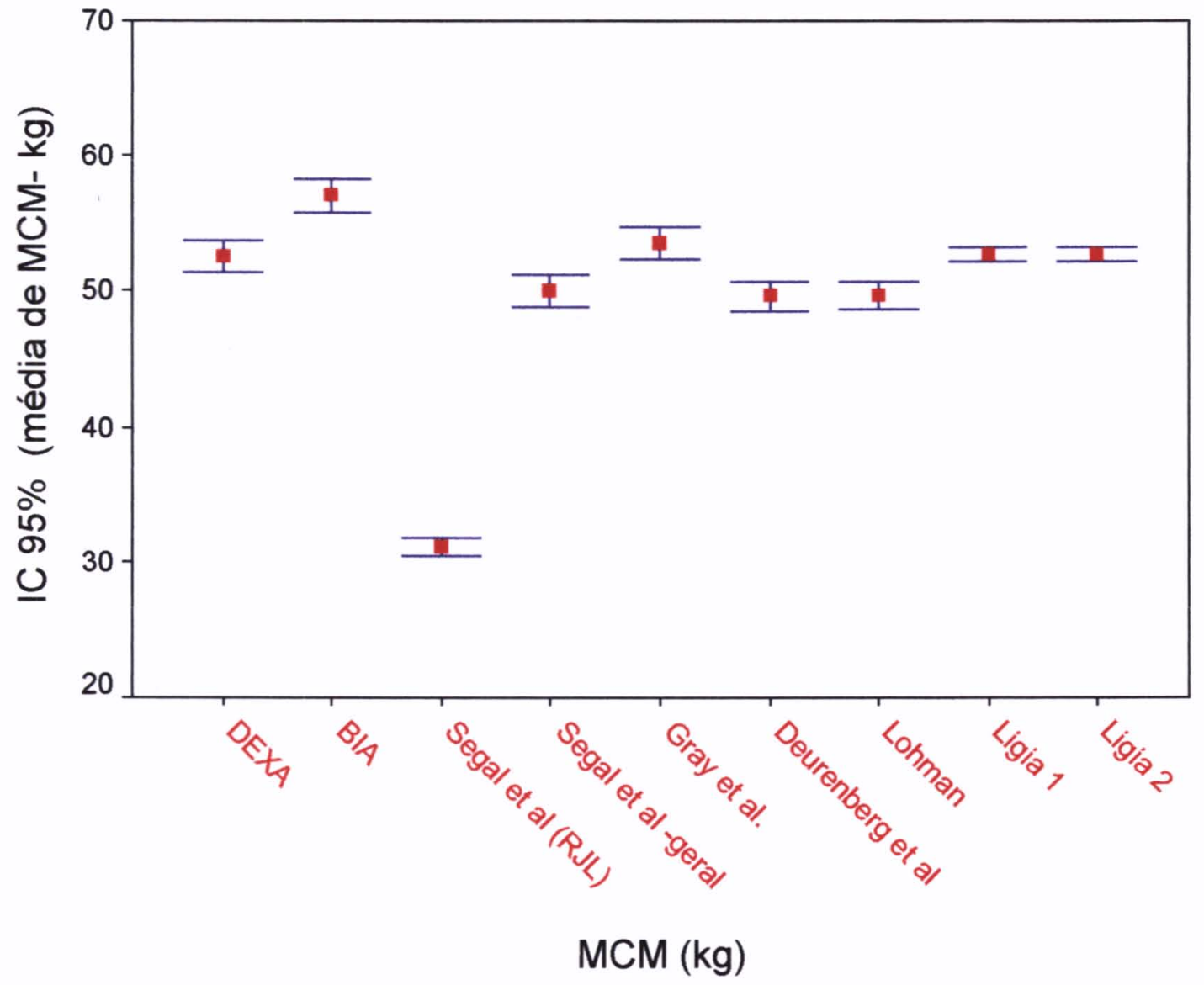


Verifica-se, na Tabela 14, que todas as equações estudadas apresentaram baixas correlações com o padrão-ouro embora significativas, assim como altos valores de erro padrão de estimativa, concluindo-se que que não são adequadas para estimar a massa corporal magra neste grupo de individuos estudados. Vale ressaltar que nem o valor estimado pela BIA foi considerado adequado para estimar a MCM. O Gráfico 5 apresenta os diagramas de dispersão desta análise.

Tabela 14 - Coeficientes de correlação intraclasse - $r_{\text {icc }}$ entre 0 valor de MCM fornecido pela DEXA e BIA e aqueles estimados pelas equações. Amostra 2. Hospital Heliópolis, São Paulo, 1997.

\begin{tabular}{|c|c|c|c|}
\hline Equações/ método & $r_{\text {Icc }}$ & $p$ & EPE (Kg) \\
\hline BIA & 0,34 & $<0,001$ & 6,9 \\
\hline $\begin{array}{l}\text { Segal et al. (1988): equaçōes } \\
\text { preditivas dos fabricantes (RJL) }\end{array}$ & 0,30 & $<0,001$ & 7,0 \\
\hline Segal et al.(1988): geral & 0,33 & $<0,001$ & 6,9 \\
\hline Gray et al.(1989) & 0,35 & $<0,001$ & 6,9 \\
\hline Deurenberg et al.(1991) & 0,33 & $<0,001$ & 6,9 \\
\hline Lohman (1992) & 0,37 & $<0,001$ & 6,8 \\
\hline Ligia1 & 0,28 & $<0,001$ & 7,0 \\
\hline Ligia2 & 0,28 & $<0,001$ & 7,0 \\
\hline
\end{tabular}


Gráfico 5 - Diagramas de dispersão entre o valor de MCM medido pela DEXA e os estimados pelas equações. Amostra 2. Hospital Heliópolis, São Paulo, 1997.
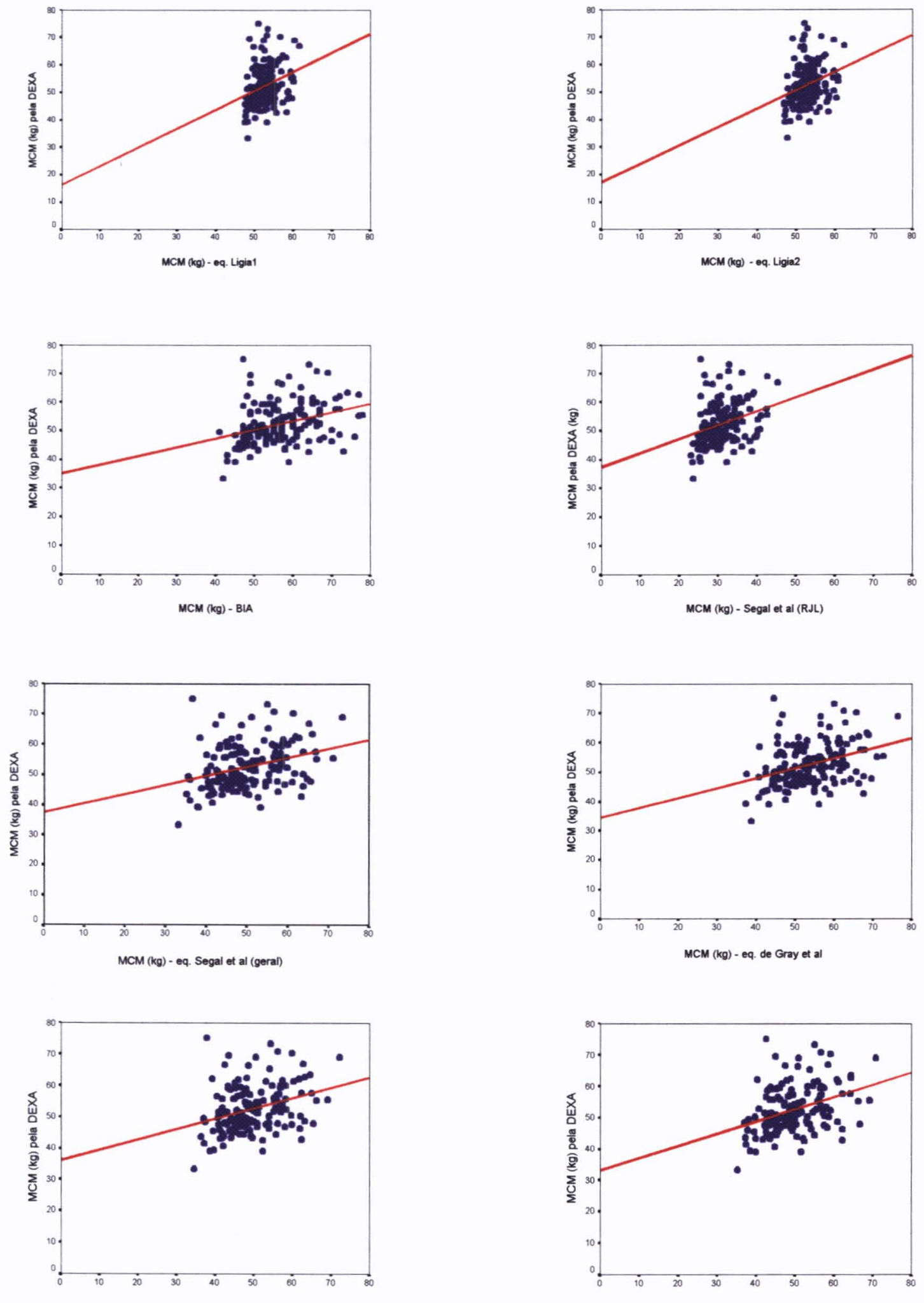

MCM $(\mathrm{kg})$ - eq. Deurenberg et al.

MCM (kg) - eq. Lohman 


\section{DISCUSSÃO}

O presente estudo teve como objetivo desenvolver equações preditivas de percentual de gordura e massa corporal magra para homens brasileiros com idades entre 50 e 85 anos e validar não somente estas equações, mas, também, aquelas referidas pela literatura para homens, e os valores fornecidos pela BIA, tendo como padrão-ouro os valores fornecidos pela DEXA.

A amostra deste estudo foi composta por 320 indivíduos voluntários do sexo masculino com idades entre 50 e 85 anos. A forma voluntária de recrutamento pode levar a um viés de seleção, pois não é representativa da população masculina com 50 anos ou mais, residente no município de São Paulo, ou na área de abrangência do hospital onde realizou-se este estudo. Viés, segundo PEREIRA (1999), é um erro que leva a conclusões diferentes da verdade, sendo viés de seleção um erro no recrutamento da população, devido a diferenças nas características dos indivíduos que fazem e daqueles que não fazem parte do estudo.

Observou-se que a maioria dos homens deste estudo estava na faixa etária de 50 a 64 anos de idade $(61,9 \%)$, era da cor branca $(80,9 \%)$ e tinha escolaridade baixa $\left(36,6 \%\right.$ com $1^{\circ}$ grau incompleto e $34,4 \%$ sabia ler e escrever). Comparando com dados do Censo Demográfico do Brasil de 2000, na população de homens com 50 anos ou mais, $65,0 \%$ está com idade 
entre 50 e 64 anos, $57,89 \%$ são da cor branca, e a taxa de analfabetismo varia de $11,6 \%$ na faixa de 40 a 49 anos a $41,3 \%$ para as pessoas de 70 anos e mais. Cerca de $40 \%$ deles possuem, apenas, de 1 a 4 anos de estudo (Fundação IBGE, 2000). Com isso, verifica-se que os voluntários estudados apresentaram caracteristicas demográficas e escolaridade semelhantes às dos homens com 50 anos e mais brasileiros. Como o recrutamento foi feito com base no oferecimento gratuito do exame da DEXA, não se acredita que esta forma de recrutamento tenha provocado viés de seleção, embora a amostra não tenha sido probabilística.

Analisando-se os dados antropométricos deste estudo com o estudo de PERISSINOTTO et al.(2002), para homens com idade de 65 anos ou mais, verificam-se valores médios muito parecidos para: massa corporal (respectivamente, $71,90 \mathrm{~kg}$ e $72,60 \mathrm{~kg}$ ), estatura (respectivamente, $1,64 \mathrm{~m} \mathrm{e}$ $1,65 \mathrm{~m}$ ), IMC (respectivamente, $26,64 \mathrm{~kg} / \mathrm{m}^{2}$ e $26,4 \mathrm{~kg} / \mathrm{m}^{2}$ ), PCint (respectivamente, $97,14 \mathrm{~cm}$ e $97,5 \mathrm{~cm}$ ), PQ (respectivamente, $100,82 \mathrm{~cm}$ e 100,2cm) e RCQ (respectivamente 0,96 e 0,97). PERISSINOTTO et al.(2002) também encontraram uma diminuição significativa em relação à estatura para homens mais velhos. Esta diminuição é normal, pois com o envelhecimento ocorre achatamento das vértebras, redução dos discos intervertebrais levando à cifose dorsal e arqueamento dos membros inferiores e do arco plantar (DUARTE et al., 2002). 
Para o desenvolvimento e validação de equações de predição, o grupo de estudo foi dividido em duas amostras aleatórias, com 160 homens em cada uma. Na primeira amostra foram desenvolvidas as equaçōes de predição para o percentual de gordura e massa corporal magra, e na segunda amostra foram validadas as equações. Segundo HEYWARD et al. (2000), para que os resultados de equações de composição corporal sejam validados é necessário que sejam testados em outras amostras, geralmente dividindo-se o grupo original em dois, como foi feito no presente trabalho. Além disso, para assegurar que os dados são representativos da população, na qual a equação foi desenvolvida, as amostras devem ter entre 100 e 400 pessoas, com pelo menos, 10 a 20 sujeitos por variável. No presente trabalho, as 4 equaçöes desenvolvidas apresentaram 2,3 e 4 variáveis preditivas, portanto a amostra de 160 homens mostrou ser adequada para tais análises.

$\mathrm{Na}$ análise da validação foram calculados o coeficiente de correlação intraclasse e o EPE. Segundo HEYWARD et al. (2000), um bom coeficiente de correlação intraclasse para equações de predição de composição corporal deve exceder à 0,80 , pois isso significa que pelo menos $64 \%$ da variância na medida de referência pode ser levada em conta pelas variáveis de predição desta equação. O EPE reflete 0 grau de desvios dos dados individuais ao longo da reta de melhor ajuste através de todos os pontos de dados da amostra. Quanto mais próximos os dados individuais estiverem da reta de regressão, menor será o erro de predição. 
Mudanças na composição corporal devido ao sexo, idade, e raça levam ao desenvolvimento de equações específicas. No presente estudo, separando-se a população em relação à faixa etária e cor da pele considerou-se que isso não seria necessário, pois as médias das variáveis de estudo não diferiram significativamente e os coeficientes de correlação foram muito semelhantes. Por isso, optou-se por fazer um modelo múltiplo para o total de homens. Mesmo assim, no processo de modelagem, foram analisadas as variáveis idade e cor da pele. Pelo fato de que várias equações de literatura consideram a idade no modelo, optou-se sempre por comparar modelo com e sem a idade, para verificar se este ajuste era necessário. A cor da pele em nenhum momento foi estatisticamente significativa e, por isso, acabou sendo desconsiderada nos modelos finais.

A partir de agora são discutidos os resultados referentes às estimativas do \%G. No desenvolvimento das equações preditivas para este componente, optou-se em elaborar equações com a presença da variável \%G BIA e sem esta variável. Isso por que ela é resultado da equação do fabricante do equipamento e que utiliza uma equação desenvolvida para outras populações que não a brasileira. $\mathrm{O}$ objetivo era avaliar se esta estimativa poderia contribuir na predição do \%G de per si, ou se esta estimativa não era precisa e para melhorar a precisão outras variáveis precisariam ser consideradas. Também estimou-se uma equação utilizando apenas a antropometria, idade e cor da pele como variáveis explicativas, 
com o objetivo de avaliar se elas poderiam fornecer informações sobre o $\% G$, sem necessidade da BIA.

Concluiu-se que, para obter uma equação com maior poder preditivo para $\circ \% \mathrm{G}$, tem-se duas opções de equação. Na primeira, a que fornece estimativas mais precisas, é importante fazer a BIA e ajustar o valor do \%G fornecido pelo aparelho através de equação específica (LigiaB), incorporando o PCint, a DCT e a idade. Na outra, LigiaD, pode-se estimar o \%G somente utilizando as duas medidas de antropometria e a idade. Considerou-se que, independente da significância estatística, a variável idade deve permanecer nas equações, pela sua importância biológica.

A média do \%G fornecido pela DEXA (22,99\%) apresentou semelhança com as médias das equações desenvolvidas neste trabalho $($ LigiaA $=23,47 \%, \quad p=0,138 ; \quad$ LigiaB $=23,37 \%, \quad p=0,227 ; \quad$ LigiaC $=23,42 \% ;$ $p=0,211$ e LigiaD=23,42\%; $p=0,206$ ), e com o valor fornecido pela BIA $(22,25 \% ; p=0,062)$. No entanto, diferiu, estatisticamente, das médias dos \%G estimados pelas equaçōes de literatura, que estavam superestimados.

A subestimação dos valores fornecidos pela BIA (equipamento) foi encontrada em outros trabalhos, que utilizaram outras técnicas, como padrão-ouro (BARBOSA et al., 2001; DEURENBERG et al.,2001; EISENKÖLBL et al,2001; MORENO et al.,2001; WATTANAPENPAIBOON et al.,1998; MAZARIEGOS et al., 1996). 
Dentre as equações estudadas para estimar \%G, apenas duas daquelas desenvolvidas neste estudo apresentaram coeficientes de correlação intra-classe superiores a 0,80 (LigiaA $r_{i c c}=0,82, p<0,001$; LigiaB $\left.r_{\text {icc }}=0,82, p<0,001\right)$, mas os valores das outras duas equações foram próximos à este valor (LigiaC $r_{i c c}=0,79, p<0,001$; e LigiaD $r_{i c c}=0,79, p<0,001$ ) Os menores erros padrão de estimativa foram os das primeiras equações deste trabalho (LigiaA e LigiaB, EPE=4,0), valores estes considerados razoavelmente bons pela classificação de LOHMAN (1992). UTTER et al.(2001) encontraram boa correlação e EPE, mas comparando \%G fornecido pela BIA (analisador Tanita) com as DCs, em cinco avaliações transversais $(r=0,67-0,83, p<0,001$. EPE $=2,1-3,5)$.

No entanto as estimativas do $\% \mathrm{G}$ dos quatro modelos ficaram muito próximas nas médias, desvios padrão, mediana e percentis 25 e 75, ocorrendo diferenças apenas na primeira casa decimal. Os valores dos $r^{2}$ ajustados foram muito próximos (de 0,68 a 0,71), bem como os $r_{\text {icc }}$ 's (de 0,79 a 0,82 ) e EPEs (de 4,0 a 4,3 ). Por isso, considera-se que qualquer uma delas fornecerá boas estimativas do \%G fornecido pela DEXA. $\dot{E}$ importante ressaltar que $0 \% \mathrm{~g}$ da $B I A$, não foi suficiente de per si e recomenda-se ajustar os valores estimados pelos softwares que acompanham os aparelhos de BIA, considerando algumas medidas específicas do homem brasileiro (no caso, PCint e a DCT). 
Ou, então, basta utilizar os dados do PCint e da DCT e a idade pode ser ou não ser considerada, pois não há diferença do ponto de vista estatístico.

As estimativas do \%G feitas pelas equações de literatura se mostraram superestimadas. Isso pode ter ocorrido tanto pelo fato destas equações terem sido estimadas em outras populações (Reino Unido e Holanda), como por utilizarem faixas etárias mais jovens (a partir de 15 anos), como por utilizarem outras variáveis. As equações propostas por Garrow e Webster e por Deurenberg et al utilizaram o IMC e neste estudo foram mais importantes, do ponto de vista estatístico, o PCInt e a DCT. Quando estes autores validaram suas equações, encontraram EPE's inferiores a 2,5. No trabalho de Deurenberg et al (1991), verificou-se que as equações de literatura superestimaram os valores do \%G.

Por tudo isso, recomenda-se sempre, utilizar equaçōes preditivas oriundas de populações com as mesmas características sócio-demográficas e de estilo de vida.

Discutindo agora as equações para estimativa da MCM, verificou-se que em nenhuma situação houve uma estimativa adequada. Observou-se que a média da MCM da DEXA $(52,60 \mathrm{Kg})$ foi semelhante às estimativas feitas pela equação de Gray et al. $(53,57 \mathrm{Kg} ; \rho=0,154)$, Ligia1 $(52,73 \mathrm{Kg}$; $p=0,813)$ e Ligia2 $(52,80 \mathrm{Kg} ; p=0,728)$. No entanto, os valores das medidas 
de posição da MCM fornecida pela DEXA (mediana=51,39Kg; $P_{25}=47,73 \mathrm{Kg}$ e $\left.\mathrm{P}_{75}=52,22 \mathrm{Kg}\right)$ e os valores mínimos e máximos $(33,42 \mathrm{Kg}$ e $75,23 \mathrm{Kg})$ foram mais próximos dos valores estimados pela equação de Gray et al. (mediana=52,69Kg; $P_{25}=47,65 \mathrm{Kg} \quad$ e $P_{75}=59,21 \mathrm{Kg} ; \quad$ mínimo=37,23 e máximo $=76,34 \mathrm{~kg}$ ). Os valores das equaçōes Ligia1 (mediana=52,37 $\mathrm{Kg}$; $\mathrm{P}_{25}=50,57 \mathrm{Kg}$ e $\mathrm{P}_{75}=54,42 \mathrm{Kg}$; mínimo=47,38 e máximo=61,50kg) e Ligia2 (mediana $=52,49 \mathrm{Kg} ; \quad P_{25}=50,62 \mathrm{Kg} \quad$ e $P_{75}=54,56 \mathrm{Kg} ; \quad$ minimo=46,85 e máximo $=62,42 \mathrm{~kg}$ ) apresentaram uma dispersão bem menor quando comparados com o padrão-ouro.

A média da MCM do DEXA foi diferente, estatisticamente, dos valores estimados pelas outras equações. Além de não apresentarem diferenças significativas das médias de MCM com a média do padräo-ouro, algumas das equações estudadas para estimar a MCM apresentaram baixas correlaçōes e altos valores de erro padrão de estimativa, demonstrando não serem boas para estimar esta medida. CABLE et al.(2001), estudando homens de 18 a 74 anos, encontraram boas correlaçōes e EPEs para MCM entre peso hidrostático e $\mathrm{BIA}(r=0,92, p<0,001, \mathrm{EPE}=3,5 \mathrm{~kg})$, mas utilizando outro equipamento (eletrodos de contato "leg-to-leg", e no presente trabalho foi utilizado eletrodos com gel "arm-to-leg"). Vale ressaltar que NUÑEZ et al.(1997), citado por CABLE et al.(2001), encontraram coeficientes de variação similares entre os dois tipos de equipamentos. 
A equação de Gray et al. utilizou a estatura, a R e a MC como variáveis preditivas da MCM. Destas, apenas a MC foi utilizada nos modelos Ligia1 e Ligia2. No estudo de Gray et al., o $r$ desta equação foi 0,97 e os deste estudo foram, respectivamente, 0,14 e 0,15 . Isso mostra que, para população de homens brasileiros de 50 a 85 anos, apenas as variáveis MC, idade e $\chi_{c}$ não são suficientes para estimar, de maneira adequada, a MCM. Isso pode ser devido à diferença de nacionalidade (brasileiros e americanos) ou da faixa etária (específica, no caso do presente estudo, e generalizada no estudo de Gray et al).

Analisando agora os valores de MCM fornecidos pela BIA, verificou-se que eles também não estimaram adequadamente os valores obtidos pela DEXA. WARD et al.(2000) encontraram pequena (2,0kg), mas significativa $(p<0,02)$ diferença na média de MCM fornecida pela BIA (Soft Tissue Analyzer) com a fornecida pela DEXA, para homens entre 16 e 78 anos de idade. $O$ coeficiente de correlação foi $r=0,87$, mas o $E P E=4,6$. CORCORAN et al.(2000) também encontraram diferença na MCM fornecida pela BIA e DEXA, em homens com AIDS.

As variáveis dos modelos Ligia1 e Ligia2 foram semelhantes às utilizadas por Lohman, com exceção da idade (Ligia1 e Ligia2) e índice de resistência (Lohman). 
A equação de Segal et al (RJL) utilizou como variáveis preditoras a MC, a Est $\mathrm{e}$ a $\mathrm{R}$ e forneceu as maiores estimativas para MCM, apresentando $r=0,857$ e EPE $=3,70 \mathrm{Kg}$. A equação de Segal et al. geral utilizou as mesmas variáveis preditivas das do Gray (estatura, $R$ e $M C$ ) e mais a idade, apresentando $r=0,898$ e $E P E=3,61 \mathrm{Kg}$, sendo o estudo realizado em população americana. É interessante notar que na equação proposta por Segal et al geral e Deurenberg et al o coeficiente de regressão referente à idade é negativo $(\beta=-0,1676$ e $\beta=-0,127)$, enquanto que nas equações de Ligia1 e Ligia2 os mesmos são positivos (respectivamente, 0,114 ; e 0,159 ). Isso levanta a hipótese de que, talvez, a idade tenha um papel diferente na MCM na população brasileira quando comparados com as populações dos outros estudos. $\mathrm{Na}$ validação do modelo Segal geral foram encontrados $r=0,989$ e $E P E=3,61$.

Por último, na equação proposta por Deuremberg estão as variáveis idade, estatura, sexo, MC, Est e R. Somente estas, foram significativas neste estudo, apresentando um $r^{2}=0,93$ e $E P E=2,63 \mathrm{Kg}$, o que mostra que estas variáveis foram importantes para predizer a MCM de grupos populacionais com faixa etária mais ampla (16 a 83 anos), mas não foram suficientes para homens brasileiros de 50 a 85 anos.

PICHARD et al.(1999) encontraram diferentes coeficientes de correlação e EPEs analisando equações preditivas de MCM pela BIA, em homens com vários tipos de doenças. KYLE et al.(1998) na validação de 
uma fórmula de BIA para estimar MCM, em indivíduos de ambos os sexos, com insuficiência respiratória, utilizando a DEXA como referência, encontraram um $r=0,95$, EPE $=1,67$ e $p<0,0001$.

Finalizando, este trabalho mostrou que é importante validar as equações para estimativas tanto do \%G quanto da MCM, bem como aqueles fornecidos pelos aparelhos de BIA, antes de utilizá-las como substitutas dos valores estimados pela DEXA, em homens brasileiros de 50 a 85 anos. Para o \%G, verificou-se que é possivel fazer esta estimativa e é importante utilizar o valor fornecido pela BIA; mas deve-se ter o cuidado de corrigi-lo pelo PCint e DCT, ajustado ou não pela idade.

Para estimar adequadamente a MCM, outros estudos ainda são necessários, tendo em vista os baixos valores de $r_{i c c}$ e altos valores de EPE encontrados em todas as estimativas. 


\section{CONCLUSÕES}

1. Para a estimativa do $\% \mathrm{G}$ em homens brasileiros de 50 a 85 anos foram definidos quatro modelos de regressão, que mostraram estimativas semelhantes. As variáveis preditivas foram \%G BIA, o PCint, a DCT, podendo ou não ser considerada a idade.

2. Para a estimativa da MCM (em kg) em homens brasilieros de 50 a 85 anos foram definidos dois modelos de regressão. Em um deles as variáveis preditivas foram $\mathrm{MC}$ e idade e no outro acrescentou-se a $\chi_{\mathrm{c}}$.

3. Na validação dos modelos para estimar $\circ \% \mathrm{G}$, observou-se que a variável mais freqüente foi o PCint e os modelos desenvolvidos no presente estudo forneceram as estimativas mais precisas.

4. Na validação dos modelos para estimar a MCM, nenhum deles forneceu estimativas precisas deste componente. 


\section{REFERÊNCIAS}

1. Aghdassi E, Tam C, Liu B, McArthur M, McGeer A, Simor A, Allard JP. Body fat of older adult subjects calculated from bioelectric impedance versus anthropometry correlated but did not agree. The American Dietetic Association 2001; 101(10):1209-1212, october.

2. Alemán-Mateo $H$, Esparza-Romero J, Valencia ME. Antropometria y composición corporal en personas mayores de 60 años. Importancia de la actividad física. Salud Pública de México 1999; 41(4), julio-agosto.

3. Barbosa AR, Santarém JM, Jacob Filho W, Meirelles ED, Marucci MFN. Comparação da gordura corporal de mulheres idosas segundo antropometria, bioimpedância e DEXA. Archivos Latinoamericanos de Nutrition 2001; 51(1):49-56.

4. Behnke $A R$, Wilmore $\mathrm{JH}$. Evaluation and regulation of body buil and composition. New Jersey: Prentice-Hall, Inc; 1974.

5. Cable A, Nieman DC, Austin M, Hogen E, Utter AC. Validity of leg-to-leg bioelectrical impedance measurement in males. J Sports Med Fitness $2001 ; 41: 411-4$. 
6. Carvalho ABR, Pires Neto CS. Desenvolvimento e validação de equações para estimativa da massa corporal magra através da impedância bioelétrica em homens. Revista Brasileira de Atividade Física \& Saúde 1998; 3(2):5-12.

7. Chumlea WC, Baumgartner RN. Status of anthropometry and body composition data in elderly subjects. American Journal of Clinical Nutrition 1989; 50:1158-1166.

8. CompCorp Ltda. Representante no Brasil da RJL Systems Corporation, 2003. Av. José Maria Whitaker, 887 - Conj.4, Fones:(11)5589-0341 e 5589-0653, Fax:(11)5589-9789, CEP:04057-000, São Paulo/SP, email:compcorp@compcorp.com:Br.

9. Corcoran C, Anderson EJ, Burrows B, Stanley T, Walsh M, Poulos AM, Grinspoon S. Comparison of total body potassum with other techniques for measuring lean body mass in men and women with AIDS wasting. Am $\mathbf{J}$ Clin Nutr 2000; 72:1053-8.

10. Costa RF. CD-Rom. Avaliação da composição corporal. Santos, FGA Multimídia, 1999.

11. Costa RF. Impedância bio-elétrica: novas tendências. Nutrição Saúde \& Performance 2001; Ano 3, Edição n9, janeiro/fevereiro/março. 
12. Coutinho W. Obesidade: conceitos e classificação. In: Nunes, M.A.A. et al. Transtornos alimentares e obesidade. Porto Alegre, ArtMed, 1998.

13. Dâmaso A. Nutrição e exercício na prevenção de doenças. Rio de Janeiro: Medsi, 2001.

14. Deurenberg P, Van Der Kooy K, Leenen R, Wetstrate JA, Seidell JC. Sex and age specific prediction formulas for estimating body composition from bioelectrical impedance: a cross-validation study. International Journal of Obesity 1991; 15:17-25.

15. Deurenberg $P$, Andreoli A, Borg P, Kukkonen-Harjula K, Lorenzo A, Lichtenbelt WDM, Testolin G, Vigano R, Vollaard N. The validity of predicted body fat percentage from body mass index and from impedance in samples of five European populations. European Journal of Clinical Nutrition 2001; 55:973-979.

16. Duarte AC, Castellani FR. Semiologia Nutricional. Rio de Janeiro: Axcel Books, 2002.

17. Eisenkölbl J, Kartasurya M, Widhalm K. Underestimation of percentage fat mass measured by bioelectrical impedance analysis compared to dual 
energy X-ray absorptiometry method in obese children. European Journal of Clinical Nutrition 2001; 55:423-429.

18. Florindo AA. Atividade física habitual e densidade mineral óssea em homens adultos e idosos. São Paulo, 2000a. [Dissertação de mestrado - Departamento de Epidemiologia - Faculdade de Saúde Pública da USP].

19. Florindo AA, Latorre MRDO, Tanaka T, Jaime PC, Zerbini CAF. Atividade física habitual e sua relação com a densidade mineral óssea em homens adultos e idosos. Revista Brasileira de Atividade Física \& Saúde $2000 b ; 5(1): 22-34$

20. Franz LBB. Bioimpedância elétrica como método de avaliação da composição corporal de individuos adultos e idosos. Cadernos Centro Universitário São Camilo 2002; 8(4):18-29.

21. Fundação IBGE. Anuário estatístico do Brasil: 1999. Rio de Janeiro; 2000. v.59.

22. Fundação IBGE. Censo demográfico 2000 [on line]. Disponivel em <URL:http:://www.ibge.gov.br/>. [2003 Mai 14]. 
23. Garrow JS, Webster J. Quetelet's index as a measure of fatness. International Journal of Obesity 1985; 9:147-153.

24. Gray DS, Bray GA, Gemayel N, Kaplan K. Effect of obesity on bioelectrical impedance. Am J Clin Nutr 1989; 50:255-60.

25. Guedes DP. Composição corporal: princípios, técnicas e aplicações. $2^{\mathrm{a}}$ ed. Londrina: APEF; 1994.

26. Gullberg B, Johnell O, Kanis JA. World-wide projections for hip fracture. Osteoporos Int 1997; 7:407-413.

27. Heymsfield SB. Body composition and bioelectric impedance. Rev Bras Nutr Clin 1997; 12(supl 2)4:S34-164.

28. Heyward VH, Stolarczyk. Avaliação da composição corporal aplicada. São Paulo: Manole, 2000.

29. Hoffman D, Heymsfield SB, Waitzberg DL. Composição corpórea. In: Waitzberg DL. Nutrição oral, eteral e parenteral na prática clínica. 3 ed. São Paulo: Atheneu, 2000.

30. Jaime PC, Marucci MFN, Latorre MRDO, Tanaka T, Florindo AA, Zerbini CAF. Influência do consumo de cálcio dietético na densidade mineral 
óssea de homens com 50 anos e mais. Rev Bras Reumatol 2000; 40(3):105-111.

31. Jaime PC. Correções em medidas de consumo alimentar: aplicação na análise da correlação do consumo de cálcio, proteína e energia com a densidade mineral óssea em homens adultos e idosos. São Paulo, 2001. [Tese de Doutorado - Departamento de Epidemiologia Faculdade de Saúde Pública da USP].

32. Jebb SA, Osborne RJ, Dixon AK, Bleehen NM, Elia M. Measurements of resting energy expenditure and body composition before and after treatment of small cell lung cancer. Annals of Oncology 1994; 5:915919.

33. Jebb SA. Measurement of soft tissue composition by dual energy $X$ - ray absorptiometry. British Journalo of Nutrition 1997; 77:151-163.

34. Jebb SA, Cole TJ, Doman D, Murgatroyd PR, Prentice AM. Evaluation of the novel Tanita body-fat analyser to measure body composition by comparison with a four-compartment model. British Journal of Nutrition 2000; 83:115-122. 
35. Kamimura MA, Baxmann A, Sampaio LR, Cuppari L. Avaliação nutricional. In: Cuppari L, coordenadora. Guia de nutrição: nutrição clínica no adulto. São Paulo: Manole; 2002. p.71-109.

36. Kim J, Wang Z, Heymsfield SB, Baumgartner RN, Gallagher D. Totalbody skeletal muscle mass: estimation by a new dual-energy $\mathrm{X}$-ray absorptiometry method. Am J Clin Nutr 2002; 76:378-83.

37. Kuczmarski. Need for body composition information in elderly subjects. American Journal of Clinical Nutrition, 1989; 50:1150-1257.

38. Kyle UG, Pichard C, Rochat T, Slosman DO, Fitting J-W, Thiebaud D. New bioelectrical impedance formula for patients with respiratory insuficiency: comparison to dual-energy X-ray absorptiometry. Eur Resp J 1998; 12:960-966.

39. Larsson EJ, Prado RR. Programa de avaliação corporal por bioimpedância. Manual do usuário CompCorp. CompCorp Ltda. Versão 2.4, s/d.

40. Lean MEJ, Han TS, Deurenberg P. Predicting body composition by densitometry from simple anthropometric measurements. Am J Clin Nutr 1996; 63:4-14. 
41. Lewy VD, Danadian K, Arslanian S. Determination of body composition in african-american children: validation of bioelectrical impedance with dual energy X-ray absorptiometry. Journal of Pediatric Endocrinology \& Metabolism 1999; 12:443-448.

42. Lohman TG. Advances in body composition assessment. Current issues in exercise sciense series. Monograph No2. Champaign, IL: Human Kinetics, 1992.

43. Lukaski, HC. Assessing regional muscle mass with segmental measurements of bioelectrical impedance in obese women during weight loss. ANYAS 2000 May; 904:154-8.

44. Mazariegos M, Valdez C, Kraaij S, Van Setten C, Liurink C, Breuer K, Haskell M, Mendoza I, Solomons NW, Deurenberg P. A comparison of body fat estimates using anthropometry and bioelectrical impedance analysis with distinct prediction equations in elderly persons in the Republic of Guatemala. Nutrition 1996; 12(3):168-175.

45. Monteiro CA, Mondini L, Souza ALM, Popkin BM. Da desnutrição para a obesidade: a transição nutricional no Brasil. In: Monteiro CA, organizador. Velhos e novos males da saúde no Brasil: a evolução do pais e suas doenças. $2^{a} e d$. rev. e aumentada. São Paulo: Hucitec, Nupens/USP, 2000. 
46. Moreno VM, Gandoy JBG, González MJA. Medición de la grasa corporal mediante impedancia bioeléctrica, pliegues cutáneos y ecuaciones a partir de medidas antropométricas, análises comparativo. Rev Esp Salud Pública 2001; 75:221-236.

47. Organización Mundial de La Salud. El estado físico: uso e interpretación de la antropometria. Informe de um Comitê de Expertos de la OMS. Ginebra, Organización Mundial de la Salud, 1995 (Serie de Informes Técnicos, $N^{\circ} 854$ ).

48. Paschoal SMP. Epidemiologia do envelhecimento. In: Papaléo Neto M, editor. Gerontologia. São Paulo, Atheneu, 1996.

49. Pereira MG. Epidemiologia: teoria e prática. $2^{\mathrm{a}}$ ed. Rio de Janeiro: Guanabara Koogan; 1999.

50. Perissinotto E, Pisent C, Sergi G, Grigoletto F, Enzi G. Anthropometric measurements in the elderly: age and gender differences. British Journal of Nutrition 2002; 87:177-186.

51. Pichard C, Kyle UG, Slosman, DO. Fat -free mass in chronic illness: comparison of bioelectrical impedance and dual-energy $x$-ray absorptiometry in 480 chronically ill and healthy subjects. Nutrition 1999; 15(9):668-676. 
52. Pichard C, Kyle UG, Bracco D, Slosman DO, Morabia A, Schutz Y. Reference values of fat-free and fat masses by bioelectrical impedance analysis in 3393 healthy subjects. Nutrition 2000; 16:245-254.

53. Pierson Jr. RN, Wang J, Thornton JC. Measurement of body composition: applications in hormone research. Horm Res 1997; 48(suppl 1):56-62.

54. Riella MC. Bioimpedância ... progressos na avaliação hemodinâmica e da composição corporal. Rev Med Paraná 1988; 46(3/4):iii - v, jul - dez.

55. Rosenbaum K, Wang J, Pierson RN, Kotler DP. Time-dependent variation in weight and body composition in healthy adults. JPEN 2000; 24(2):52-55.

56. Secretaria Municipal de Saúde e Meio Ambiente. 2003, ljuí, RS.

57. Segal KR, Gutin B, Presta E, Wang J, Itallie TBV. Estimation of human body composition by electrical impedance methods: a comparative study. J Appl Physiol 1985; 58(5):1565-1571.

58. Segal KR, Van Loan M, Fitzgerald PI, Hodgdon A, Van Italle TB. Lean body mass estimation by bioelectrical impedance analysis: a four-site cross-validation study. Am J Clin Nutr 1988; 47:7-14. 
59. Silvestre JA, Kalache A, Ramos LR, Veras RP. O envelhecimento populacional brasileiro e o setor saúde. Arquivos de Geriatria e Gerontologia 1996; 0(1):81-89.

60. Stewart $A D$, Hannan WJ. Prediction of fat and fat-free mass in male athletes using dual $\mathrm{X}$-ray absorptiometry as the reference method. Journal of Sports Sciences 2000; 18:263-274.

61. Taaffe DR, Lewis B, Marcus R. Regional fat distribution by dual-energy X-ray absorptiomentry: comparison with anthropometry and application in a clinical trial of growth hormone and exercise. Clinical Science 1994; $87: 581-586$.

62. Tanaka T. Fatores de risco para osteoporose em fêmur proximal em homens com idade igual ou maior que $\mathbf{5 0}$ anos. São Paulo, 2000. [Dissertação de mestrado - Departamento de Epidemiologia Faculdade de Saúde Pública da USP].

63. Tatarani PA, Ravussin E. Use of dual-energy X-ray absorptiometry in obese individuals. Am J Cli Nutr 1995; 62:730-4.

64. Tyrrell VJ, Richards GE, Hofman P, Gillies GF, Robinson E, Cutfield WS. Obesity in Auckland school children: a comparison of the body mass 
index and percentage body fat as the diagnostic criterion. International Journal of Obesity $2001 ; 25: 164-169$.

65. Utter AC, Scott JR, Oppliger RA, Visich PS, Goss FL, Marks BL, Nieman DC, Smith BW. A comparison of leg-to-leg bioelectrical impedance and skinfolds in assessing body fat in Collegiate Wrestlers. Journal of Strenght and Conditioning Research 2001; 15(2):157-160.

66. Van Loan MD, Mayclin PL. Body composition assessment: dual-energy $x-$ ray absorptiometry (DEXA) compared to reference methods. European Journal of Clinical Nutrition 1992; 46:125-130.

67. Wattanapenpaiboon N, Lukito W, Strauss BJG, Hsu-Hage BHH, Wahlqvist ML, Stroud DB. Agreement of skinfold measurement and bioelectrical impedance analysis (BIA) methods with dual energy $\mathrm{X}$-ray absorptiometry (DEXA) in estimating total body fat in Anglo-Celtic Australians. International Journal of Obesity 1998; 22:854-860.

68. Wellens R, Chumlea WC, Guo S, Roche AF, Reo NV, Siervoguel RM. Body composition in white adults by dual-energy $x$-ray absorptiometry, densitometry, and total body water. Am J Clin Nutr 1994; 59:547-55.

69. Willet W. Nutritional epidemiology. Oxford: Oxford University Press; 1998. 
70. World Health Organization. Obesity: preventing and managing the global epidemic. Report of a WHO Consultation. Geneva, World Health Organization, 2000 (Technical Report Series, N894).

71. World Health Organization. Diet, nutrition and the prevention of chronic diseases. Report of a WHO Consultation. Geneva, World Health Organization, 2003 (Technical Report Series, №916).

72. Zerbini CAF. Composição corpórea como determinante da densidade mineral óssea em homens. São Paulo, 1998. [Tese de livre-docente - Departamento de Clínica Médica - Disciplina de Imunologia -Faculdade de Medicina de Ribeirão Preto da USP].

73. Yannakoulia M, Keramopoulos A, Tsakalakos N, Matalas A. Body composition in dancers: the bioelectrical impedance method. Med Sci Sports Exerc 2000; 32(1):228-234. 


\section{ANEXOS}

\section{RELAÇĀO DE ANEXOS}

Anexo 1 - Termo de Consentimento Informado do Paciente.

Anexo 2 - Aprovação da Comissão de Ética Médica do Hospital Heliópolis.

Anexo 3 - Aprovação do Comitê de Ética em Pesquisa da Faculdade de Saúde Pública da Universidade de São Paulo.

Anexo 4 - Gráfico de Análises de Resíduos.

Anexo 5 - Artigo 
Anexo 1 - Termo de Consentimento Informado do Paciente. 


\section{TERMO DE CONSENTIMENTO INFORMADO DO PACIENTE}

INVESTIGADOR: DR. CRISTIANO A. F. ZERBINI

TÍTULO: AVALIAÇĀo CLÍNICA DOS FATORES DE RISCO PARA OSTEOPOROSE EM HOMENS

No PROTOCOLO: HH REUMA 001-97

Eu,

serei um dos pacientes participantes deste estudo no PAM Heliópolis.

0 objetivo deste estudo é reunir informaçōes sobre a prevalência da osteoporose em homens no Brasil.

Eu compreendo que minha participação è inteiramente voluntária, não sendo de forma alguma prè-condição para que receba tratamento médico nesta instituição.

Fui informado que responderei a um questionário de saúde, serei examinado por uma equipe médica e farei densitometria ossea.

Fui informado que a densitometria óssea é um exame de rotina utilizado para avaliar a quantidade de massa óssea do esqueleto. Trata-se de exame simples, semelhante a um exame radiológico e não invasivo.

Fui informado que este è um estudo epidemiologico. isto é. um estudo para avaliar o estado de saúde da população. Este estudo não inclui a administração de remédios e tambèm não inclui exames de laboratório 
Fui informado que a equipe médica me informará dos resultados da densitometria óssea e. se necessário, poderei fazer tratamento médico para perda de massa óssea com esta mesma equipe no PAM Heliópolis.

Se eu tiver qualquer dúvida ou perguntas relativas ao estudo, no que diz respeito à minha participaçāo, posso contactar o Dr. Cristiano Zerbini no telefone (011) 8524105.

Eu concordo em seguir as instruçōes das pessoas conduzindo e monitorizando este estudo, de forma a obter o máximo de beneficios da atenção médica oferecida por esta pesquisa.

Nome do paciente:

Assinatura do paciente:

Data:



Endereço e telefone do paciente:

Nome da testemunha:

Data:

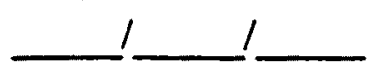

Assinatura do investigador:

Data:

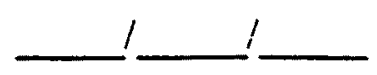


Anexo 2 - Aprovação da Comissão de Ética Médica do Hospital Heliópolis. 


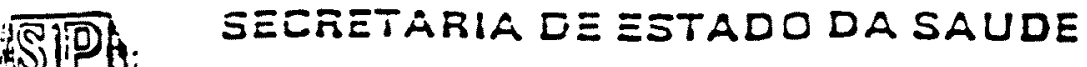

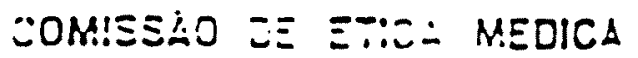

DO

H巨ミ?!Tロ-

10

Serth

Douto= Cadxtiano L. J. Zezblad

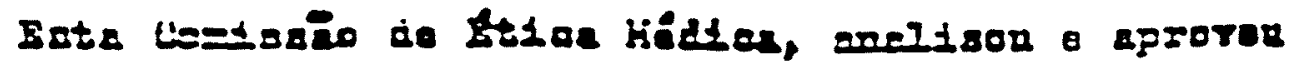

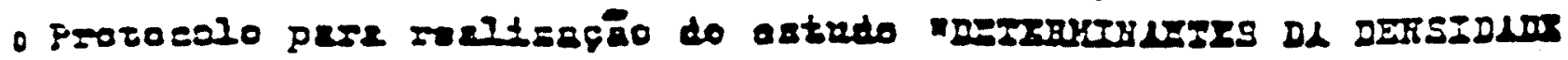

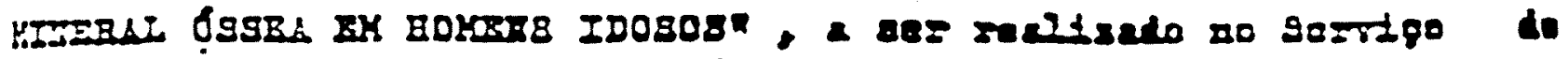

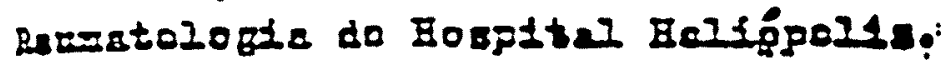

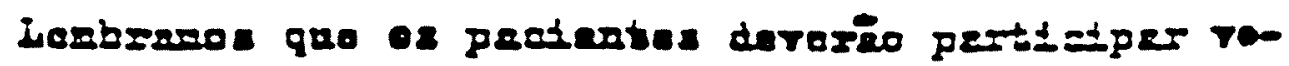

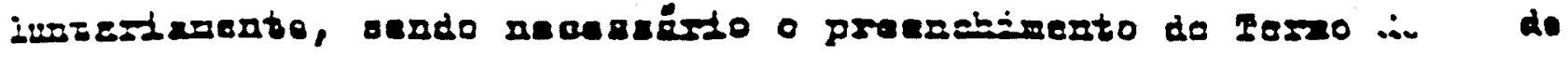

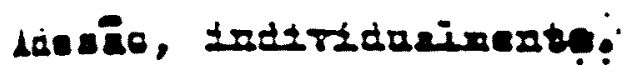

\section{8as ands.}

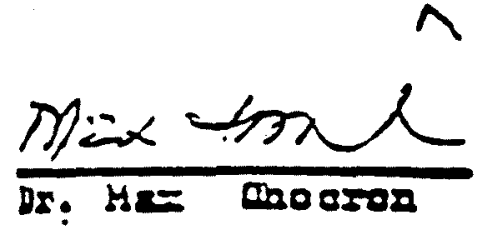

PLoo-Frestdento
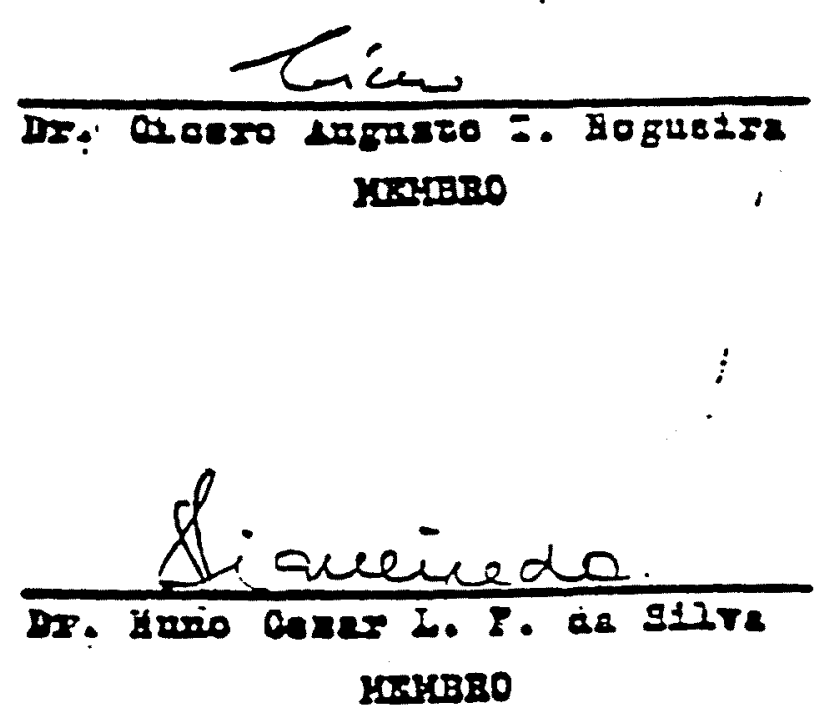

${ }^{0} h^{\circ}$

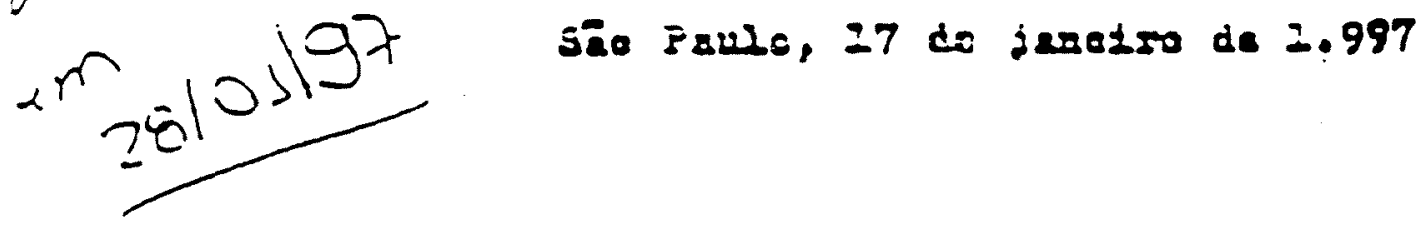


Anexo 3 - Aprovação do Comitê de Ética em Pesquisa da

Faculdade de Saúde Pública da Universidade de São Paulo. 


\section{UNIVERSIDADE DE SÃO PAULO FACULDADE DE SAÚDE PÚBLICA COMITÉ DE ÉTICA EM PESQUISA-COEP \\ Av. Dr. Arnaldo, 715 - Cerqueira César \\ São Paulo-SP - CEP: 01246-904 \\ Telefone: (Oxx11) 3066-7779 - e-mail: mdgracas@usp.br}

\section{Of.COEP/121/01}

03 de agosto de 2001

Pelo presente, informo que o Comitê de Ética em Pesquisa da Faculdade de Saúde Pública da Universidade de São Paulo-COEP, analisou e aprovou, em sua 5. $\% 101$, Sessão Ordinária, realizada em 10.07.01, de acordo com os requisitos da Resolução CNS/196/96, o Protocolo de Pesquisa n. ${ }^{\circ}$ 508, intitulado: "COMPARAÇÃo DE TÉCNICAS DE MEDIDAS DE MASSA MAGRA E MASSA GORDA EM HOMENS ADULTOS E IDOSOS", apresentado pela pesquisadora Ligia Beatriz Bento Franz.

Atenciosamente,

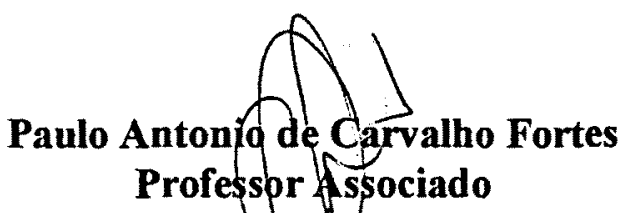

Vice-Coordenador do Comitêde 1 tica em Pesquisa da FSP-COEP 
Anexo 4 - Gráficos de Análises de Resíduos. 


\section{ANÁLISE DE RESÍDUOS}

\section{Modelo LigiaA}

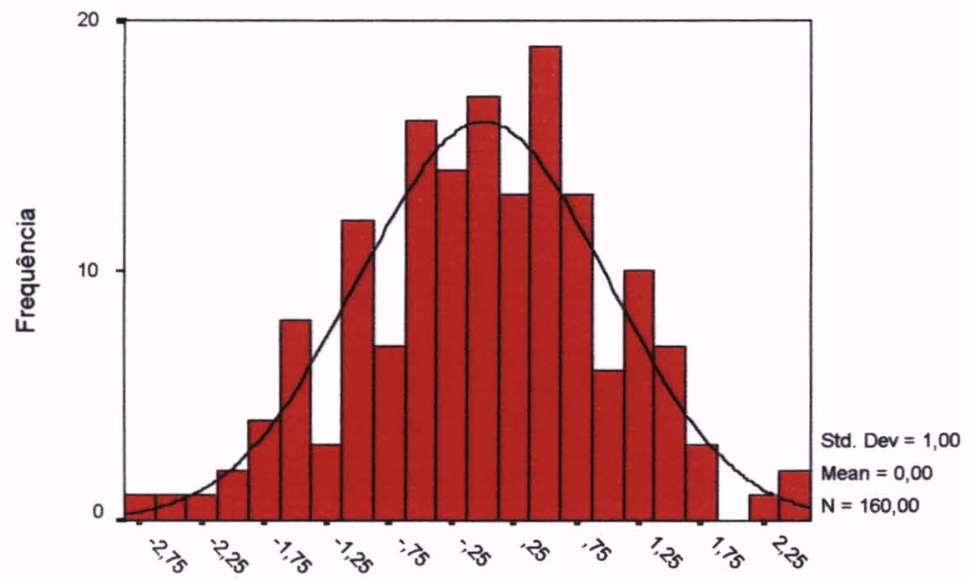

Regressão Residual Padronizada
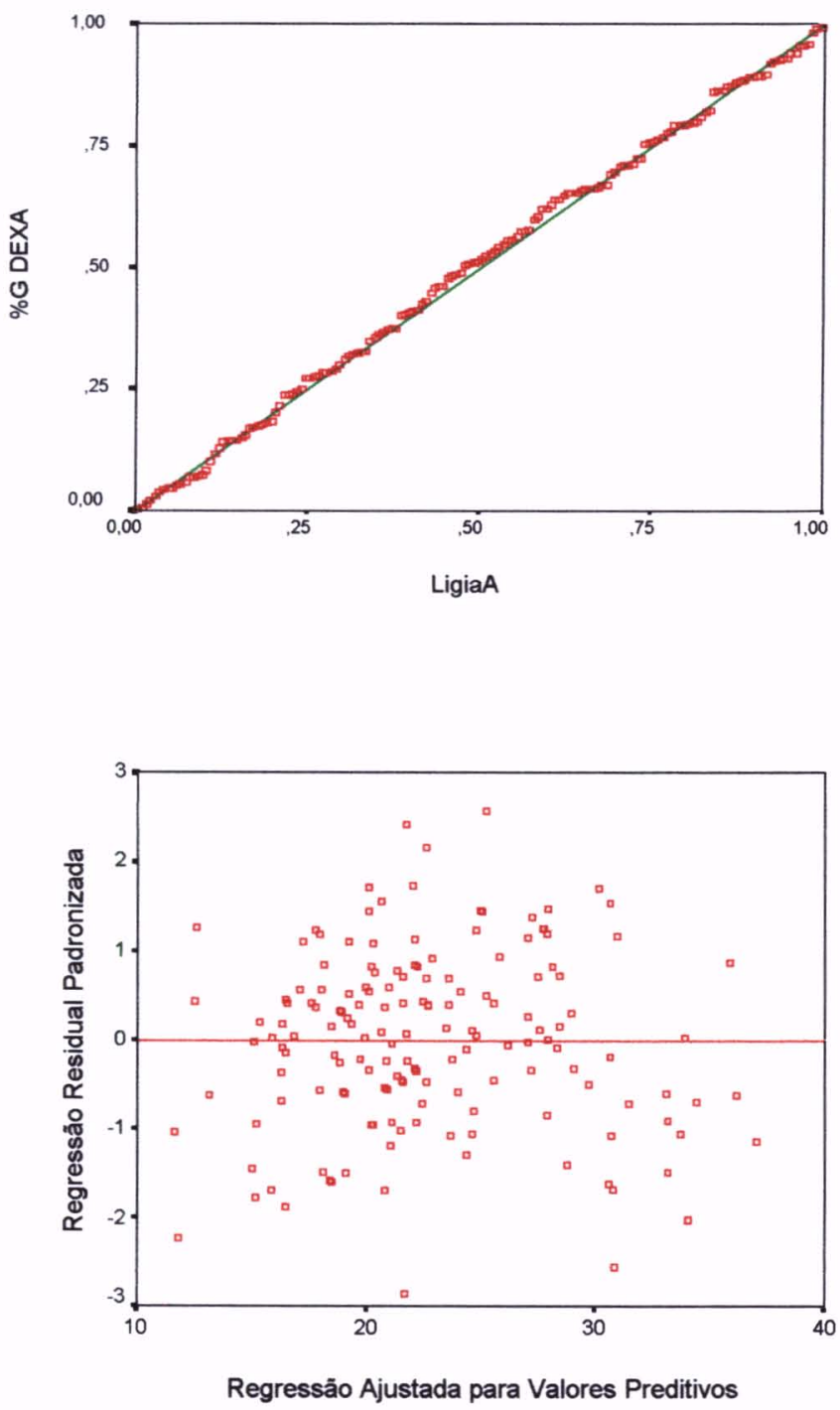


\section{ANÁLISE DE RESÍDUOS}

Modelo LigiaB
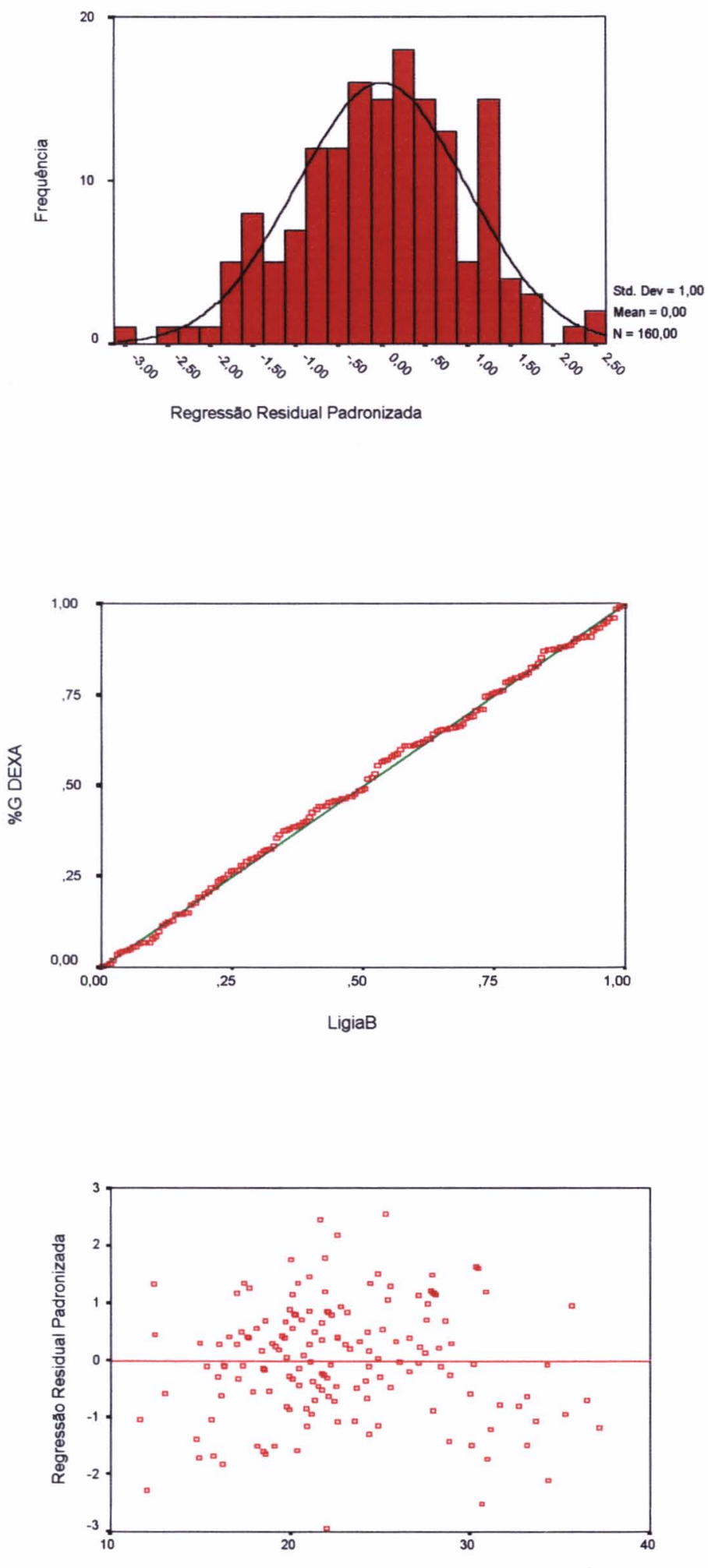

Regressão Ajustada para Valores Preditivos 
ANÁLISE DE RESÍDUOS

Modelo LigiaC
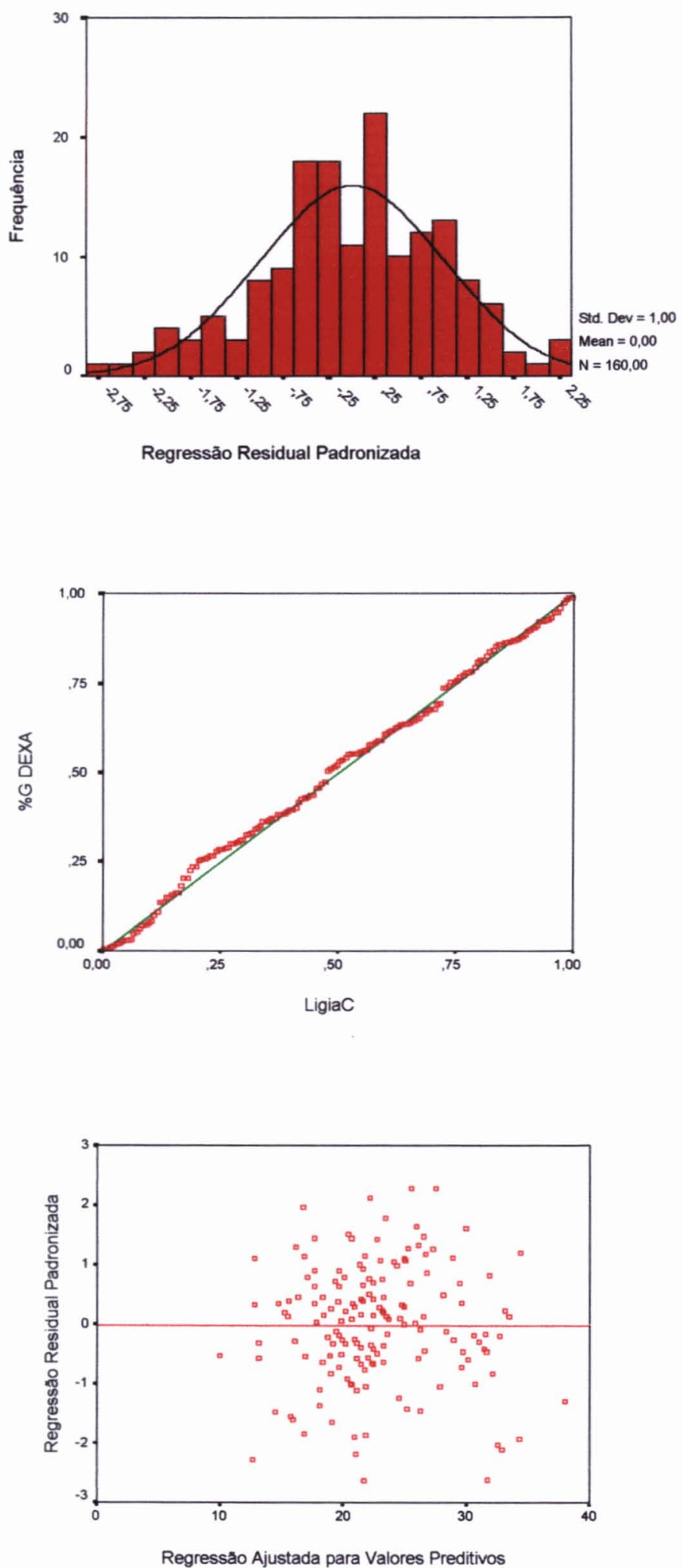


\section{ANÁLISE DE RESÍDUOS}

Modelo LigiaD
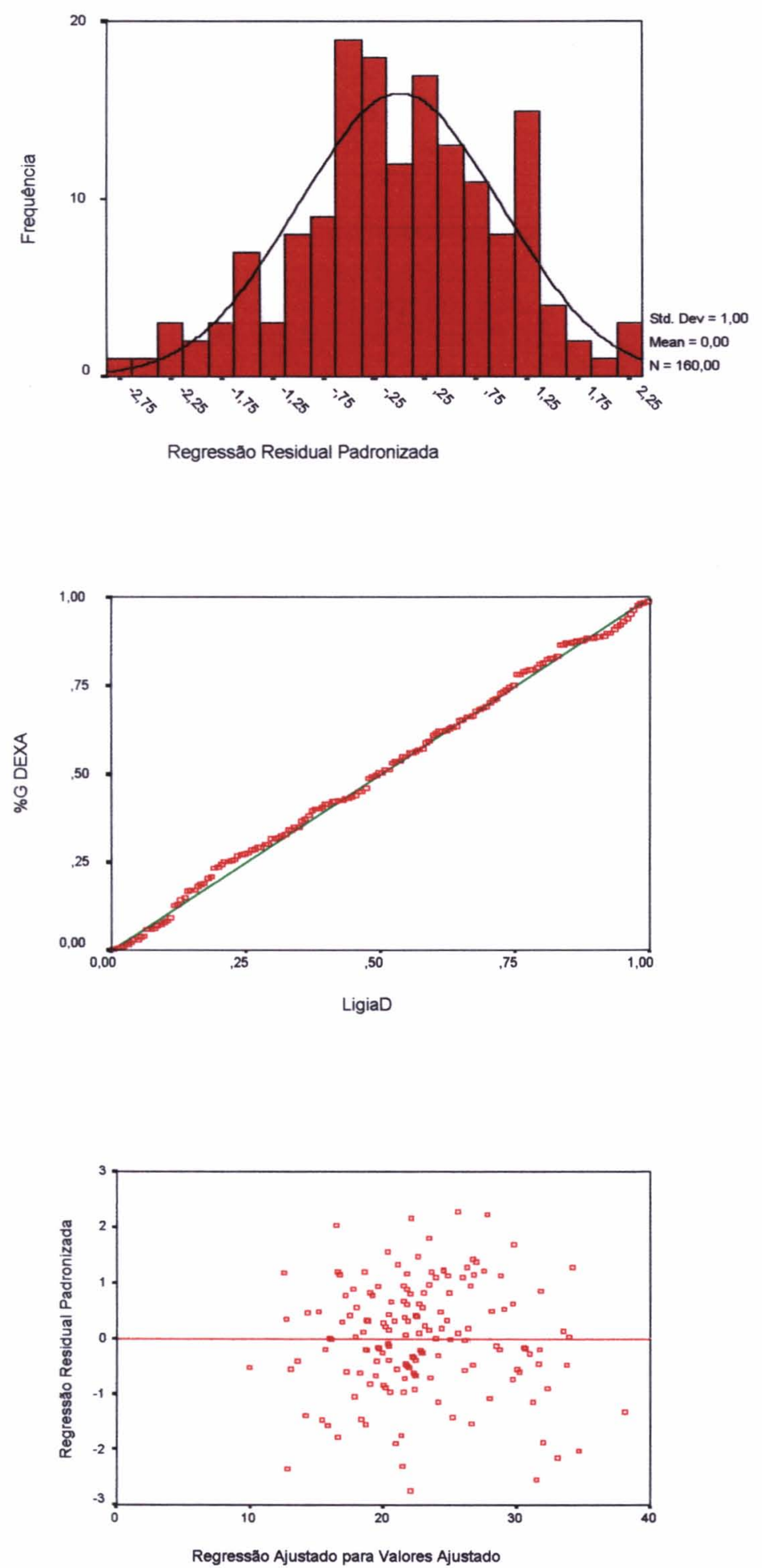
ANÁLISE DE RESÍDUOS

Modelo Ligia1
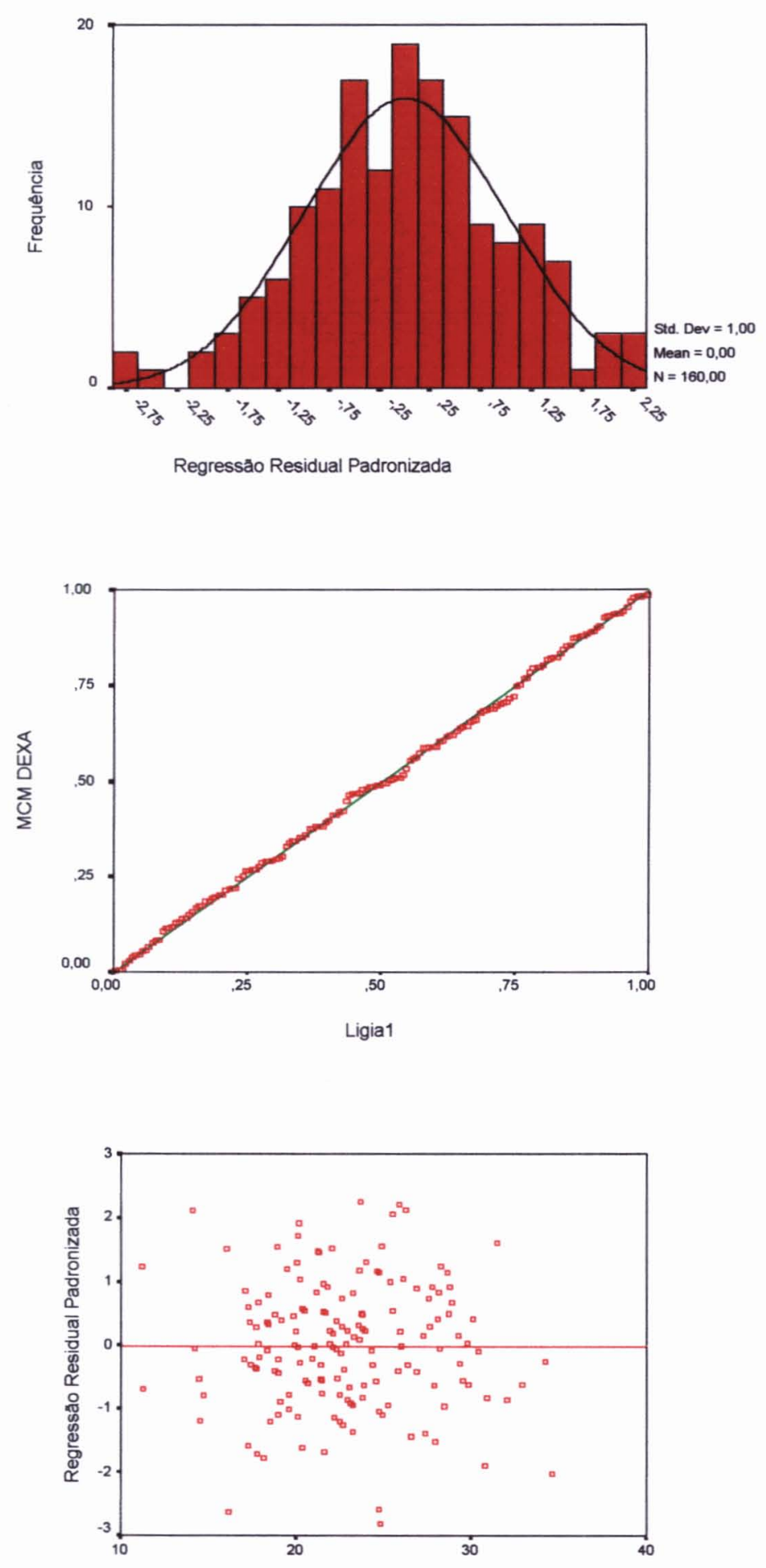

Regressåo Ajustada para Valores Preditivos 


\section{ANÁLISE DE RESÍDUOS}

\section{Modelo Ligia2}
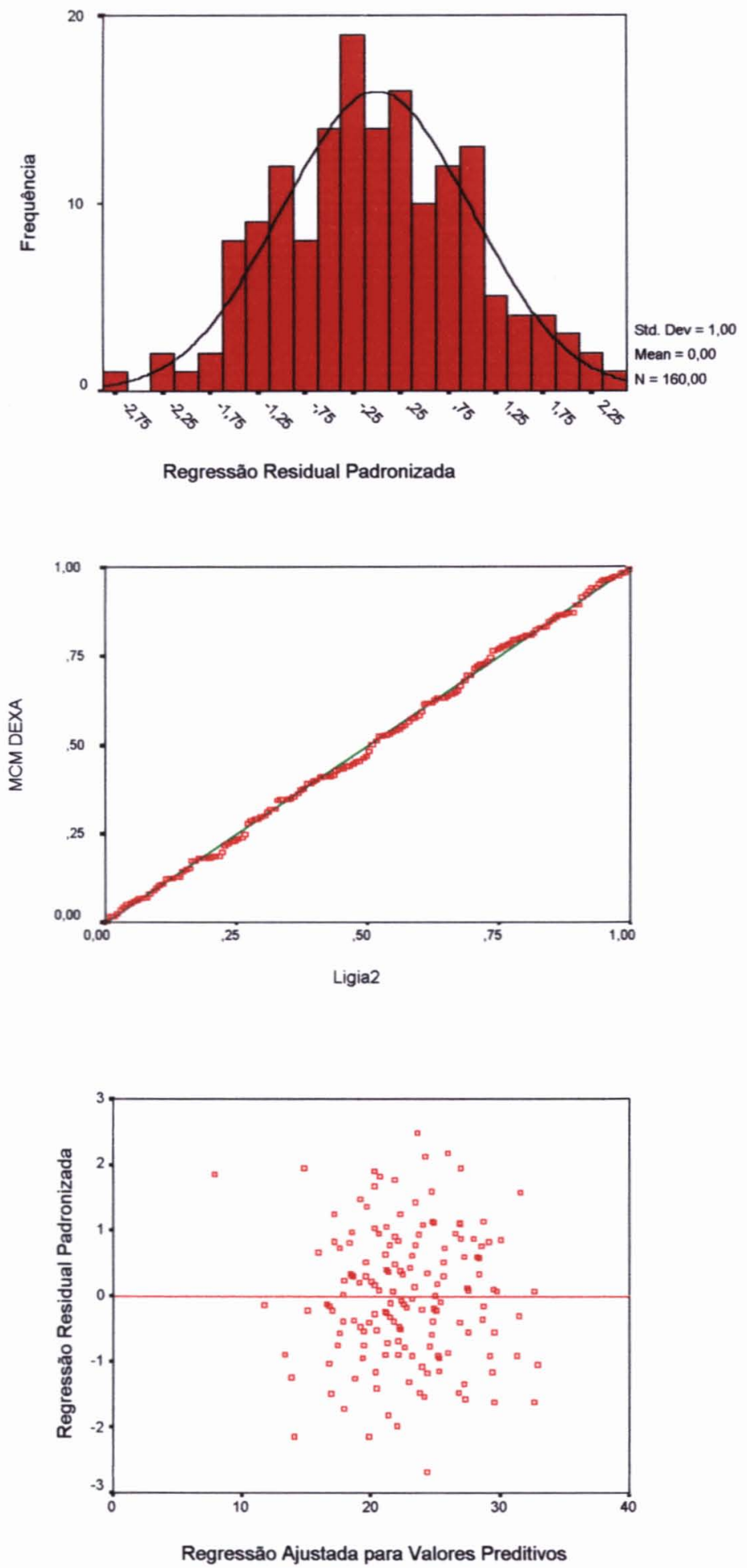
Anexo 5 - Artigo 
REVISTA DE SAÚDE PÚBLICA - ARTIGO ORIGINAL

\title{
ESTIMATIVA DE MASSA MAGRA E MASSA GORDA EM HOMENS BRASILEIROS COM 50 ANOS E MAIS DE IDADE: PROPOSTA DE EQUAÇÕES
}

\section{LEAN MASS AND FAT MASS IN MEN AGED FROM 50 AND OLDER: PROPOSITION OF EQUATIONS}

\author{
LIGIA BEATRIZ BENTO FRANZ ${ }^{1}$ \\ MARIA DO ROSARIO DIAS DE OLIVEIRA LATORRE ${ }^{2}$ \\ PATRÍCIA CONSTANTE JAIME ${ }^{3}$ \\ ALEX ANTONIO FLORINDO ${ }^{2}$ \\ TOMOE TANAKA ${ }^{2}$ \\ CRISTIANO AUGUSTO DE FREITAS ZERBINI ${ }^{4}$
}

1. CURSO DE NUTRIÇÃO DO DEPARTAMENTO DE CIÊNCIAS DA SAÚDE DA UNIVERSIDADE REGIONAL DO NOROESTE DO RS-UNIJUÍ

2. DEPARTAMENTO DE EPIDEMIOLOGIA DA FACULDADE DE SAÚDE PÚBLICA DA UNIVERSIDADE DE SÃO PAULO

3. DEPARTAMENTO DE NUTRIÇÃO DA FACULDADE DE SAÚDE PÚBLICA DA UNIVERSIDADE DE SÃO PAULLO

4.SERVIÇO DE REUMATOLOGIA DO HOSPITAL HELIÓPOLIS - SÃO PAULO

Trabalho realizado no Hospital Heliópolis em São Paulo e no Departamento de Epidemiologia da Faculdade de Saúde Pública da USP

Endereço para correspondência:

Ligia Beatriz Bento Franz

UNIJUII / Departamento de Ciências da Saúde

Rua do Comércio, 3000 - Fone: (55)3332-0200 - Fax: (55)3332-9100

ljuí-RS - CEP: $98700-000$

Endereço eletrônico: <ligiafra@unijui.tche.br>

Total de palavras: 2630

Trabalho baseado na tese de doutorado intitulada "Desenvolvimento e validação de equações para estimativa de massa magra e massa gorda em homens brasileiros com 50 anos e mais", que será defendida na Faculdade de Saúde Pública da Universidade de São Paulo em 15/12/2003.

estimativa de massa magra e massa gorda 


\section{RESUMO}

\section{Introdução}

O objetivo deste trabalho foi desenvolver e validar equações para estimar massa magra e massa gorda em homens com 50 anos e mais de idade.

\section{Métodos}

A população de estudo foi dividida em duas amostras aleatórias. Uma amostra foi utilizada para o desenvolvimento das equações de regressões, e a outra para validar as equaçöes desenvolvidas. Os modelos foram desenvolvidos através da análise de regressão linear múltipla, tendo como variáveis dependentes a massa gorda (em \%-\%MG) e a massa magra (em $\mathrm{kg}-\mathrm{MM}$ ) medidas pela absorciometria por raio-X de dupla energia-DEXA, e, como variáveis independentes, idade, medidas antropométricas (massa corporal, estatura, índice de massa corporal, dobra cutânea tricipital, perímetro da cintura, perimetro do quadril e relação cintura-quadril) e medidas fornecidas pela impedância bioelétrica ( $M M, \% M G$, reatância e resistência).

\section{Resultados/Conclusões}

A melhor equação para estimar a \%MG teve, como variáveis independentes, a idade, o perimetro da cintura, a dobra cutânea tricipital e a \%MG medida pela impedância bioelétrica $\left(r^{2}=0,71\right)$. Esta equação mostrou-se a mais adequada quando comparada às de literatura, pois apresentou média semelhante à da DEXA $(p=0,227)$, coeficiente de correlação intraclasse=0,82 e EPE $=4,0 \%$. Quanto a MM, a melhor equação incluiu massa corporal e idade $\left(r^{2}=0,14\right)$, estimativa de massa magra e massa gorda 
apresentando baixa correlação intraclasse e alto valore de $\operatorname{EPE}(7,0 \%)$, demonstrando não ser adequada para estimar a MM. Verifica-se com este estudo que equações preditivas para avaliar a composição corporal devem ser específicas para cada população, levando-se em consideração as características de cada grupo a ser estudado.

Descritores: equações; homens com 50 anos e mais; composição corporal. Número de palavras: 242 


\section{ABSTRACTS}

\section{LEAN MASS AND FAT MASS IN MEN AGED FROM 50 AND OLDER: PROPOSITION OF EQUATIONS}

\section{Introduction}

The objective of this work is to develop and validate equations to estimate the lean mass and the fat mass in men who are 50 years old and older.

\section{Methods}

The study group was divided into two random samples. One sample was used for the development of the regression equations, and the other one to validate the developed equations. The models were developed through the analysis of the multiple linear regression, having as dependent variables the fat mass (in \%-\%FM) and the lean mass (in $\mathrm{Kg}-\mathrm{LM}$ ) measured by the dual-energy X-ray absorptiometry-DEXA, and, as independent variables, age, anthropometric measures, (body mass, height, body mass index, triceps skinfold thickness, waist circunference, hip circunference and the waist:hip ratio) and the measures offered by the bioelectrical impedance analysis (BIA) (LM, \% of FM, reactance and resistance).

\section{Results/Conclusion}

The best equation to estimate the \%FM had the age, the waist circunference, the triceps skinfold thickness and the $\%$ of FM measured by the BIA $\left(r^{2}=0,71\right)$ as independent variables. This equation showed itself to be the most adequate when compared to the ones in literature, since it presented an average estimativa de massa magra e massa gorda 
similar to the DEXA $(p=0,227)$, intraclass correlation coefficient $=0,82$ and $S E E=4,0 \%$. In relation to the $L M$ prediction, the best equation included the body mass and the age $\left(r^{2}=0,14\right)$, where presented low intra-class correlation and high value of $\operatorname{SEE}(7,0)$, showing not suitable to estimate the $\mathrm{LM}$. It was verified with this study that the prediction equations to evaluate the body mass should be specified for each group, taking into account the features of each group to be studied.

Key Words: equations; 50-year olds and older; body composition.

Word count: 259 


\section{INTRODUÇÃO}

A composição corporal pode ser composta em dois componentes a massa gorda (MG) e a massa magra (MM). A MG é distribuída em gordura corporal essencial (localizada nos órgãos, intestino, músculos e tecidos ricos em lipídios no sistema nervoso central) e gordura corporal de reserva, estocada para proteger os órgãos internos de traumatismo e também na região subcutânea, que tem papel predominante nos processos de obesidade e emagrecimento ${ }^{3}$. Verifica-se, na literatura, o uso de dois termos: lean body mass (massa corporal magra-MM) e fat-free mass (massa livre de gorduraMLG), sendo que a MLG constitui-se da massa corporal livre de toda a gordura, excluindo até mesmo os lipídios essenciais (possível apenas em análise de cadáveres), o que não acontece com a MM. Neste trabalho será utilizado o termo $\mathrm{MM}$, pois se considera este o conceito mais apropriado ao se referir ao componente que é formado pelos tecidos muscular e esquelético, pele, órgãos, além de todos os outros tecidos não-gordurosos 5 .

Prevalências de sobrepeso e obesidade estão aumentando mundialmente, e as conseqüências do aumento da gordura corporal na saúde dos indivíduos, principalmente nos idosos são muitas: desde riscos aumentados de morte prematura até riscos severos, mas não fatais, que levam a efeitos contrários a uma qualidade de vida satisfatória. Não foi encontrado estudo epidemiológico descrito na literatura brasileira tratando da análise das equações que estimam a composição corporal em homens com idade de 50 anos ou mais, comparando-as com medidas fornecidas pela absorciometria por estimativa de massa magra e massa gorda 
raio-X de dupla energia-DEXA. Optou-se trabalhar especificamente com homens, tendo em vista que a maioria dos estudos avalia mulheres, ou não fazem separação segundo sexo.

O objetivo do presente estudo foi desenvolver e validar modelos preditivos para MM e MG estimados a partir de uma amostra de homens brasileiros e comparar suas estimativas com equações preditivas da literatura, tendo como padrão-ouro os valores fornecidos pela DEXA.

\section{MÉTODOS}

Este estudo é do tipo transversal, observacional, abrangendo indivíduos voluntários do sexo masculino e faz parte da pesquisa intitulada "Avaliação clínica dos fatores de risco para osteoporose em homens", desenvolvida pelo Serviço de Reumatologia do Complexo Hospitalar Heliópolis, em conjunto com - Departamento de Epidemiologia da Faculdade de Saúde Pública (FSP) da Universidade de São Paulo (USP) ${ }^{13}$.

Foram recrutados indivíduos voluntários do sexo masculino com idade igual ou superior a 50 anos, através da imprensa (anúncios em jornal), avisos colocados no posto de atendimento médico do Hospital Heliópolis, indivíduos submetidos a controle periódico pelo serviço de cardiologia do hospital, cônjuges de mulheres que compareceram para realizar a densitometria óssea e funcionários do complexo hospitalar. A coleta de dados para a pesquisa citada foi efetuada no período de fevereiro a setembro de 1997. 
Os critérios de inclusão foram estar em bom estado de saúde e possuir estatura até $190 \mathrm{~cm}$ devido à limitação de visibilidade do corpo no aparelho de DEXA. Foram excluidos os indivíduos cuja ingestão de medicamentos poderiam afetar o metabolismo ósseo ou causar osteoporose, tais como portadores de doenças endócrinas, gastrointestinais, doença reumatóide, cálculo renal, mieloma múltiplo e outras neoplasias. Também foram excluídos os indivíduos que faziam uso de suplementos de cálcio e proteína. A população de estudo foi dividida em duas amostras aleatórias independentes. Uma amostra foi utilizada para o desenvolvimento das equações de regressões, e a outra para validar as equaçōes desenvolvidas.

As medidas da massa magra e massa gorda fornecida pela DEXA foram consideradas como padrão-ouro. Estas medidas foram realizadas por uma única técnica, utilizando um único equipamento de dupla energia por raios-X, modelo DPX (Lunar Corp., Madison, WI, Estados Unidos), e adotado procedimento padrão para o posicionamento dos pacientes durante a fase de realização do exame, que foi analisado com o software Lunar versão $3,6 z$.

As medidas antropométricas e de impedância bioelétrica-IB foram realizadas por um único pesquisador, nutricionista treinada para esta atividade, na primeira visita, e foram coletadas segundo recomendações da OMS, $1995^{10}$ e do Manual do Usuário CompCorp ${ }^{8}$, respectivamente. As medidas de resistência-Res e reatância-Rea foram obtidas com um aparelho analisador modelo BIA 101 Q - portátil, fabricado pela RJL Systems Inc, o qual era testado a cada dia de coleta de dados, anteriormente à série de medidas. 
A massa corporal-MC foi medida em quilograma $(\mathrm{kg})$, com balança Filizola, capacidade de $150 \mathrm{~kg}$ e sensibilidade de $100 \mathrm{~g}$, e os entrevistados pesados sem sapatos e com roupas leves. A estatura-E foi medida em $\mathrm{cm}, \mathrm{com}$ um estadiômetro, e os indivíduos medidos descalços em posição ortostática, com o corpo erguido em extensão máxima e a cabeça ereta, olhando à frente plano Frankfurt. O índice de massa corporal-IMC, foi calculado como a razão entre a massa corporal (em $\mathrm{kg}$ ) e a estatura ao quadrado (em m). A dobra cutânea tricipital-DCT' foi medida com compasso tipo Lange (Cambridge Scientific Instruments), com sensibilidade de $1 \mathrm{~mm}$. Os perímetros: cintura e quadril - PC e PQ foram medidos com fita métrica flexível, mas não elástica.

Com os dados da amostra 1, primeiramente as variáveis foram analisadas de forma descritiva por meio de médias, desvios padrão, valores mínimos e máximos e medianas. Nesta etapa foi avaliado se as variáveis tinham distribuição normal pelo teste de Kolmogorov Smirnov, e, de acordo com os resultados, foi feita a análise de correlação de Pearson ou Spearman. Por último, foram desenvolvidos modelos de predição para a MG e MM através da análise de regressão linear múltipla, tendo como variáveis dependentes a MM e MG medidas pela DEXA e as demais variáveis (MM e MG medidas pela IB, indice de massa corporal-IMC, dobra cutânea tricipital-DCT, perímetro da cintura-PC, perímetro do quadrial- $P Q$, relação cintura/quadrial-RC/Q, massa corporal-MC, estatura-E, Res, Rea e idade-I) como variáveis independentes. 
Para a elaboração do modelo múltiplo foi utilizado o procedimento stepwise forward selection, sendo que a ordem de entrada das variáveis no modelo foi definida pelo valor do coeficiente de correlação. Foram desenvolvidos modelos incluindo todas as variáveis do presente estudo, e modelos sem as variáveis de MG e MM fornecidas pela IB, pois já são resultantes de equações preditivas utilizadas no software que acompanha 0 aparelho analisador de impedância bioelétrica RJL, utilizado no presente trabalho.

Em uma segunda etapa, utilizando a segunda amostra, foram estimados os valores de MG e MM pelas equações propostas e de literatura, e, feita análise de validação das mesmas, assim como das medidas derivadas da IB, através do coeficiente de correlação intra-classe, teste $t$-Student pareado, e erro padrão de estimativa (EPE) ${ }^{6}$. Para o cálculo e análise do EPE foi utilizada a fórmula $\mathrm{EPE}=s=\sqrt{1-r^{2}}$. Em todas as análises foi utilizado o nivel de significância de $5 \%$.

\section{RESULTADOS}

\section{Desenvolvimento das equações}

Foram analisados 160 homens, sendo 128 brancos (80\%) e 32 não brancos (20\%). A idade variou de 50 a 85 anos, sendo $61,9 \%$ entre 50 a 64 anos de idade e $38,1 \%$ entre 65 a 85 anos, com média de 62,21 anos. A Tabela 1 apresenta a estatística descritiva das variáveis de estudo onde observa-se que os valores médios para MC, $E$, e IMC foram $72,14 \mathrm{~kg}, 1,65 \mathrm{~m}$ e estimativa de massa magra e massa gorda 
$26,32 \mathrm{~kg} / \mathrm{m}^{2}$, respectivamente. Os valores medianos foram muito semelhantes aos da média e apenas DCT e O \%MG IB não tiveram aderência à distribuição normal.

Modelo de regressão linear múltiplo foi elaborado com a finalidade de estimar a MG, sendo, a ordem de entrada das variáveis no modelo feita a partir do valor da correlação encontrada com o \%MG DEXA (Tabela 2). Houve correlação estatisticamente significativa com todas as variáveis para o total da população, exceto com relação à I $(p=0,428)$ e $E(p=0,872)$. As variáveis foram acrescentadas uma a uma no modelo, iniciando-se pelo PC. O IMC na presença do PC perdeu sua significância, sendo então, retirado do modelo. $\mathrm{O}$ \%MG fornecido pela IB, e a DCT tiveram efeitos independentes, permanecendo no modelo. As demais variáveis, $P Q$, massa corporal, $R C / Q$, Res, Rea, idade e estatura, não foram significativas, porém optou-se por deixar a idade em um dos modelos, independente de sua significância. Os dois modelos escolhidos para a estimativa do \%MG tiveram $r^{2}$ ajustado $=0,71$ e suas equações são:

LigiaA: \% MG = -16,177+0,306(PC(cm))+0,352(\% MG IB)+0,152(DCT(mm)) LigiaB: \% MG = -17,970+0,296(PC(cm))+0,349(\%MGIB)+0,173(DCT(mm))+0,039((lanos))

Foi elaborado outro modelo de regressão linear múltiplo com a finalidade de estimar a massa gorda, mas retirando a variável \%MG IB, pois esta já é resultante de outra equação, utilizada pelos fabricantes do equipamento RJL, utilizado nesta pesquisa. A diferença da modelagem anterior verifica-se a partir do modelo 3 , em que é acrescentado o $P Q, \circ$ qual perdeu sua significância, sendo então, retirado do modelo, assim como a massa corporal, RC/Q, Rea, estimativa de massa magra e massa gorda 
idade e estatura, porém optou-se em deixar a idade em um dos modelos, independente de sua significância. Os dois modelos escolhidos tiveram $r^{2}$ ajustado=0,66 e 0,67 e suas equações são:

LigiaC:\% MG=-21,007+0,430(PC(cm))+ 0,195(DCT(mm))

LigiaD:\% MG=\%MG=-23,060+0,418(PC(cm))+0,219(DCT(mm))+0,046(Idade(anos))

Assim como para a MG, um modelo de regressão linear múltiplo foi elaborado com a finalidade de estimar a MM, sendo, a ordem de entrada das variáveis no modelo feita a partir do valor da correlação encontrada com o valor da MM DEXA (Tabela 3). Houve correlação estatisticamente significativa, porém apenas razoável, com todas as variáveis para o total da população, exceto com relação à I $(p=0,300)$, DCT $(p=0,344)$ e Rea $(p=0,389)$ que não foram significativas. As variáveis foram acrescentadas uma a uma no modelo, a partir da MC. Na presença da MC, a MM IB, OPC, OPQ, o IMC, a Res, a E, a $R C / Q$, e a $D C T$ não foram significativas. A variável idade foi mantida no modelo, independente de sua significância estatística, porém, ao acrescentar a Rea, a I passou a ser significativa. Por isso, optou-se por escolher dois modelos. A análise de resíduos, para os dois modelos mostrou que os erros tinham distribuição normal e não demonstraram vieses. Houve a presença de 10 valores aberrantes, em cada modelo, porém foram mantidos na análise.

Ligia1: $M M(k g)=28,904+0,226(M C(k g))+0,114(1($ anos $))$

Ligia2: $M(\mathrm{~kg})=18,432+0,252(M C(\mathrm{~kg}))+0,159(\mathrm{l}($ anos $))+0,111(\operatorname{Rea}(\Omega))$

Não foi desenvolvida equação para MM sem a variável de MM IB, pois seria a mesma da população total, sendo que ela foi acrescentada no modelo estimativa de massa magra e massa gorda 
em segundo lugar perdendo sua significância e prejudicando a MC.

\section{Validação das equações}

A amostra 2 constou de 160 homens, sendo 131 brancos (82\%) e 29 não brancos (18\%). A idade variou de 50 a 81 anos, sendo que a maioria estava entre 50 a 64 anos de idade $(62,5 \%)$, com média de 56,95 anos.

Verifica-se, na Tabela 4, que as equações estudadas para estimar a MG que apresentaram maiores coeficientes de correlação intraclasse com o padrão ouro foram as equações resultantes do presente trabalho, LigiaA, LigiaB, LigiaC e LigiaD ( $r_{i c}=0,82,0,82,0,79$ e 0,79 respectivamente), apresentaram, também, menores valores de EPEs $(4,0 \%, 4,0 \%, 4,3 \%$ e $4,3 \%$ respectivamente). Estes valores, seguindo as classificações referenciadas por LOHMAN (1992) ${ }^{9}$, resultam em um razoavelmente bom coeficiente de correlação e um erro EPE razoavelmente bom. As outras estimativas, tiveram $r_{\text {ic }}$ sempre superiores a 0,70 , porém inferiores a 0,80 , e seus EPE's foram iguais ou superiores a 4,5\%. Por tudo isto, optou-se por escolher a equação LigiaB como preditora do \% de MG em homens brasileiros com 50 anos e mais.

Verifica-se, na Tabela 5, que as equações estudadas para estimar a MM apresentaram baixas correlações com o padrão-ouro embora significativas, assim como altos valores de erro padrão de estimativa, mostrando-se não adequadas para estimar este compartimento corporal. 


\section{DISCUSSÃO}

Para o desenvolvimento e validação de equações de predição, a população foi dividida em duas amostras aleatórias. Segundo HEYWARD e STOLARCZYK, $(2000)^{6}$ para que a os resultados de equações de composição corporal sejam precisos é necessário que sejam testados em outras amostras, geralmente dividindo-se a população original em dois grupos, como foi feito no presente trabalho, e, para assegurar que os dados são representativos para a população, para a qual a equação foi desenvolvida, as amostras devem ser grandes ( $N=100$ a 400) e deve haver pelo menos, 10 a 20 sujeitos por variável. No presente trabalho, as 4 equações desenvolvidas apresentaram 2,3 e 4 variáveis preditivas; portanto a amostra de 160 homens mostrou ser adequada para tais análises.

As diferenças de médias de MG e MM estimadas pelas equações desenvolvidas neste estudo e pelas equações de literatura com as medidas fornecidas pelo método de referência, DEXA, foram calculadas pelo teste $t$ Student pareado. Também foi realizado o coeficiente de correlação intraclasse e calculado o EPE. Segundo HEYWARD e STOLARCZYK, (2000) ${ }^{6}$, um bom coeficiente de correlação múltipla para equações de predição de composição corporal deve exceder à 0,80 , significando que pelo menos $64 \%$ da variância na medida de referência pode ser levada em conta pelas variáveis de predição desta equação. O EPE reflete o grau de desvios dos dados individuais ao longo da reta de melhor ajuste através de todos os pontos de dados da amostra. estimativa de massa magra e massa gorda 
Quanto mais próximos os dados individuais estiverem da reta de regressão, menor será o erro de predição.

Dentre as equações estudadas para estimar \% MG, apenas as desenvolvidas neste estudo, apresentaram coeficientes de correlação intraclasse $>0,80$ (LigiaA $r_{i c}=0,82, p<0,001$; LigiaB $r_{i c}=0,82, p<0,001 ;$ LigiaC $r_{i c}=0,79, p<0,001$; e LigiaD $\left.r_{i c}=0,79, p<0,001\right)$ com o padrão-ouro, assim como estas também foram as que apresentaram menor erro padrão de estimativa (LigiaA EPE=4,0; LigiaB EPE $=4,0$; LigiaC $=4,3$ e LigiaD=4,3) considerados razoavelmente bons pela classificação de LOHMAN $(1992)^{9}$, mas segundo STOLARCZYK et al.(1997) $)^{12}$ o EPE para o \% MG estimado pela IB não deve exceder à 3,5. UTTER et al. ${ }^{14}$ (2001) encontraram boa correlação e EPE, mas comparando \% MG fornecido pela IB, utilizando o analisador Tanita, com DCs, em cinco avaliações tranversais $(r=0,67-0,83, p<0,001$. EPE=2,1-3,5).

Quanto a predição da MM, as equações estudadas apresentaram baixas correlações e altos valores de erro padrão de estimativa, demonstrando não serem boas para estimar esta medida, já CABLE et al. ${ }^{1}$ (2001) estudando homens de 18 a 74 anos, população heterogênea, encontraram boas correlações e EPEs para MM entre peso hidrostático e IB $(r=0,92, p<0,001$, $E P E=3,5 \mathrm{~kg}$ ), mas utilizando equipamento para estimar a MM IB diferente do utilizada neste trabalho (utilizando eletrodos de contato "leg-to-leg", e no presente trabalho foi utilizado eletrodos com gel "arm-to-leg"), apesar de que NUÑEZ et al.(1997) citado por CABLE et al. ${ }^{1}$ (2001), apresentaram coeficientes similares de variação entre os dois tipos de equipamentos. 
WARD et al. ${ }^{15}(2000)$ encontraram pequena $(2,0 \mathrm{~kg})$ mas significativa ( $p$ $<0,02$ ) diferença na média de MM fornecida pela IB (Soft Tissue Analyzer) com a fornecida pela DEXA, para homens entre 16 e 78 anos de idade. 0 coeficiente de correlação foi $r=0,87$, mas o EPE=4,6. CORCORAN et al. ${ }^{2}$ (2000), também encontraram diferença na MM fornecida pela IB e DEXA, em homens com AIDS. PICHARD et al. ${ }^{11}$ (1999) encontraram diferentes coeficientes de correlação e EPEs analisando equações preditivas de MM IB, em homens com vários tipos de doenças. KYLE et al. ${ }^{7}$ (1998) na validação de uma fórmula de IB para estimar MM, em indivíduos de ambos os sexos, com insuficiência respiratória, utilizando a DEXA como referência, encontraram um $r=0,95, \mathrm{EPE}=1,67$ e $p<0,0001$.

Verifica-se com este estudo que equações preditivas para avaliar a composição corporal devem ser especificas para cada população, levando-se em consideração as características de cada grupo a ser estudado. 


\section{REFERENCIAS BIBLIOGRÁFICAS}

1. Cable A, Nieman DC, Austin M, Hogen E, Utter AC. Validity of leg-to-leg bioelectrical impedance measurement in males. J Sports Med Fitness 2001; $41: 411-4$

2. Corcoran $\mathrm{C}$, et al. Comparison of total body potassum with other techniques for measuring lean body mass in men and women with AIDS wasting. Am J Clin Nutr 2000; 72:1053-8.

3. Dâmaso A. Nutrição e exercício na prevenção de doenças. Rio de Janeiro: Medsi, 2001.

4. Guedes DP. Composição corporal: princípios, técnicas e aplicações. $2^{\mathrm{a}}$ ed. Londrina: APEF; 1994.

5. Heyward VH, Stolarczyk. Avaliação da composição corporal aplicada. São Paulo: Manole, 2000.

6. Kyle UG, Pichard C, Rochat T, Slosman DO, Fitting J-W, Thiebaud D. New bioelectrical impedance formula for patients with respiratory insuficiency: comparison to dual-energy X-ray absorptiometry. Eur Resp J 1998; 12:960966.

7. Larsson EJ, Prado RR. Programa de avaliação corporal por bioimpedância. Manual do usuário CompCorp. CompCorp Ltda. Versão 2.4, s/d.

8. Lohman TG. Advances in body composition assessment. Current issues in exercise sciense series. Monograph $\mathrm{N}^{0} 2$. Champaign, IL: Human Kinetics, 1992. 
9. Organización Mundial De La Salud. El estado físico: uso e interpretación de la antropometria. Informe de um Comitê de Expertos de la OMS. Ginebra, Organización Mundial de la Salud, 1995 (Serie de Informes Técnicos, No 854).

10. Pichard C, Kyle UG, Slosman, DO. Fat -free mass in chronic illness: comparison of bioelectrical impedance and dual-energy x-ray absorptiometry in 480 chronically ill and healthy subjects. Nutrition 1999; 15(9):

11. Stolarczyk LM, Heyward VH, Van Loan MK, Hicks VL, Wilson WL, Reano LM. The fatness-specific bioelectrical impedance analysis equations of Segal et al: are they generalizable and practical? Am J Clin Nutr 1997; 66:8-17.

12. Tanaka T. Fatores de risco para osteoporose em fêmur proximal em homens com idade igual ou maior que 50 anos. São Paulo, 2000. [Dissertação de mestrado - Departamento de Epidemiologia - Faculdade de Saúde Pública da USP].

13. Utter AC, Scott JR, Oppliger RA, Visich PS, Goss FL, Marks BL, Nieman DC, Smith BW. A comparison of leg-to-leg bioelectrical impedance and skinfolds in assessing body fat in Collegiate Wrestlers. Journal of Strenght and Conditioning Research 2001; 15(2):157-160. 
14. Ward LC, Doman D, Jebb SA. Evaluation of a new bioelectrical impedance instrument for the prediction of body cell mass independently of height or weight. Nutrition 2000; 16:745-750.

estimativa de massa magra e massa gorda 
TABELA 1 - Estatística descritiva das variáveis de estudo. Amostra 1. Hospital Heliópolis, São Paulo, 1997.

\begin{tabular}{l|l|c|l}
\hline Variáveis & Média (dp) & Mínimo - Máximo & Mediana \\
\hline Idade (anos) & $62,21(7,97)$ & $50-85$ & 61,00 \\
Massa corporal (kg) & $72,14(11,87)$ & $42,10-108,20$ & 71,50 \\
Estatura (m) & $1,65(0,06)$ & $1,48-1,82$ & 1,65 \\
IMC (kg/m²) & $26,32(3,90)$ & $15,48-35,38$ & 26,00 \\
DCT (mm) & $14,30(6,20)$ & $5,00-43,67$ & 13,00 \\
PC (cm) & $95,30(10,04)$ & $69,00-123,00$ & 95,00 \\
PQ (cm) & $100,12(6,90)$ & $83,00-117,00$ & 99,00 \\
RC/Q & $0,95(0,06)$ & $0,82-1,12$ & 0,95 \\
\% MG IB & $21,65(5,59)$ & $11-38$ & 20,00 \\
\% MG DEXA & $22,76(6,32)$ & $4-39$ & 22,50 \\
MM IB (kg) & $56,11(7,63)$ & $35-82$ & 56,00 \\
MM DEXA (kg) & $52,30(6,95)$ & $36,30-70,59$ & 51,87 \\
Res (ohms) & $484,34(65,28)$ & $355-738$ & 475,50 \\
Rea (ohms) & $52,28(7,90)$ & $31-72$ & 52,00 \\
\hline
\end{tabular}


TABELA 2 - Coeficientes de correlação ( $r$ ) entre ० \% de MG fornecido pela DEXA e as outras variáveis e ordem da entrada da variável no modelo. Amostra 1. Hospital Heliópolis, São Paulo, 1997.

\begin{tabular}{l|c|c}
\hline \multicolumn{1}{c|}{ Variáveis } & $\begin{array}{c}\text { Total } \\
r(p)\end{array}$ & $\begin{array}{c}\text { Ordem da entrada no } \\
\text { modelo }\end{array}$ \\
\hline PC (cm) & ${ }^{*} 0,81(<0,001)$ & 1 \\
IMC (kg/m²) & ${ }^{*} 0,76(<0,001)$ & 2 \\
\% MG IB & ${ }^{*} 0,76(<0,001)$ & 3 \\
PQ (cm) & ${ }^{*} 0,71(<0,001)$ & 4 \\
Massa corporal (kg) & ${ }^{*} 0,69(<0,001)$ & 5 \\
DCT (mm) & $\star^{*} 0,68(<0,001)$ & 6 \\
RC/Q & ${ }^{*} 0,61(<0,001)$ & 7 \\
Res (ohm) & ${ }^{*} 0,31(<0,001)$ & 8 \\
Rea (ohm) & ${ }^{*}-0,21(0,009)$ & 9 \\
Idade (anos) & ${ }^{*} 0,06(0,428)$ & 10 \\
Estatura (m) & ${ }^{*} 0,01(0,872)$ & 11 \\
\hline
\end{tabular}


TABELA 3 - Coeficientes de correlação entre o valor da MM (kg) fornecido pela DEXA e as outras variáveis e ordem da entrada da variável no modelo. Amostra 1. Hospital Heliópolis, São Paulo, 1997.

\begin{tabular}{|c|c|c|}
\hline Variáveis & $\begin{array}{l}\text { Total } \\
\mathbf{r}(\mathbf{p})\end{array}$ & $\begin{array}{c}\text { Ordem da entrada no } \\
\text { modelo }\end{array}$ \\
\hline Massa corporal (kg)* & $0,37(<0,001)$ & 1 \\
\hline MM IB (kg)* & $0,34(<0,001)$ & 2 \\
\hline $\mathrm{PC}(\mathrm{cm})^{*}$ & $0,32(<0,001)$ & 3 \\
\hline $\mathrm{PQ}(\mathrm{cm})^{*}$ & $0,31(<0,001)$ & 4 \\
\hline $\operatorname{IMC}\left(\mathrm{kg} / \mathrm{m}^{2}\right)^{*}$ & $0,29(<0,001)$ & 5 \\
\hline $\operatorname{Res}(\mathrm{ohm})^{*}$ & $-0,22(0,005)$ & 6 \\
\hline Estatura $(\mathrm{m})^{*}$ & $0,22(0,005)$ & 7 \\
\hline $\mathrm{RC} / \mathrm{Q}^{*}$ & $0,21(0,006)$ & 8 \\
\hline Idade $(\operatorname{anos})^{*}$ & $0,08(0,300)$ & 9 \\
\hline $\operatorname{DCT}(\mathrm{mm})^{* *}$ & $0,07(0,344)$ & 10 \\
\hline Rea (ohm)* & $-0,07(0,389)$ & 11 \\
\hline
\end{tabular}

Pearson* Spearman's** 
Tabela 4 - Coeficientes de correlação intraclasse $-r_{\text {ic }}$ entre o percentual de MG formecido pela DEXA, e aqueles fornecidos pela IB e estimados pelas equações. Amostra 2. Hospital Heliópolis, São Paulo, 1997.

\begin{tabular}{l|c|c|c}
\hline \multicolumn{1}{c|}{ Equaçōes } & \multicolumn{1}{c}{$\boldsymbol{P}$} & EPE \\
& & \\
\hline IB & 0,71 & $<0,001$ & 4,9 \\
Garrow \& Webster & 0,72 & $<0,001$ & 4,8 \\
(1985) & 0,72 & $<0,001$ & 4,8 \\
Deurenberg et al.(1991) & 0,76 & $<0,001$ & 4,5 \\
Lean et al. (1996) & 0,82 & $<0,001$ & 4,0 \\
Ligia & 0,82 & $<0,001$ & 4,0 \\
LigiaB & 0,79 & $<0,001$ & 4,3 \\
LigiaC & 0,79 & $<0,001$ & 4,3 \\
\hline
\end{tabular}


Tabela 5 - Coeficientes de correlação intraclasse - $r_{i c}$ entre o valor de MM fornecido pela DEXA e IB e aqueles estimados pelas equações. Amostra 2. Hospital Heliópolis, São Paulo, 1997.

Equações $\quad r_{i c}$

$r_{i c}$

$P \quad$ EPE

\begin{tabular}{l|l|l|l}
\hline IB & 0,34 & $<0,001$ & 6,9 \\
Segal et al. (1988):equações & 0,30 & $<0,001$ & 7,0 \\
preditivas dos fabricantes (RJL) & & & \\
Segal et al.(1988): geral & 0,33 & $<0,001$ & 6,9 \\
Gray et al.(1989) & 0,35 & $<0,001$ & 6,9 \\
Deurenberg et al.(1991) & 0,33 & $<0,001$ & 6,9 \\
Lohman (1992) & 0,37 & $<0,001$ & 6,8 \\
Ligia1 & 0,28 & $<0,001$ & 7,0 \\
Ligia2 & 0,28 & $<0,001$ & 7,0 \\
\hline
\end{tabular}

